\title{
Recent advances in all-solid-state rechargeable lithium batteries
}

\author{
Chunwen Sun*, Jin Liu, ${ }^{\mathrm{b}}$ Yudong Gong, ${ }^{\mathrm{a}, \mathrm{c}}$ David P. Wilkinson ${ }^{\mathrm{e}}$, and Jiujun Zhang*
}

${ }^{a}$ Beijing Institute of Nanoenergy and Nanosystems, Chinese Academy of Sciences; National Center for Nanoscience and Technology (NCNST), Beijing,100083, China

${ }^{b}$ School of Metallurgy and Environment, Central South University, Changsha City, Hunan, 410083, China

${ }^{\mathrm{c}}$ Institute of Physics, Chinese Academy of Sciences, Beijing 100190, China

${ }^{\mathrm{d} C o l l e g e}$ of Sciences \& Institute for Sustainable Energy, Shanghai University, Shanghai, 200444, China

${ }^{\mathrm{e}}$ Department of Chemical \& Biochemical Engineering, University of British Columbia, Vancouver, BC, Canada

* Corresponding author.

Emails: sunchunwen@binn.cas.cn, (C. Sun), jiujun@shaw.ca (J.J. Zhang) 


\begin{abstract}
The all-solid-state lithium batteries using solid electrolytes are considered to be the new generation of devices for energy storage. Recent advances in this kind of rechargeable batteries have brought them much closer to a commercial reality. However, several challenges such as insufficient room temperature ionic conductivity $\left(10^{-5} \sim 10^{-3} \mathrm{~S} \mathrm{~cm}^{-1}\right)$ when compared to those of conventional organic liquid electrolytes $\left(10^{-2} \mathrm{~S} \mathrm{~cm}^{-1}\right)$, the difficulty in informing an effective electrode-electrolyte interface and insufficient fundamental understanding of the interfacial process after charge/discharge, hindering the reality of such devices. To accelerate the research and development, the overall picture about the current state of all solid-state lithium batteries was reviewed in this article with major focus on the material aspects, including inorganic ceramic and organic solid polymer electrolyte materials. In particular, the importance of the electrolytes and their associated interfaces with electrodes as well as their effects on the battery performance are emphasized by in-depth discussion and data analysis. To overcome the challenges, several possible research directions are also suggested for facilitating further improvement on the battery performance.
\end{abstract}

Key words: all-solid-state lithium batteries, solid electrolyte; electrode-electrolyte interface; electrolyte thin film 


\section{Introduction}

Chemical batteries have played important roles in energy storage and conversion $[1,2]$. Among currently available battery technologies, lithium-based batteries, such as Li-ion batteries (LIBs), are considered the most promising ones due to their relatively higher energy density [1,3]. Normally, the conventional Li batteries use organic liquid electrolytes, which have relatively low ionic resistance, leading to some drawbacks such as safety issue, insufficient lifetime, high cost, and low power density. However, all-solid-state Li batteries with nonflammable solid electrolytes can avoid some of the issues, in particular, the safety one. Relatively speaking, when compared to liquid-electrolyte Li batteries, all-solid-state ones are believed to be safer, and to have longer cycle life, higher energy density, less requirements on packaging and state-of-charge monitoring circuits [4]. With respect to this, there is a growing interest in all-solid-state batteries. However, inferior cycle performance induced by the continuous development of interfacial resistance layer between cathode and electrolyte materials is one of the major drawbacks that needs to be overcome for the successful commercialization of secondary $\mathrm{Li}$ batteries [5,6]. It is expected that all-solid-state batteries should be used widely in large electrical power storage systems such as electrical vehicles as well as electronic devices due to their high energy density and safety. Thus, there are intensive researches on Li-ion-conducting inorganic materials used as solid-state electrolyte for all-solid-state Li batteries in recent years.

In the most recent years, a significant progress has been made for all-solid-state Li batteries by experimentally developing and optimizing solid electrolytes. Moreover, an in-depth fundamental understanding of the potential profile and its distribution across the electrode/electrolyte interface has gained by employing advanced characterization approaches [7]. Regarding commercialization efforts, some companies have been devoted to promote the application of all-solid-state Li batteries in electronic devices and electric vehicles, including Toyota, Solid Energy, Infinite 
Power Solution, Seeo, Sakti3, Front Edge Technology Inc., Quantum Scape, Bolloré, etc. Overall, in this review we describe the advances in all-solid-state Li batteries and the remaining challenges, and also propose several possible research directions for circumventing the challenges.

\section{Fundamentals of solid electrolytes in all-solid-state Li batteries}

\subsection{Theory of Li-ion conduction in solid-state electrolytes}

Defects widely exist in real crystals, and they play an important role in the properties of solids. Point defects are atomic defects whose effects are limited only to their immediate surroundings [8]. Examples are ionic vacancies in the regular crystal lattice, or interstitial atoms or ions. Ionic conduction in ceramics can be induced by either mobile cations or anions. Ionic conduction can be derived from the motion of vacancies or interstitial ions. These point defects can be intrinsic and stoichiometric defects, such as Frenkel defects (the defects are vacancies accompanied by an interstitial ion), and Schottky defects (the defects are anion vacancies accompanied by a cation vacancy) [9]. A transition-metal cation can have a mixed valence state and thus the intrinsic defects are not necessarily limited to a stoichiometric composition in transition-metal oxides. Electroneutrality can be maintained by the oxidation or reduction of a cation [10]. The formation of intrinsic defects is driven by thermal energy, and the number of defects obeys an Arrhenius-type equation:

$$
N_{D}=N \exp \left[-\frac{E_{F}}{2 k T}\right]
$$

where $N_{\mathrm{D}}$ is the number of defects, $\mathrm{N}$ is the number of ion pairs, $E_{\mathrm{F}}$ is the energy of formation, $k$ is the Boltzmann constant and $T$ is the temperature. The point defects can also be extrinsic, introduced by impurities or dopants substituted in the lattice.

The conductivity of a material with multiple conducting species is given by

$$
\sigma=\sum n_{j} q_{j} \mu_{j}
$$

Where $\sigma_{j}$ is the total conductivity, $n_{j}$ is the density, $q_{j}$ is the charge and $\mu_{j}$ is the mobility of the conducting species. 
The total conductivity of a mixed conducting material is the sum of the ionic and electric conductivities:

$$
\sigma=\sigma_{\mathrm{i}}+\sigma_{\mathrm{e}}
$$

The transference numbers are parameters defined to characterize the ionic and electronic contributions to the total conductivity:

$$
\begin{aligned}
& t_{i}=\frac{\sigma_{i}}{\sigma} \\
& t_{e}=\frac{\sigma_{e}}{\sigma}
\end{aligned}
$$

where $t_{\mathrm{i}}$ and $t_{\mathrm{e}}$ are ionic and electronic transference numbers, respectively. The sum of $t_{\mathrm{i}}$ and $t_{\mathrm{e}}$ is unity [8].

Ionic conduction also obeys an Arrhenius temperature dependence:

$$
\sigma_{i}=\frac{A}{T} \exp \left[-\frac{E_{a}}{k T}\right]
$$

The mobility of charge carrier is

$$
\mu=\frac{q D}{k T}
$$

where $D$ is the diffusion coefficient [11]. The motion of a single particle jumping from an occupied site to an energetically equivalent unoccupied site may be described by a random-walk theory [12], and its diffusion coefficient is expressed as Equation (7):

$$
D=\left[\frac{z}{2 d}\right] l^{2}(1-c) v_{h}
$$

where $d$ is 1,2 or 3 for one-, two-, or three-dimensional motion, $l$ is the jumping distance, $c$ is the concentration of mobile ions, and $\mathrm{z}$ is the number of like nearest neighbors. The jump frequency $\left(v_{h}\right)$ is defined to be Equation (8):

$$
v_{h}=v_{o} \exp \left[\frac{-\Delta G_{m}}{k T}\right]
$$

where $v_{0}$ is the attempt frequency, and $\left(\Delta G_{m}\right)$ is the migrational free energy, which can be expressed as Equation (9):

$$
\Delta G_{m}=\Delta H_{m}-T \Delta S_{m}
$$

Substitution of Equation (6) into Equation (2) yields the Nernest-Einstein relation [10]: 


$$
\sigma_{i}=\frac{N_{c} q^{2} D}{k T}
$$

where $N_{c}$ is the number of mobile ions. It can be seen that the ionic conductivity is proportional to the $N_{c}$ and $D$.

A comprehensive physical description of ion transport in polymer electrolytes is actually not easy because the systems are complex and the lack of simple structure-properties correlations. In this regard, the ionic conductivity of these systems is usually modeled by the Arrhenius or Vogel-Tammann-Fulcher (VTF) equations or both of them together [13-15].

As described, the VTF behavior seemed more suitable for the solid polymer electrolytes [13], which could be described by Equation (11)

$$
\sigma_{i}=\sigma_{0} T^{-\frac{1}{2}} \exp \left[-\frac{B}{T-T_{0}}\right]
$$

where $B$ is the pseudo-activation energy of the conductivity (expressed in units of $E_{\mathrm{a}} / \mathrm{k}$ ), and $T_{0}$ is the reference temperature which normally falls $10-50 \mathrm{~K}$ below the experimental (kinetic) glass transition temperature, $T_{\mathrm{g}}$. The VTF parameters can be obtained by fitting the conductivity data with the linear Equation (12)

$$
\log _{10}\left(\sigma T^{\frac{1}{2}}\right)=\log _{10} \sigma_{0}-0.43 \frac{E_{a}}{k\left(T-T_{0}\right)}
$$

The VTF equation could be derived by the quasi-thermodynamic models with free volume [16] and configurational entropy [17], and its behavior could be related to ion motion coupled with long range motions of the polymer segments.

As for the composite electrolyte materials consisting of a conducting and an insulating phase, its conductivity could be described by the effective media theories [18].

\subsection{Structures and electrochemical processes of all-solid-state $\mathrm{Li}$ batteries}

Figure 1 is a schematic diagram showing the structure of an all-solid-state lithium battery, consisting of cathode, electrolyte, anode and current collectors. As identified, the electrolyte plays a critical role in the all-solid-state Li batteries. It functions as both an ionic conductor and separator. It can be seen that the electrodes are attached to both sides of the electrolyte. This structure is actually simpler than the conventional 
Li-ion batteries with liquid electrolytes. All-solid-state $\mathrm{Li}$ batteries need fewer requirements on packaging and thus may significantly reduce the fabrication cost. As for the working principle of an all-solid-state Li battery, it is similar to the Li-ion batteries with liquid electrolytes. During charging, Li-ions de-intercalate from the crystal lattice of the cathode and transfer to the anode via the ionic conductive solid electrolyte, while the electrons transfer to the anode via the external circuit. During discharging, the Li-ions de-intercalate from the anode and transfer to the cathode via the solid electrolyte while the electrons are passed through the external circuit and drive a device to work. The following reaction steps are involved at the electrode/electrolyte interface: (i) Li diffusion in the electrolyte, (ii) Adsorption on the electrode surface, (iii) Charge transfer, (iv) Intercalation into the electrode, (v) Li diffusion in the electrode and (vi) Surface reaction, etc.

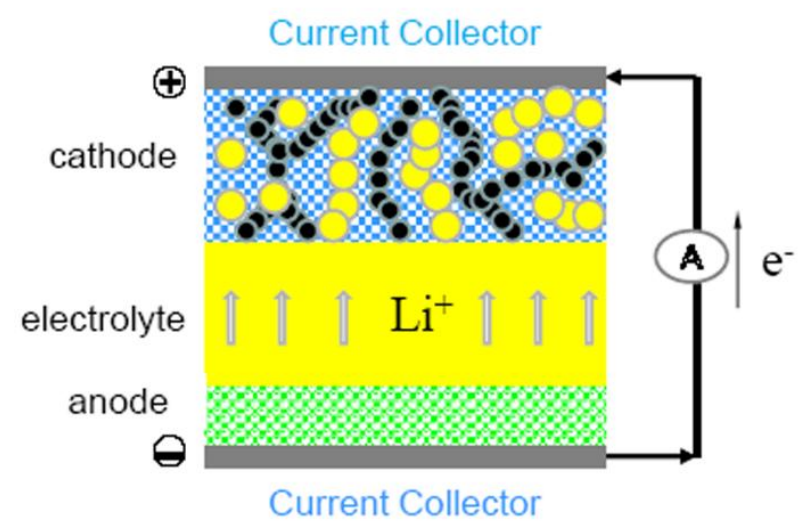

Figure 1 Schematic illustration of an all-solid-state lithium battery based on Li-ion conduction

\subsection{Functions and performance of the solid-state electrolytes}

Solid electrolyte is a key component for the practical application of rechargeable all-solid-state Li batteries. Generally, solid electrolytes for all-solid-state batteries should possess the properties such as high ionic conductivity and negligible electronic conductivity, wide voltage window, chemical compatibility with the electrodes, as well as relatively simple to fabricate on a large scale with low cost. Material design of crystalline ionic conductors are mainly based on the following structural criteria: (i) a 
suitable conduction pathways for mobile ions, (ii) disorder in a mobile ion sub-lattice, (iii) highly polarizable mobile ions and anion sub-lattices, (iv) high total ionic conductivities with ion transference number close to unity and negligible electronic conductivity, and (v) chemical compatibility with the anode and cathode during battery manufacture and operation $[19,20]$. There are two kinds of all-solid-state batteries which can complement each other to satisfy these requirements. The first kind of all-solid-state batteries uses polymer films as electrolytes or separators, and the other one uses inorganic glassy or ceramic electrolytes. In the past decades, lithium ion-conducting solid electrolytes have been extensively studied, and a number of solid materials, such as, $\mathrm{Li}_{3} \mathrm{~N}$, $\mathrm{LiPON}, \mathrm{Li}_{2} \mathrm{~S}$-based glass, NaSICON-type oxides, $\mathrm{Li}_{0.05-3 \mathrm{x}} \mathrm{La}_{0.5+\mathrm{x}} \mathrm{TiO}_{3}, \mathrm{Li}_{7} \mathrm{La}_{3} \mathrm{Zr}_{2} \mathrm{O}_{12}$ and polymer electrolytes have demonstrated fairly good Li-ion conductivity. It seems that the inorganic solid electrolyte or hybrid electrolyte materials have obtained more attention and been considered to be the electrolyte materials [13, 21-40].

\subsubsection{Solid ceramic electrolytes}

The early solid electrolyte was introduced by Bates et al. [41] with lithium-phosphorous-oxynitride (LiPON). They incorporated $\mathrm{N}_{2}$ to form LiPON, an amorphous analog to the lithium super ionic conductor (LiSICON), by radio frequency magnetron sputtering of lithium silicates, phosphates, or phosphosilicates [42]. Thin-film batteries with $\mathrm{Li}$ anodes and LiPON separators demonstrated thousands of cycles $[43,44]$. However, the mechanical stability of bulk-type batteries based on this electrolyte material design seemed to be insufficient. The low

conductivity of LiPON at room temperature $\left(2 \times 10^{-6} \mathrm{~S} \mathrm{~cm}^{-1}\right)$ could also prevent the further development of batteries with thick LiPON membranes [42].

Lithium ion conducting sulfide glasses such as $\mathrm{Li}_{2} \mathrm{~S}-\mathrm{GeS}_{2}, \mathrm{Li}_{2} \mathrm{~S}-\mathrm{P}_{2} \mathrm{~S}_{5}, \mathrm{Li}_{2} \mathrm{~S}-\mathrm{B}_{2} \mathrm{~S}_{3}$, and $\mathrm{Li}_{2} \mathrm{~S}-\mathrm{SiS}_{2}$ systems were reported to exhibit electrical conductivities higher than $10^{-4} \mathrm{~S} \mathrm{~cm}^{-1}$ at room temperature [45]. Among these systems, lithium thiosilicate $\mathrm{Li}_{2} \mathrm{~S}-\mathrm{Si}_{2}$ glasses showed several advantages such as higher conductivity, higher glass 
transition temperatures and easy preparation without vacuum sealing [46,47]. If these $\mathrm{Li}_{2} \mathrm{~S}-\mathrm{SiS}_{2}$ glasses were composited with small amounts of ortho-oxosalts such as $\mathrm{Li}_{3} \mathrm{PO}_{4}, \mathrm{Li}_{4} \mathrm{SiO}_{4}$ and $\mathrm{Li}_{4} \mathrm{GeO}_{4}$, considerable high conductivities over $10^{-3} \mathrm{~S} \mathrm{~cm}^{-1}$ at room temperature and wide electrochemical window could be obtained $[48,49]$. Furthermore, the addition of a small amount of those ortho-oxosalts to the $\mathrm{Li}_{2} \mathrm{~S}-\mathrm{SiS}_{2}$ sulfide system could also improved the glass stability against crystallization [48]. Both high conductivity and high thermal stability of the $\mathrm{Li}_{2} \mathrm{~S}-\mathrm{SiS}_{2}$-based oxy-sulfide glasses have made these glasses being the most promising solid electrolytes for all-solid-state Li batteries.

Thio-LiSICON-based electrolytes have high conductivity and low activation energy at room-temperature. For example, glass ceramics with thio-LiSICON structures could exhibit even better performance $\left(3.2 \times 10^{-3} \mathrm{~S} \mathrm{~cm}^{-1}\right.$ for $\left.70 \mathrm{Li}_{2} \mathrm{~S}_{-}-30 \mathrm{P}_{2} \mathrm{~S}_{5}\right)$ [50,51], which showed about an order of magnitude higher conductivity at room temperature than their amorphous counterparts. Glass electrolytes have several advantages such as isotropic properties for ion migration and easy control of properties by changing chemical compositions [52]. However, the disadvantage of glass ceramic electrolytes is their sensitivity to humidity.

Elemental substitution is an effective approach to increasing conductivity of crystals. For example, Kanno et al.[53] reported that the conductivity of $\mathrm{Li}_{3} \mathrm{PS}_{4}$ crystal could be significantly increased by incorporating phosphorus and germanium into $\mathrm{Li}_{3} \mathrm{PS}_{4}$ crystal, the resultant $\mathrm{Li}_{3.25} \mathrm{P}_{0.75} \mathrm{Ge}_{0.25} \mathrm{~S}_{4}$ crystal exhibited a high conductivity of $2.2 \times 10^{-3} \mathrm{~S} \mathrm{~cm}^{-1}$ at room temperature. Recently, they reported $\mathrm{Li}_{10} \mathrm{GeP}_{2} \mathrm{~S}_{12}$ with a new three-dimensional framework structure, which exhibited an extremely high lithium ionic conductivity of $12 \mathrm{mS} \mathrm{cm}^{-1}$ at room temperature [53]. Figure 2 shows the thermal evolution of the ionic conductivity of the new $\mathrm{Li}_{10} \mathrm{GeP}_{2} \mathrm{~S}_{12}$ phase in comparison with other electrolytes used in practical batteries. This solid-state electrolyte was claimed to have many advantages in term of fabrication, safety and electrochemical properties. 


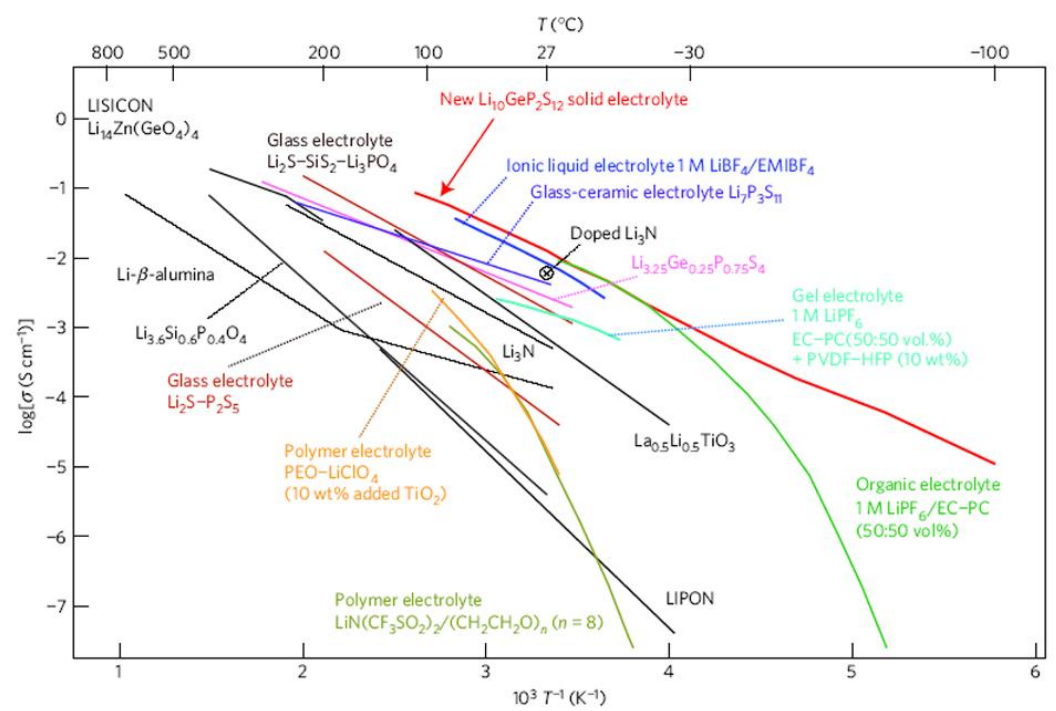

Figure 2 Ionic conductivity of $\mathrm{Li}_{10} \mathrm{GeP}_{2} \mathrm{~S}_{12}$ phase in comparison with other kinds of electrolytes. (Reprinted from ref. 53 with permission from Nature Publishing Group)

Figure 3 shows the crystal structure of $\mathrm{Li}_{10} \mathrm{GeP}_{2} \mathrm{~S}_{12}$. The framework is composed of $\left(\mathrm{Ge}_{0.5} \mathrm{P}_{0.5}\right) \mathrm{S}_{4}$ terahedra and $\mathrm{LiS}_{6}$ octahedra, which are connected to $\mathrm{LiS}_{6}$ octahedra by a common corner (Figure $3 \mathrm{~b}$ ). $\mathrm{LiS}_{4}$ tetrahedra at the $16 h$ and $8 f$ sites share a common edge, forming a 1D conducting pathway along the $c$ axis.

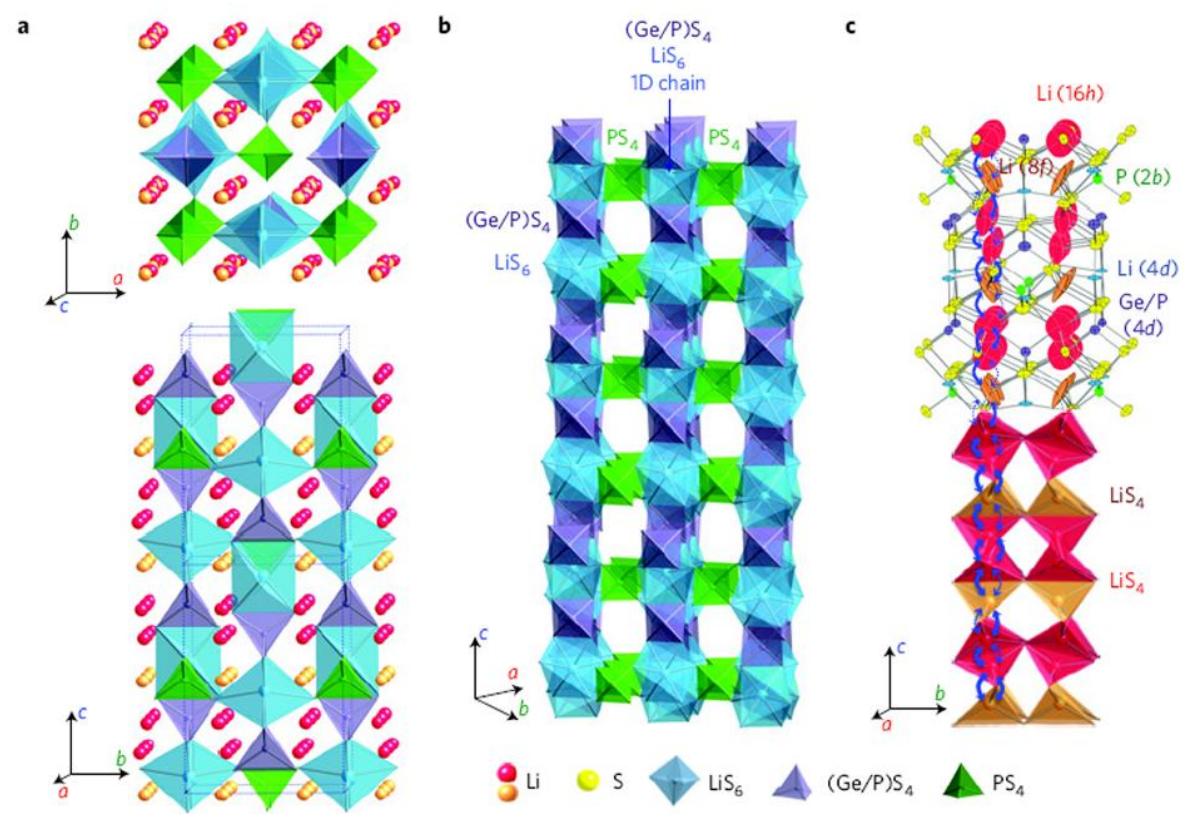

Figure 3 Crystal structure of $\mathrm{Li}_{10} \mathrm{GeP}_{2} \mathrm{~S}_{12}$. (a) Framework structure and lithium ions 
that participate in ionic conduction; (b) Framework structure of $\mathrm{Li}_{10} \mathrm{GeP}_{2} \mathrm{~S}_{12}$; (c) Conduction pathways of lithium ions. (Reprinted from ref. 53 with permission from Nature Publishing Group)

As observed, the content of germanium in Li-Ge-P-S electrolyte materials tended to be reduced at low potentials [54]. Moreover, sulfide in the materials easily reacted with the moisture in the atmosphere, producing harmful $\mathrm{H}_{2} \mathrm{~S}$ gas. Recently, Sahu et al. [55] reported that the solid electrolyte with a composition of $\mathrm{Li}_{3.833} \mathrm{Sn}_{0.833} \mathrm{As}_{0.166} \mathrm{~S}_{4}$ showed a high ionic conductivity of $1.39 \mathrm{mS} \mathrm{cm}^{-1}$ at $25^{\circ} \mathrm{C}$. Soft acids of $\mathrm{As}^{5+}$ and $\mathrm{Sn}^{4+}$ were used to form a stable compound against hydrolysis and oxidation. Although chemical compatibility with metallic Li was compromised by the Sn and As atoms, surface modification of the solid electrolyte was shown to be effective method for suppressing the interfacial reactions and thus achieving a remarkable cyclability.

The sodium super ionic conductors, such as (NASICON)-type lithium ion conductors, seemed to be promising electrolytes due to their high conductivity $\left(\sim 7 \times 10^{-4} \mathrm{~S} \mathrm{~cm}^{-1}\right)$ at room temperature and their stability in both atmosphere and water [56]. For example, Hosono et al. [57,58] and Chowdari et al. [59] reported lithium-ion conductive glass-ceramics with an ionic conductivity over $10^{-4} \mathrm{~S} \mathrm{~cm}^{-1}$ at room temperature. $\mathrm{Al}^{3+}$ substitution to form $\mathrm{Li}_{1+\mathrm{x}} \mathrm{Al}_{\mathrm{x}} \mathrm{Ti}_{2-\mathrm{x}}\left(\mathrm{PO}_{4}\right)_{3}$ system $(\mathrm{x}=0.4)$ could make two orders of magnitude enhancement in conductivity [60]. Furthermore, the substitution of $\mathrm{Ti}^{4+}$ by smaller sized $\mathrm{Al}^{3+}$ cation could reduce the unit-cell dimension of NASICON framework, significantly increasing $\mathrm{Li}^{+}$conductivity [61]. The commercialized $\mathrm{Li}_{1+\mathrm{x}} \mathrm{Al}_{\mathrm{x}} \mathrm{Ti}_{2-\mathrm{x}}\left(\mathrm{PO}_{4}\right)_{3}$ with a high conductivity up to $1.3 \times 10^{-3} \mathrm{~S} \mathrm{~cm}^{-1}$ was also developed [62]. Tan et al. [63] reported a synergistic effect of chemical substitutions and structural modifications in an amorphous $\mathrm{Li}_{1+\mathrm{x}} \mathrm{Al}_{\mathrm{x}} \mathrm{Ti}_{2-\mathrm{x}}\left(\mathrm{PO}_{4}\right)_{3}$ system.

Perovskite $\mathrm{Li}_{0.05-3 x} \mathrm{La}_{0.5+\mathrm{x}} \mathrm{TiO}_{3}$ (LLTO) showed a bulk conductivity as high as $1 \times 10^{-3} \mathrm{~S} \mathrm{~cm}^{-1}$, but the total conductivity in the cell was lower $\left(\sim 2 \times 10^{-5} \mathrm{~S} \mathrm{~cm}^{-1}\right)$ due to a higher grain boundary resistance [64-67]. Figure 4 shows the crystal structure of LLTO [68]. It can be seen that LLTO has a mixture of a high-temperature cubic phase 
with Pm3m symmetry ( $\alpha$-LLTO) and a lower temperature tetragonal phase $\beta$-LLTO with a $P 4 / m m m$ symmetry. $\mathrm{Li}^{+}$and $\mathrm{La}^{3+}$ at $\mathrm{A}$ sites in the cubic $\alpha$-LLTO phase are randomly distributed while the A sites of the ordered $\beta$-LLTO phase have an alternating arrangement of La-rich and Li-vacancy-rich layers along the $c$ axis. The conductivity of LLTO electrolytes is mainly dominated by the bottleneck size and site percolation. The crystal structure of tetragonal LLTO accounts for the high $\mathrm{Li}^{+}$ conductivity due to a large concentration of A site vacancies. Lithium ions conduct by a vacancy mechanism through square planar bottleneck between A sites in LLTO [68]. It should be noted that both LATP and LLTO electrolytes with Ti element are easily reduced by metallic lithium anode. Thus, for these electrolytes, it is actually difficult to be used in lithium metal batteries.

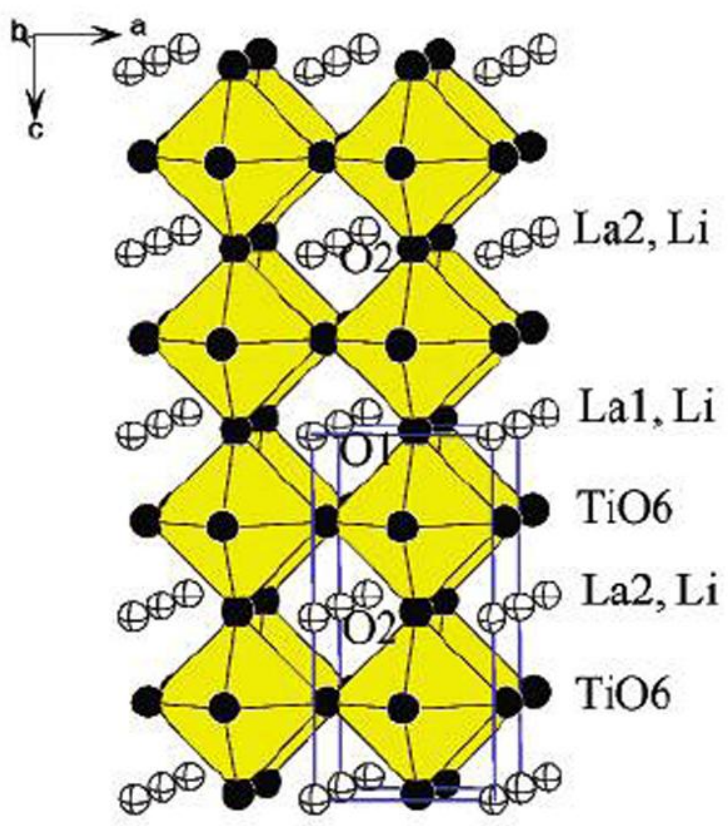

Figure 4 Crystal structure of $\mathrm{Li}_{3 x} \mathrm{La}_{2 / 3-x} \square_{1 / 3} \mathrm{TiO}_{3}$. The $\mathrm{TiO}_{6}$ octahedra are connected to each other by corners. (Reprinted from ref. 68. Copyright 2003 American Chemical Society)

Garnet-like structural compounds was studied as solid electrolytes by Weppner et al. [69-72]. In particular, $\mathrm{Li}_{5} \mathrm{La}_{3} \mathrm{Ta}_{2} \mathrm{O}_{12}$ (LLTa) and $\mathrm{Li}_{7} \mathrm{La}_{3} \mathrm{Zr}_{2} \mathrm{O}_{12}$ (LLZ) have been given much attention due to their stable nature against Li metal $[69,72]$. For example, 
Awaka et al. [73] determined the detailed crystal structure of cubic $\mathrm{Li}_{7} \mathrm{La}_{3} \mathrm{Zr}_{2} \mathrm{O}_{12}$ by single-crystal X-ray structure analysis, as shown in Figure 5a [73]. It can be seen that the garnet framework structure is composed of dodecahedral $\mathrm{LaO}_{8}$ and octahedral $\mathrm{ZrO}_{6}$. As shown in Figure 5b, the Li1 and Li2 atoms are located in the tetrahedral $24 d$ site and distorted octahedral $96 \mathrm{~h}$ site, respectively. The Li2 site is vacant in the ideal garnet structure. The disordering and partial occupation of the Li atoms at the Li2 site plays a key role for Li-ion conduction [74]. A three-dimensional conducting pathway of Li-ions is shown in Figure 4b. The basic unit of the pathway is a loop constructed by the Li1 and Li2 sites. Besides high bulk Li-ion conductivity of $5 \times 10^{-4} \mathrm{~S} \mathrm{~cm}^{-1}$ at room temperature, this material also exhibits excellent thermal performance and chemical compatibility against molten lithium, air and moisture.

(a)

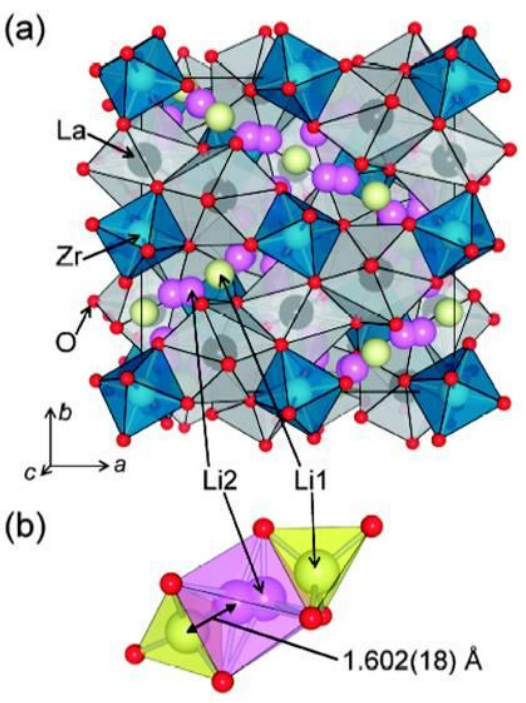

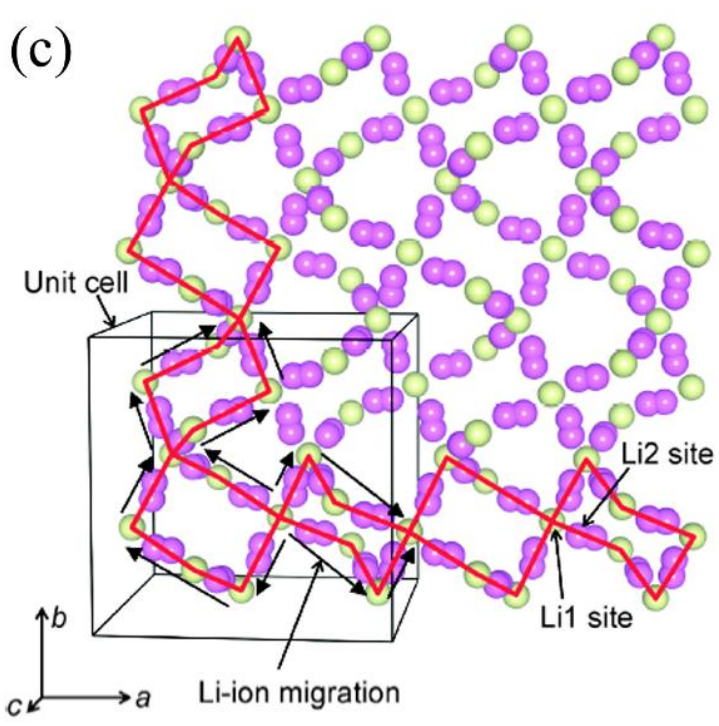

Figure 5 (a) Crystal structure of cubic $\mathrm{Li}_{7} \mathrm{La}_{3} \mathrm{Zr}_{2} \mathrm{O}_{12}$, (b) Coordination polyhedra around the Li1 and Li2 sites; (c) Three-dimensional conducting network of the Li-ion in cubic $\mathrm{Li}_{7} \mathrm{La}_{3} \mathrm{Zr}_{2} \mathrm{O}_{12}$. (Reprinted from ref. 73 with permission from Chemical Society Japan.)

It is noteworthy that a small amount of $\mathrm{Al}$ seems to be favorable to stabilize the structure in a higher conducting cubic phase, leading to a less conducting tetragonal 
phase transformation to the cubic phase at higher temperatures [75]. Substitution of $\mathrm{La}^{3+}$ with the divalent ions and tri- and tetravalent ions for pentavalent $\mathrm{Nb}$ or $\mathrm{Ta}$ ions could lead to an increased occupancy of the $\operatorname{Li}(2)$ sites and decreased occupancy of the $\operatorname{Li}(1)$ sites, thus the concentration of the vacancies on the tetrahedral (24d) sites was increased and the concentration of vacancies on the octahedral $(96 \mathrm{~h} / 48 \mathrm{~g})$ sites decreased in the $\mathrm{Li}_{6}$ phased compared to $\mathrm{Li}_{5}$ phases [30]. The high conductivity was ascribed to the increased cubic lattice constant and lithium ion concentration and the decreased Li-ion interactions with other ions in the structure [72]. However, Li-rich garnets tended to undergo fast proton-exchange in water, dilute acids, and aqueous $\mathrm{LiCl} / \mathrm{LiOH}$ solutions, particularly at the tetrahedral sites [50].

Various experimental methods have been employed to characterize the properties of solid electrolytes. Li ion conduction in solid electrolyte materials is commonly investigated using AC impedance spectroscopy [76]. The contribution of grain boundary and lattice impedance in $\mathrm{Li}_{7} \mathrm{La}_{3} \mathrm{Zr}_{2} \mathrm{O}_{12}$ garnet electrolytes can be well elucidated by AC impedance spectroscopy as well [77]. The ratio of electronic conductivity $\left(\sigma_{\mathrm{e}}\right)$ in total electrical conductivity is usually determined using the DC polarization method employing "inert" $\mathrm{Au}$ and Li reversible electrodes [72,76]. Li-ion conduction mechanism is investigated by means of solid state Li nuclear magnetic resonance (NMR) [78-83] and temperature-dependent neutron powder diffraction (NPD) [84-86].

\subsubsection{Solid polymer electrolytes}

Compared to both inorganic solid electrolytes and liquid ones, solid polymer electrolytes (SPEs), in general, have better flexibility and higher safety, which have been one kind of the most promising candidate electrolytes for all-solid-state lithium batteries including Li-ion, Li-sulfur and Li-air ones [87]. The studies of SPEs started from the exploration of polyethylene oxide (PEO) incorporating with lithium salts, and observed that lithium salts could be dissolved by the polymer solvents to form cations and anions in a SPE system [88]. The $\mathrm{Li}^{+}$cations were solvated by the 
polymer chains and became movable through the chain movement. The number of free $\mathrm{Li}^{+}$cations and their moving ability of the chains would significantly affect the $\mathrm{Li}^{+}$transportability within SPE; in turn affect the battery's performance. Since lithium ion transportability in SPE at room temperature is lower than that in liquid electrolyte, even lower than that in inorganic solid electrolyte, strategies have been developed to enhance the conductivity with well understanding of the conducting mechanisms. In this section, the SPE will be reviewed according to three types of polymer hosts.

\subsubsection{PEO based solid electrolyte}

PEO polymers with oligoether $\left(-\mathrm{CH}_{2}-\mathrm{CH}_{2}-\mathrm{O}-\right)_{\mathrm{n}}$ constitutes have been extensively studied as a host of SPEs for nearly 40 years since Wright's discovery of the ionic conductivity of PEO complexes with alkali metal salts [89], and Armand's suggestion using PEO conductors for electrochemical devices [90]. Due to the low ionic conductivity of such a SPE (about $10^{-7} \mathrm{~S} \mathrm{~cm}^{-1}$ at room temperature) [13], a variety of methods have been explored to make improvement. In 1983, Tsuchida et al. [91] blended PEO with poly(methacrylic acid) (PMAA) to prepare a hydrogen-bonding type inter-macromolecular complex matrix with dissolving $\mathrm{LiClO}_{4}$ salt, the SPE showed a maximum conductivity of $1.3 \times 10^{-5} \mathrm{~S} \mathrm{~cm}^{-1}$ at $60{ }^{\circ} \mathrm{C}$.

Since the report by Weston and Steele in 1982 [92], PEO-based composite polymer electrolytes (CPEs) have been widely studied [93-96]. The CPEs composing of a filler and polymer matrix could obviously improve the ionic conductivity, mechanical and interfacial properties when compared to the bare polymer electrolytes. In 1998, Scrosati et al. [97] added nanometer-sized ceramic powder into PEO polymer, leading to an increase in the ionic conductivity by 1-2 orders of magnitude. Subsequently, Bruce [88] investigated the ionic transport in PEO-based SPE with crystalline phase. They found that the ions could transport in the crystalline state (Figure 6), which opened a new trend for the research of PEO-based SPEs. 


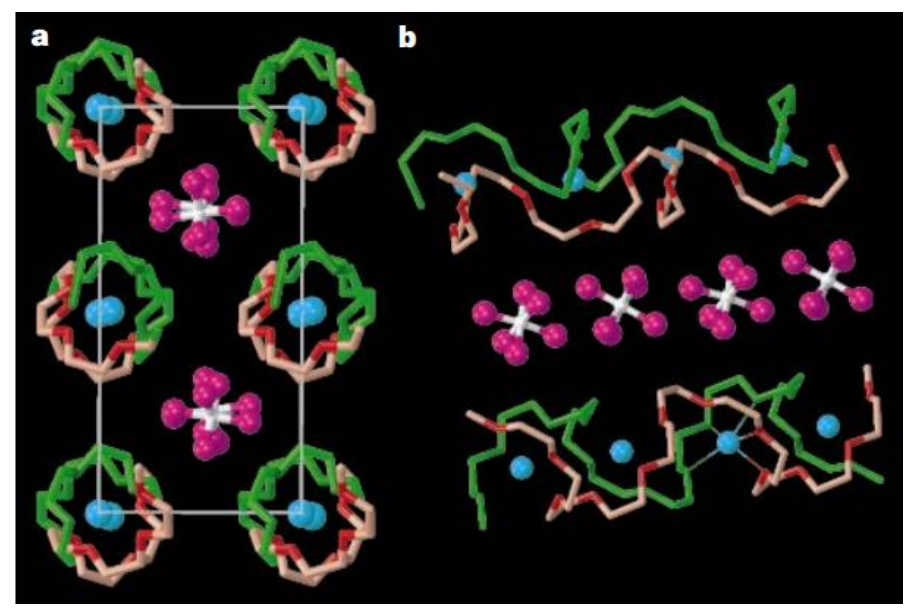

Figure 6 Ion transport structure of $(\mathrm{PEO})_{6}: \mathrm{LiAsF}_{6}$ (hydrogen atoms are not shown). a) A view of the structure along the a axis, showing rows of $\mathrm{Li}^{+}$ions perpendicular to the page. Blue spheres, lithium; white spheres, arsenic; magenta, fluorine; green, carbon and oxygen in chain 1; pink, carbon in chain 2; red, oxygen in chain 2. b) A view of the structure showing the relative positions of the chains and their conformations. Thin lines indicate the coordination around the $\mathrm{Li}^{+}$cation. (Reprinted from ref. 88 with permission from Nature Publishing Group.)

Later, Shriver et al. [98] systematically studied the ionic transport mechanism and relaxation coupling of the polymer electrolytes, which provided a theoretical basis for the development of solid polymer electrolytes. The ionic conductive behavior could be generally modeled in terms of Arrhenius (crystalline phase) and Vogel-Tammann-Fulcher (amorphous phase). In 2001, Scrosati et al. [99] investigated the surface effect of the ceramic filler on $\mathrm{P}(\mathrm{EO})_{20} \mathrm{LiSO}_{3} \mathrm{CF}_{3}$ polymer electrolyte. The results demonstrated that the role of the filler was not limited to preventing crystallization of the polymer but also promoting specific interactions among the surface groups, the PEO segments and the electrolyte ionic species.

In 2013, the metal organic framework (MOF) nanoparticles were used in the preparation of PEO-based CPEs [100], and high ionic conductivity of $3.16 \times 10^{-5} \mathrm{~S}$ $\mathrm{cm}^{-1}$ at $25{ }^{\circ} \mathrm{C}$ was obtained for the electrolyte film. However, the electrolyte was unstable in air due to its sensitivity to moisture. To improve the performance, a water-insensitive stable MOF material of MIL-53(Al) was applied as the filler for 
PEO-based CPE [101]. With the Lewis acidic surface property of MIL-53(Al), the PEO-MIL-53(Al)-LiTFSI electrolyte presented an ionic conductivity of $1.62 \times 10^{-5} \mathrm{~S}$ $\mathrm{cm}^{-1}$ at room temperature, which was 2.6 times higher than that without MIL-53(Al). However, the room temperature ionic conductivity was still lower than $10^{-4} \mathrm{~S} \mathrm{~cm}^{-1}$. In 2014, Archer et al. [102] reported a cross-linked polyethylene/poly(ethylene oxide) (PE/PEO) SPE (Figure 7) with both high ionic conductivity $\left(1.6 \times 10^{-4} \mathrm{~S} \mathrm{~cm}^{-1}\right.$ at $\left.25^{\circ} \mathrm{C}\right)$ and mechanical property. This cross-linking method effectively could balance the ionic conductivity and mechanically rigid that could be used to suppress dendrite growth.
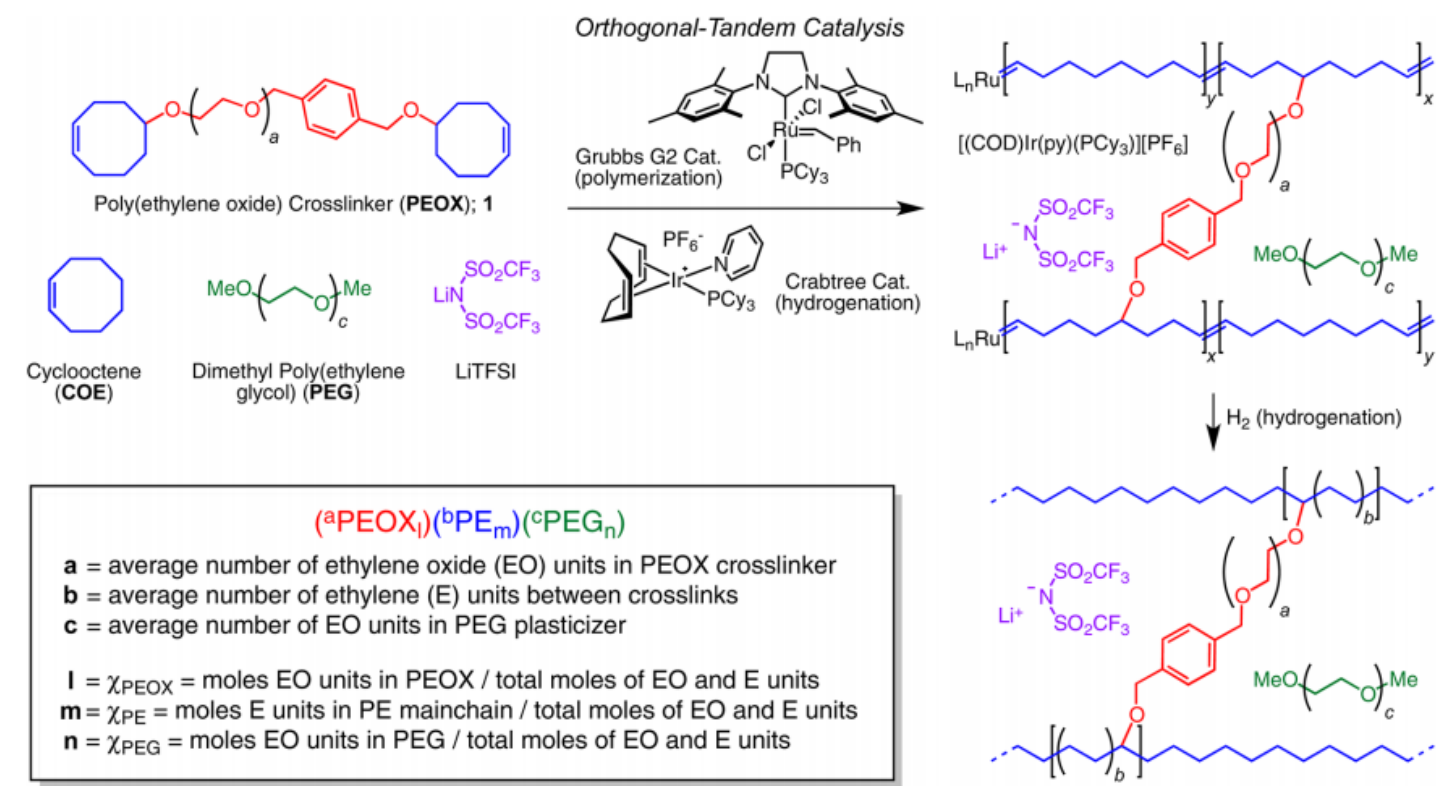

Figure 7 Synthesis routes of PE/PEO electrolyte and nomenclature. (Reprinted from ref. 102 with permission from American Chemical Society.)

In the previous work, the CPEs were usually synthesized by mechanically blending ceramic particles with polymers. Recently, Cui et al. [103] prepared a CPE $\left(4.4 \times 10^{-5} \mathrm{~S} \mathrm{~cm}^{-1}\right.$ at $\left.30{ }^{\circ} \mathrm{C}\right)$ by introducing an in-situ hydrolysis method to synthesize ceramic filler directly in solid polymer electrolyte (Figure 8), which suppressed the crystallization of PEO and facilitated polymer segmental motion for ionic conduction. 

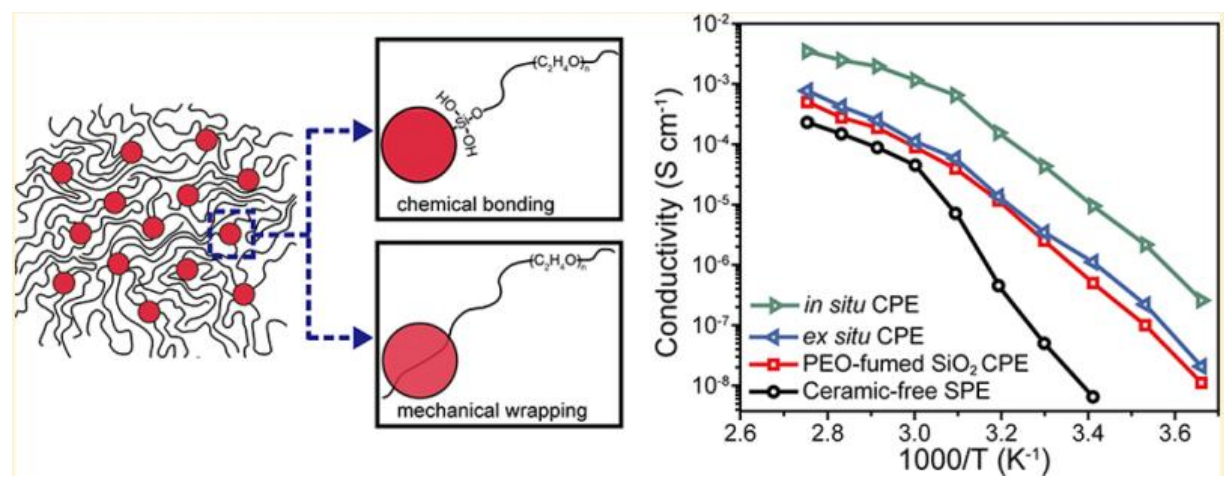

Figure 8 Left: two possible interaction mechanisms including chemical bonding and mechanical wrapping among $\mathrm{PEO}$ chains and monodispersed ultrafine $\mathrm{SiO}_{2}$ $\left(\mathrm{MUSiO}_{2}\right)$. Right: Arrhenius plots of ionic conductivity of ceramic-free SPE, PEO-fumed $\mathrm{SiO}_{2} \mathrm{CPE}$, ex situ CPE, and in situ CPE. (Reprinted from ref. 103 with permission from John Wiley and Sons, Inc.)

\subsubsection{Polysiloxane based solid electrolyte}

Besides PEO, polysiloxane has also been a candidate host for SPEs. The research on this kind of electrolytes started from 1980s [104,105]. Most of the works were focused on grafting functional groups into the polysiloxane backbone (Figure 9). The polysiloxane-based solid electrolyte displayed a relatively high conductivity due to the highly flexible of polysiloxane backbones, low glass-transition temperature $\left(T_{g}\right)$ and high free volumes. By hydrosilylation of polymethylhydrosiloxane with cyclic [(allyloxy)methyl]ethylene ester carbonic acid and vinyl tris(2-methoxyethoxy)silane, a tunable two-side-chain modified polysiloxane (VC-PMHS) was obtained [106]. The electrolyte showed an ionic conductivity of $1.55 \times 10^{-4}$ and $1.50 \times 10^{-3} \mathrm{~S} \mathrm{~cm}^{-1}$ at 25 and $100{ }^{\circ} \mathrm{C}$, respectively. Interestingly, natural materials, such as starch and sugars were also used as the hosts for SPEs by crosslinking with silane coupling reagent [107]. The electrolyte had an excellent ionic conductivity of $3.39 \times 10^{-4} \mathrm{~S} \mathrm{~cm}^{-1}$ and lithium ionic transference number of 0.8 at $25{ }^{\circ} \mathrm{C}$. 


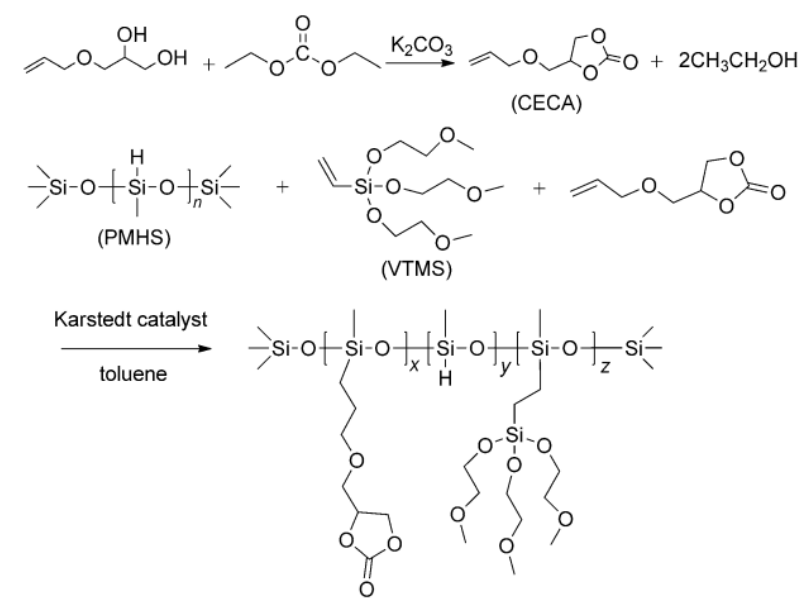

Figure 9 Synthesis of bifunctional polysiloxane (VC-PMHS). (Reprinted from ref. 106 with permission from John Wiley and Sons, Inc.)

One of the most obvious advantages for solid polymer electrolyte is its flexibility. Hence, the development of the filming technologies is particularly important. In general, polysiloxane-based solid electrolyte films were prepared by the solvent casting method. For example, a facile one-pot reaction was adopted to synthesize polysiloxane electrolyte by using polyhedral oligomeric silsesquioxane (POSS) as the cross-linker and poly(ethylene glycol) (PEG) as the lithium ion solvating polymer [108]. In preparation, all reagents were dissolved in a solvent, cast on glass plates, cured at $90{ }^{\circ} \mathrm{C}$ and then filmed at $120{ }^{\circ} \mathrm{C}$. In addition, a hot-press filming method was also used to prepare the cross-linked polysiloxane-based electrolyte in the absence of solvent. Through $-\mathrm{OCH}_{3}$ in 3-glycidoxypropyltrimethoxysilane (KH560) reacting with -OH in polyethylene glycol (PEG), the polysiloxane-based electrolyte film could be fabricated [109].

\subsubsection{Single lithium-ion conducting polymer solid electrolyte}

In 1984, Ward et al. [110] proposed the substitution of conventional dual-ion polymer electrolyte with single-ion polymer electrolyte. This kind of SPEs, which have anions covalently bonded to polymers or immobilized by anion acceptors, showed almost the unity lithium ion transference number $\left(t_{\mathrm{Li}+} \approx 1\right)$. The research on the electrolyte seems to be attractive due to the advantage of the absence of detrimental 
effect of anion polarization. However, the room temperature ionic conductivity is usually lower than $10^{-5} \mathrm{~S} \mathrm{~cm}^{-1}$. Later, Armand et al. [111] prepared a multifunctional single-ion polymer electrolyte based on polyanionic block copolymers comprising polystyrene segments, which showed a lithium-ion transport number close to unity, ionic conductivity of $1.3 \times 10^{-5} \mathrm{~S} \mathrm{~cm}^{-1}$ at $60{ }^{\circ} \mathrm{C}$, and electrochemical stability window spanning $5 \mathrm{~V}$ versus $\mathrm{Li}^{+} / \mathrm{Li}$.

Recently, hybrid and composite solid electrolyte is becoming an attractive research interest. Zhou et al. [112] presented a novel single Li-ion conducting electrolyte composed of the lithium salt of a polyanion, poly[(4-styrenesulfonyl)(trifluoromethyl(S-trifluoromethylsulfonylimino)sulfonyl)imi de] (PSsTFSI-) and PEO. The complex of LiPSsTFSI/PEO exhibited a Li-ion transference number of 0.91 , thermal stability up to $300{ }^{\circ} \mathrm{C}$, and lithium ion conductivity of $1.35 \times 10^{-4} \mathrm{~S} \mathrm{~cm}^{-1}$ at $90{ }^{\circ} \mathrm{C}$, as shown in Figure 10 .

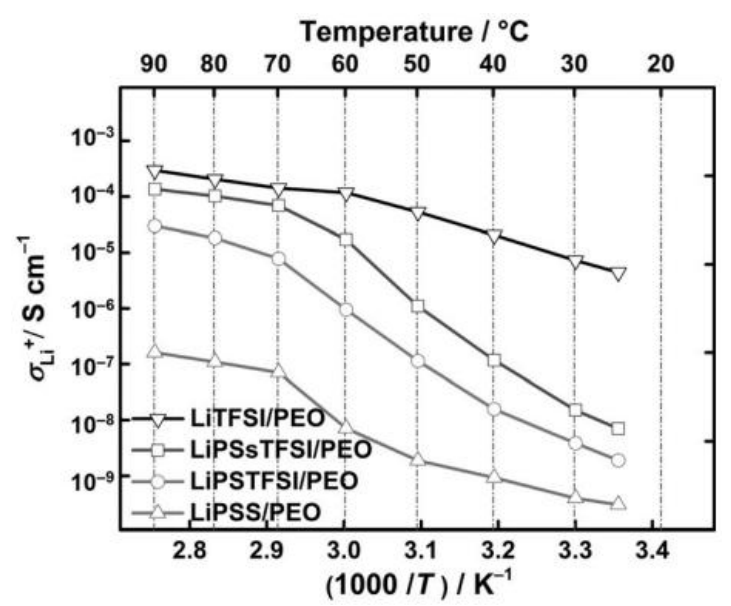

Figure 10 Temperature dependence of Li-ion conductivities for the LiX/PEO (X=PSS, PSTFSI, PSsTFSI, TFSI) blended polymer electrolytes $\left(\mathrm{EO} / \mathrm{Li}^{+}=20 / 1\right)$. (Reprinted from ref. 112 with permission from John Wiley and Sons, Inc.)

Most recently, $\mathrm{Hu}$ et al. [113] reported a 3D lithium-ion-conducting ceramic network based on garnet-type $\mathrm{Li}_{6.4} \mathrm{La}_{3} \mathrm{Zr}_{2} \mathrm{Al}_{0.2} \mathrm{O}_{12}$ (LLZO) lithium-ion conductor to provide continuous $\mathrm{Li}^{+}$transfer channels in a PEO-based composite (Figure 11). The flexible solid electrolyte membrane exhibited an ionic conductivity of $2.5 \times 10^{-4} \mathrm{~S} \mathrm{~cm}^{-1}$ 
at room temperature.

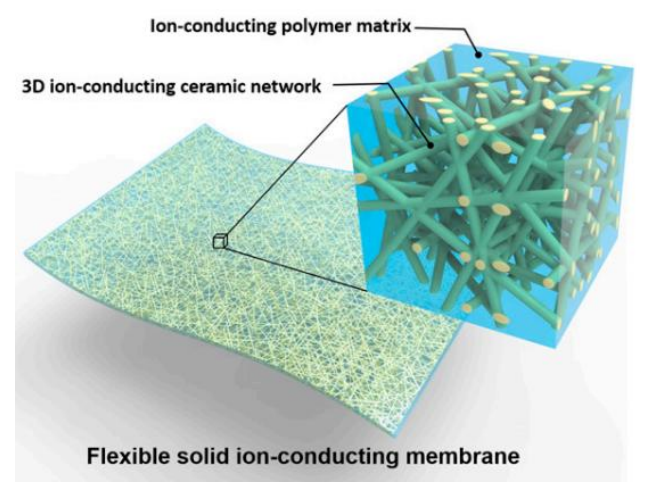

Figure 11 Schematic of the hybrid solid-state composite electrolyte. (Reprinted from ref. 113 with permission from National Academy of Sciences, USA.)

\section{All-solid-state Li batteries}

Based on the type of solid electrolytes discussed above, there are various all-solid-state Li batteries, which will be discussed in the following sections in term of the solid electrolytes used.

\subsection{Lithium-phosphorous-oxynitride (LiPON) electrolytes-based all-solid-state Li batteries}

All-solid-state thin-film rechargeable lithium batteries are important components for micro devices. In particular, thin-film batteries with LiPON electrolyte have been extensively investigated [114-124]. Thin electrode film, solid electrolyte, and current collectors are usually sequentially constructed on a substrate using various vapor deposition techniques [114-124]. Figure 12 shows a typical thin film battery configuration [125]. The full stack of films is only 10 to $15 \mu \mathrm{m}$ in thickness with a support which at least doubles the overall battery thickness. The battery can be made into flexible when the support is thin enough [126]. The batteries typically have capacities of 0.1 to $5 \mathrm{mAh}$. Such all-solid-state thin film batteries will witness wide applications in sensors, RFID tags, and smarter cards [125]. 


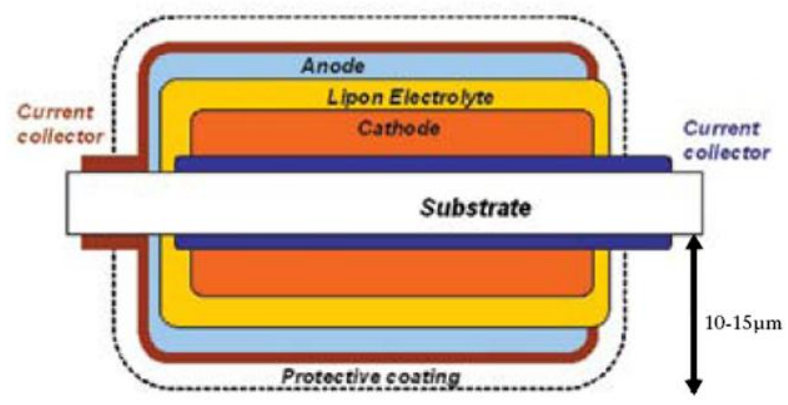

Figure 12 Schematic cross section of a thin film battery with a substrate support. (Reproduced from ref. 125 by permission of ECS- The Electrochemical Society)

Ideally the battery and its powered electronic device should be functionally integrated with maximum efficiency and voltage control [125-136]. Lethien et al. [137] reported the fabrication of a regular pattern with sputtered thin films material $\left(\mathrm{LiPON} / \mathrm{LiFePO}_{4}\right)$ as the solid electrolyte/positive electrode for a solid state 3D micro-battery. The 3D overview of the solid state micro-battery is schematically shown in Figure 13 [137]. Radio frequency (RF) sputtering deposition is used for fabricating the positive $\mathrm{LiFePO}_{4}$ electrode. Furthermore, the preparation of a self-aligned and high aspect ratio silicon nanopillar (SiNPL) based negative electrode was performed by a top down approach combined a deep reactive ion etching (DRIE) and the low cost photolithography processes. The conformal deposition of these $\mathrm{LiFePO}_{4} / \mathrm{LiPON}$ bilayers has also been achieved on the SiNPL array by RF sputtering as well.

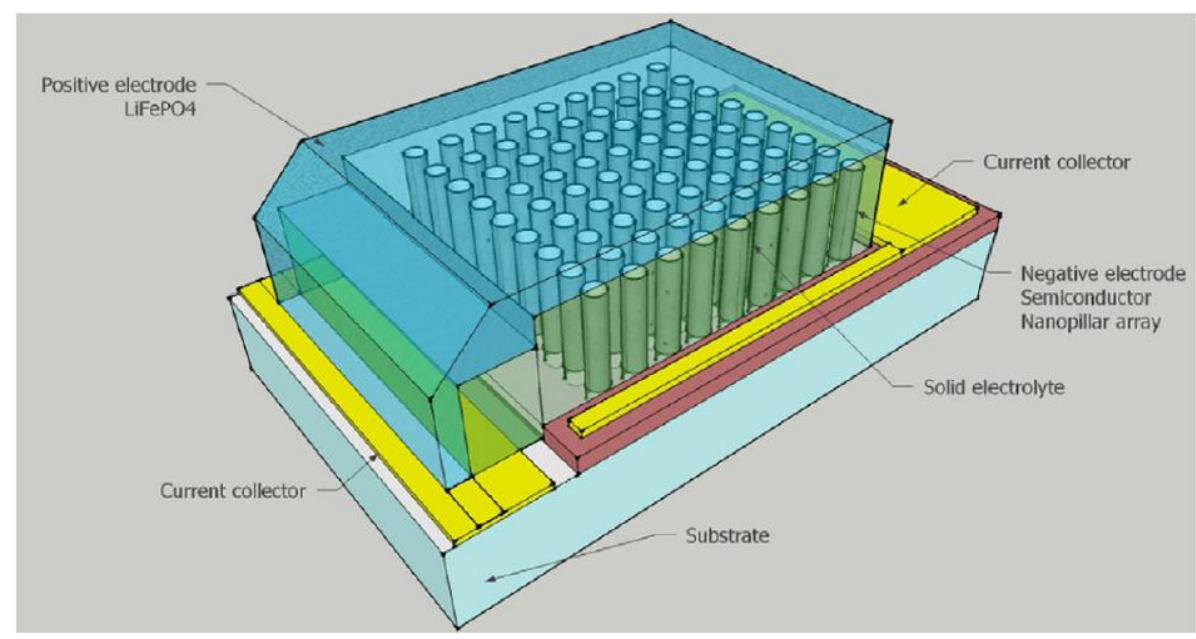


Figure 13 Overview of the lithium-ion solid state micro-battery. (Reprinted from ref. 137 with permission from Elsevier Ltd.)

\subsection{Sulfide glass solid electrolytes-based all-solid-state Li batteries}

The sulfides $\left(\mathrm{Li}_{2} \mathrm{~S}-\mathrm{P}_{2} \mathrm{~S}_{5}\right)$ with high ionic conductivity and wide electrochemical windows have been demonstrated as a kind of attractive solid electrolytes for all-solid-state Li batteries [138-142]. Tatsumisago et al. [141] reported an all-solid-state $\mathrm{Li}$ battery with $\mathrm{LiCoO}_{2}$ and $80 \mathrm{Li}_{2} \mathrm{~S} \cdot 20 \mathrm{P}_{2} \mathrm{~S}_{5}$ glass-ceramic electrodes, exhibited a long cycle performance [141]. The charge-discharge performance of the battery of $\mathrm{In} / 70 \mathrm{Li} 2 \mathrm{~S} .29 \mathrm{P}_{2} \mathrm{~S}_{5} \cdot 1 \mathrm{P}_{2} \mathrm{~S}_{3}$ glass-ceramic/Li $\mathrm{Li}_{4} \mathrm{Ti}_{12}$ is shown in Figure 14 [141]. It can be seen that the cell works reversibly even at a high current density of over $10 \mathrm{~mA} \mathrm{~cm}^{-2}$.

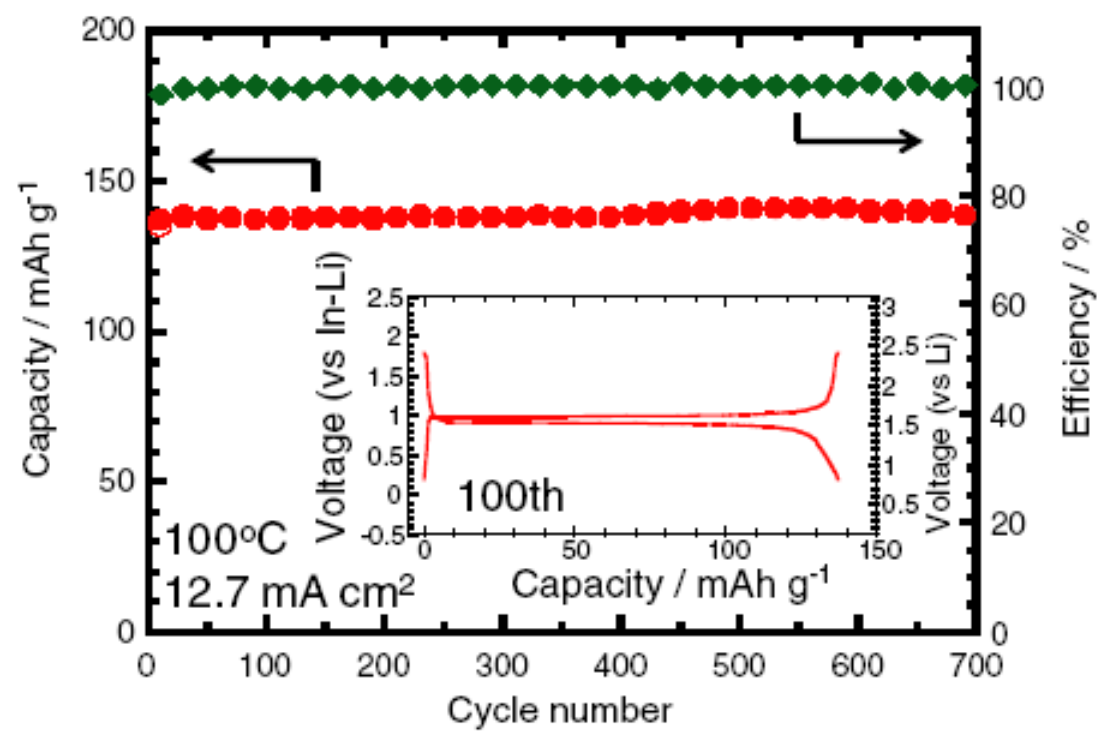

Figure 14 Battery performance of the all-solid-state Li cell: In-Li/70Li 2 S.29P $\mathrm{P}_{2} \mathrm{~S}_{5} .1 \mathrm{P}_{2} \mathrm{~S}_{3}$ glass-ceramic $/ \mathrm{Li}_{4} \mathrm{Ti}_{5} \mathrm{O}_{12}$. (Reprinted from ref. 141 with permission from Elsevier Ltd.)

It should be mentioned that $\mathrm{Li}_{2} \mathrm{~S}-\mathrm{P}_{2} \mathrm{~S}_{5}$ glass-ceramic electrolytes could also used to fabricate Li-S batteries. For example, Tatsumisago et al. [143] fabricated various types of all-solid-state $\mathrm{Li}-\mathrm{S}$ batteries with $\mathrm{Li}_{2} \mathrm{~S}-\mathrm{P}_{2} \mathrm{~S}_{5}$ glass-ceramic electrolytes. Figure 15 shows the charge-discharge curves of the all-solid-state Li-S batteries with the 
S-Cu and S-C composites together with that of $\mathrm{LiCoO}_{2}$ electrode-based battery. The batteries with sulfur displayed a much larger capacity, $>1000 \mathrm{mAh} \mathrm{g}^{-1}$, than the battery with $\mathrm{LiCoO}_{2}$. For the $\mathrm{Li} / \mathrm{S}$ batteries with the $\mathrm{S}-\mathrm{C}$ composites, the capacity could be maintained at more than $1000 \mathrm{mAh} \mathrm{g}^{-1}$ with a high charge-discharge efficiency of almost $100 \%$.

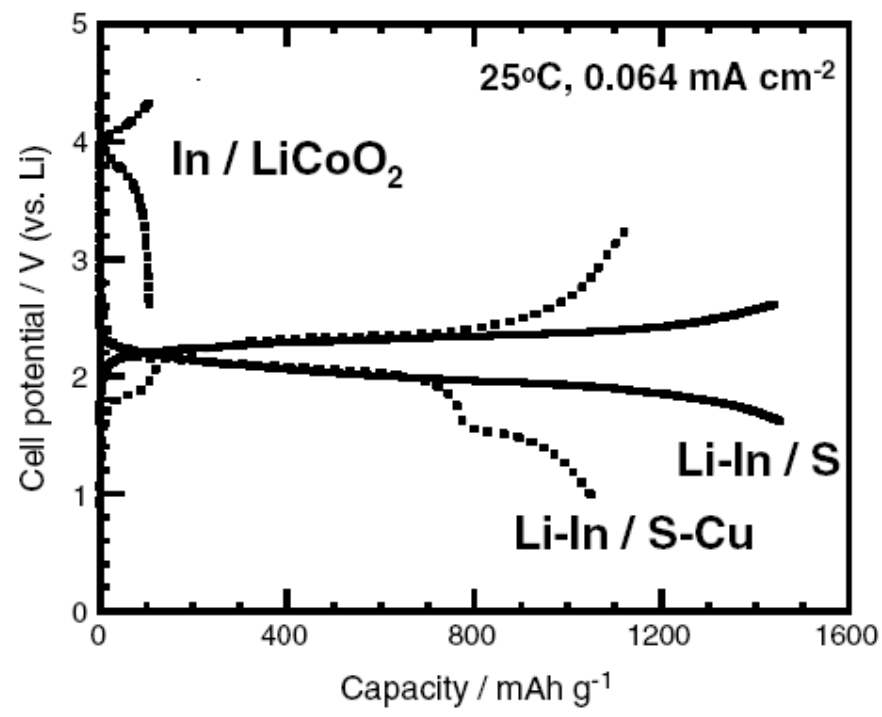

Figure 15 Charge-discharge curves for the all-solid-state $\mathrm{Li}-\mathrm{S}$ batteries with $\mathrm{Li}_{2} \mathrm{~S}-\mathrm{P}_{2} \mathrm{~S}_{5}$ glass-ceramic electrolytes. (Reprinted from ref. 143 with permission from Elsevier Ltd.)

Besides the conductivity, the mechanical property of solid electrolytes is also an important parameter. Sakuda et al. [144] found that sulfide electrolytes with low bond energy and a highly covalent character were beneficial in achieving high ionic conductivity. The Young's moduli of sulfide electrolytes fell in between those of typical oxides and organic polymers.

Recently, Kanno et al. [53] reported the feasibility of $\mathrm{Li}_{10} \mathrm{GeP}_{2} \mathrm{~S}_{12}$ as a solid electrolyte for practical lithium batteries. Figure 16 shows the charge-discharge curves of an all-solid-state battery $\left(\mathrm{LiCoO}_{2} / \mathrm{Li}_{10} \mathrm{GeP}_{2} \mathrm{~S}_{12} / \mathrm{In}\right)$ at a current density of $14 \mathrm{~mA} \mathrm{~g}^{-1}$. The battery delivers a discharge capacity of over $120 \mathrm{mAh} \mathrm{g}^{-1}$ and an excellent discharge efficiency of about $100 \%$ after the second cycle. These results showed that $\mathrm{Li}_{10} \mathrm{GeP}_{2} \mathrm{~S}_{12}$ should be applicable as a practical electrolyte for all-solid-state batteries 


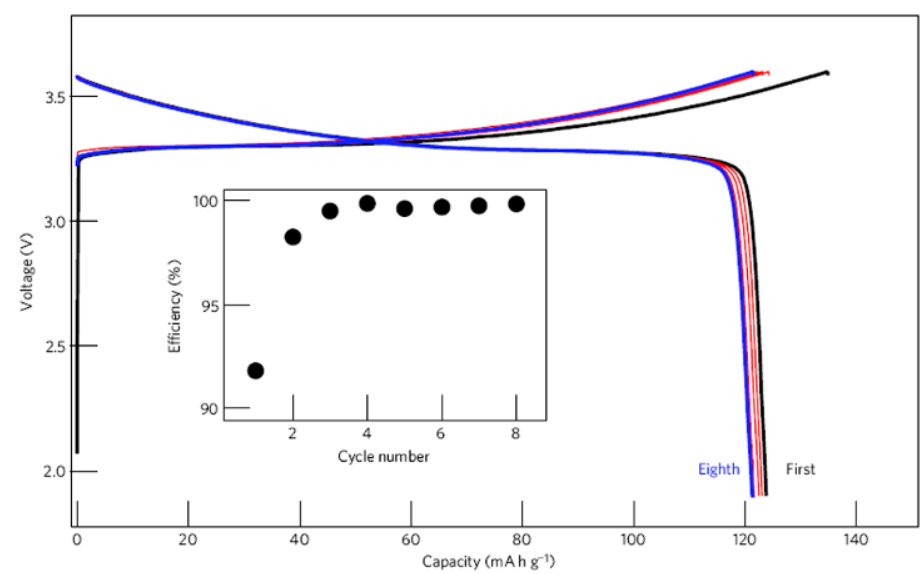

Figure 16 Charge-discharge curves of an all-solid-state battery with $\mathrm{Li}_{10} \mathrm{GeP}_{2} \mathrm{~S}_{12}$ as electrolyte. (Reprinted from ref. 53 with permission from Nature Publishing Group)

Most recently, Kato et al. [145] designed a new solid-state electrolyte ( $\mathrm{Li}_{9.54} \mathrm{Si}_{1.74} \mathrm{P}_{1.44} \mathrm{~S}_{11.7} \mathrm{Cl}_{0.3}$ ) with a high ionic conductivity of about $25 \mathrm{mS} \mathrm{cm}{ }^{-1}$ at room temperature. The remarkably enhanced conductivity was attributed to the change of $\mathrm{Li}^{+}$ion transport from one-dimensional to three-dimensional pathways originating from a different lithium distribution in the structure. To solve the electrochemical instability of $\mathrm{Li}_{9.54} \mathrm{Si}_{1.74} \mathrm{P}_{1.44} \mathrm{~S}_{11.7} \mathrm{Cl}_{0.3}$ with a lithium metal, they synthesized another Ge-free compound, $\mathrm{Li}_{9.6} \mathrm{P}_{3} \mathrm{~S}_{12}$, which was stable at a low potential relative to metallic lithium. They prepared two types of solid-state cells: one cell used $\mathrm{LiCoO}_{2}$ as the cathode and $\mathrm{Li}_{4} \mathrm{Ti}_{5} \mathrm{O}_{12}$ as the anode, and $\mathrm{Li}_{9.54} \mathrm{Si}_{1.74} \mathrm{P}_{1.44} \mathrm{~S}_{11.7} \mathrm{Cl}_{0.3}$ as the electrolyte; the other cell used $\mathrm{LiCoO}_{2}$ as the cathode, graphite as the anode, and $\mathrm{Li}_{10} \mathrm{GeP}_{2} \mathrm{~S}_{12}$ (LGPS) or $\mathrm{Li}_{9.6} \mathrm{P}_{3} \mathrm{~S}_{12}$ as the electrolyte. The former cell was able to generate large current while the latter could produce high voltage. Both cells could operate in a wide temperature range from $-30^{\circ} \mathrm{C}$ to $100^{\circ} \mathrm{C}$. The large current-type cell delivered $\sim 70 \%$ capacity in one minute at $25^{\circ} \mathrm{C}$ or in a few seconds at $100^{\circ} \mathrm{C}$. Both cells could also keep $\sim 75 \%$ capacity after 500 cycles at high-rates of charge-discharge, as shown in Figure 17 [142]. These properties are superior to those of conventional lithium-ion batteries, which cannot operate at temperatures such as $-30^{\circ} \mathrm{C}$ and do not have such a high capacity retention after cycles. This work represents a large progress in the development of all-solid-state Li batteries. 

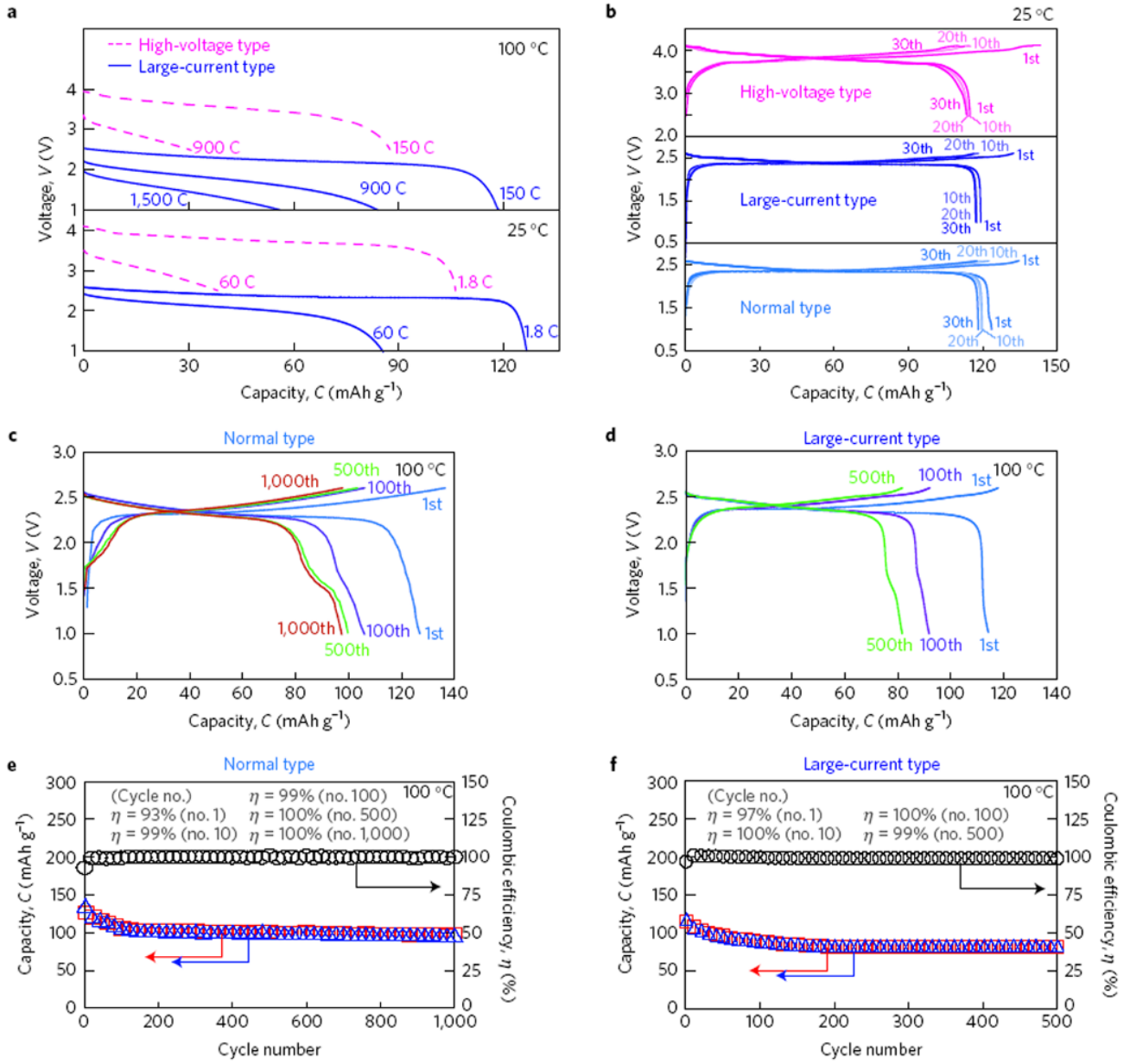

Figure 17 Performance of all-solid-state Li batteries. (a) Extraction of discharge curves for the prepared batteries, (b) Charge-discharge profiles for batteries at a rate of $0.1 \mathrm{C}$ at $25^{\circ} \mathrm{C}$, (c, d) Cycling performance of the charge-discharge curves for the normal-type batteries and the large-current-type batteries, respectively at $100^{\circ} \mathrm{C}$ (current density =18 C), (e, f) Cycling characteristics for charge-discharge capacity and efficiency for the normal-type batteries and the large-current-type batteries, respectively. (Reprinted from ref. 145 with permission from Nature Publishing Group)

\subsection{NASICON-type glass-ceramic electrolyte (LAGP/LATP)-based all-solid-state}

\section{Li batteries}

The lithium-air battery has a high theoretical energy density of 3500-5200 $\mathrm{Wh} \mathrm{kg}^{-1}$ due to the reaction of lithium and oxygen. All-solid-state lithium-air batteries with 
inorganic solid electrolytes represent a kind of safe and high energy density batteries. A solid-state $\mathrm{Li}$-air battery with a $18.5 \mathrm{Li}_{2} \mathrm{O}: 6.07 \mathrm{Al}_{2} \mathrm{O}_{3}: 37.05 \mathrm{GeO}_{2}: 37.05 \mathrm{P}_{2} \mathrm{O}_{5}(\mathrm{LAGP})$ electrolyte was built by Kumar et al. [146], which was composed of a Li anode, a composite cathode with $25 \mathrm{wt} \%$ of carbon and $75 \mathrm{wt} \%$ of 18.5 $\mathrm{Li}_{2} \mathrm{O}: 6.07 \mathrm{Al}_{2} \mathrm{O}_{3}: 37.05 \mathrm{GeO}_{2}: 37.05 \mathrm{P}_{2} \mathrm{O}_{5}$, LAGP membrane, and two layers of poly(ethylene oxide) (PEO) incorporated with a $\mathrm{Li}$ salt $\mathrm{LiN}\left(\mathrm{SO}_{2} \mathrm{CF}_{2} \mathrm{CF}_{3}\right)_{2}(\mathrm{LiBETI})$ on both sides of a LAGP membrane. The function of interlayer PEO-LiBETI was to reduce the impedance of the battery and increase the charge transfer reaction. The other interlayer between the LAGP and the carbon cathode was to improve their interfacial contact and electrochemically couple between the carbon cathode and the LAGP membrane.

The all-solid-state lithium-air cells with the $\mathrm{Li}_{1+\mathrm{x}} \mathrm{Al}_{\mathrm{y}} \mathrm{Ge}_{2-\mathrm{y}}\left(\mathrm{PO}_{4}\right)_{3}$ solid electrolyte were also constructed by Zhou et al. [147,148]. The discharge and charge capacities were about $1700 \mathrm{mAh} \mathrm{g}^{-1}$ and $900 \mathrm{mAh} \mathrm{g}^{-1}$, respectively, at a current density of 500 $\mathrm{mA} \mathrm{g}^{-1}$ in the voltage range of $2.0-4.2 \mathrm{~V}$ (vs. $\mathrm{Li}^{-\mathrm{Li}^{+}}$). Figure $18 \mathrm{a}$ shows the rate performance of the all-solid-state Li/CE/LAGP@CNT-air cell. In this battery, the multi-walled carbon nanotube plays a role as both a nanosized catalyst and a continuous electron conduction path in the air electrode. The cell could be discharged and charged even at a current density of $10 \mathrm{~A} \mathrm{~g}^{-1}$. The all-solid-state type lithium-air batteries also show a low polarization (Figure 18b).

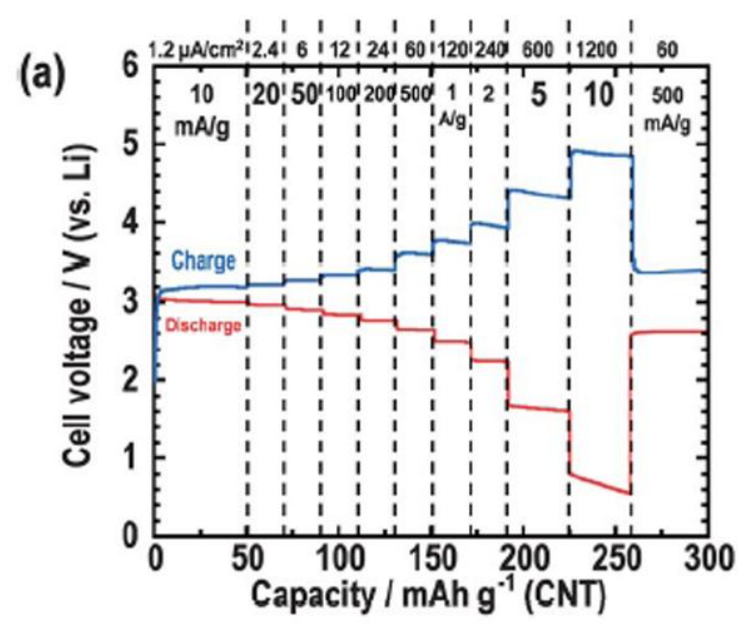




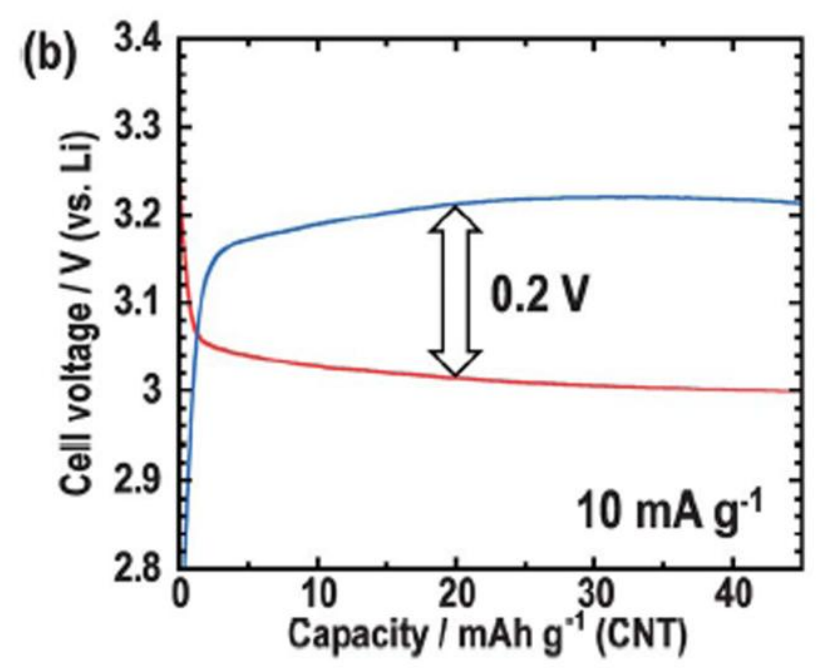

Figure 18 (a) Rate performance and (b) magnified charge-discharge curve at $10 \mathrm{~mA}$ $\mathrm{g}^{-1}$ of the solid-state Li/LAGP/LAGP@CNT-air battery. (Reprinted from ref. 147 with permission from Royal Society of Chemistry)

Symmetric cell configuration can simplify the fabrication process and reduce the interfacial issues as well as decrease manufacturing costs for all-solid-state batteries. Kobayashi et al. [149] prepared all-solid-state phosphate symmetric batteries with $\mathrm{Li}_{3} \mathrm{~V}_{2}\left(\mathrm{PO}_{4}\right)_{3}$ as both the positive and negative electrodes, and the phosphate $\mathrm{Li}_{1.5} \mathrm{Al}_{0.5} \mathrm{Ge}_{1.5}\left(\mathrm{PO}_{4}\right)_{3}$ as the solid electrolyte. Amorphous $\mathrm{Li}_{1.5} \mathrm{Al}_{0.5} \mathrm{Ge}_{1.5}\left(\mathrm{PO}_{4}\right)_{3}$ was added into the electrode to increase the interface area between the active materials and the electrolyte. The discharge capacity could reach $92 \mathrm{mAh} \mathrm{g}^{-1}$ at a current density of $22 \mu \mathrm{A} \mathrm{cm}^{-2}$ at $80{ }^{\circ} \mathrm{C}$, and $38 \mathrm{mAh} \mathrm{g}^{-1}$ at $25^{\circ} \mathrm{C}$, respectively.

Hoshina et al. prepared $\mathrm{LiNi}_{0.5} \mathrm{Mn}_{1.5} \mathrm{O}_{4}$ thin film on $\mathrm{Au}$ and LATP substrates by a PVP sol-gel method [150]. The electrochemical properties were improved by optimizing the preparation process of the interface between $\mathrm{LiNi}_{0.5} \mathrm{Mn}_{1.5} \mathrm{O}_{4}$ and LATP electrolytes. Iriyama et al. [151] fabricated a new kind of all-solid-state thin-film-type lithium-ion battery by applying a high D.C. voltage. Negative electrode material at the $\mathrm{Cu} /$ glass ceramics sheet interface was in situ formed by applying a high D.C. voltage to a layer of $\mathrm{Cu} / \mathrm{Li}_{2} \mathrm{O}-\mathrm{Al}_{2} \mathrm{O}_{3}-\mathrm{TiO}_{2}-\mathrm{P}_{2} \mathrm{O}_{5}$-based glass ceramics sheet/amorphous Li-Mn-O/Pt. The obtained battery could perform a stable charge-discharge reaction at $1.4 \mathrm{~V}$. 


\subsection{Perovskite-type (LLTO) electrolytes for all-solid-state Li batteries}

$$
\mathrm{Li}_{0.35} \mathrm{La}_{0.55} \mathrm{TiO}_{3} \text { (LLT) [123,152-155] and } \mathrm{LiTi}_{2}\left(\mathrm{PO}_{4}\right)_{3} \text { (LTP) [56,60] with high }
$$
ionic conductivities of $10^{-3}$ to $10^{-4} \mathrm{~S} \mathrm{~cm}^{-1}$ [107], could be used as the electrolytes for all-solid-state batteries. However, the cell performance is usually limited by facile reduction of $\mathrm{Ti}^{4+}$ in LLT and LTP electrolytes.

$\mathrm{Li}_{0.35} \mathrm{La}_{0.55} \mathrm{TiO}_{3}$ with a honeycomb structure, which has micro-sized holes on both sides of a membrane, was prepared as an electrolyte for three-dimensional all-solid-state $\mathrm{Li}$ batteries. The impregnation of active material $\mathrm{LiCoO}_{2}$ and $\mathrm{Li}_{4} \mathrm{Mn}_{5} \mathrm{O}_{12}$ particles mixed with the precursor sol into the honeycomb holes enabled a good contact between the LLT electrolyte and the active material, thus reduce the internal resistance of the cell and improve the discharge capacity [156]. A low resistant interface between cathode material and LLT using $\mathrm{LiMn}_{2} \mathrm{O}_{4}$ could be obtained. For example, the $\mathrm{LiCoO}_{2} / \mathrm{LLT} / \mathrm{Li}_{4} \mathrm{Mn}_{5} \mathrm{O}_{12}$ all-solid-state battery was successfully operated at $1.1 \mathrm{~V}$ with a discharge capacity of $7.3 \mu \mathrm{Ah} \mathrm{cm}^{-2}$. It should be emphasized that the formation of low resistance at active material/electrolyte interface is desired for high-performance all-solid-state batteries [157].

Thin films with amorphous lithium lanthanum titanate solid electrolyte were fabricated by e-beam evaporation under a higher power [158]. An all-solid-state $\mathrm{Li} / \mathrm{LiPON} / \mathrm{LLTO} / \mathrm{LiCoO}_{2}$ cell with LLTO thin-film as a solid electrolyte showed a discharge capacity of about $50 \mu \mathrm{Ah} / \mathrm{cm}^{2}-\mu \mathrm{m}$ and the capacity degradation was about $0.5 \%$ per cycles after 100 discharge-charge cycles at a discharge current of $7 \mu \mathrm{A} / \mathrm{cm}^{2}$. This result shows the feasibility of e-beam evaporation deposition for the fabrication of LLTO thin-film for all-solid-state Li batteries.

\subsection{Garnet-type electrolyte $\mathrm{Li}_{7} \mathrm{La}_{3} \mathrm{Zr}_{2} \mathrm{O}_{12}$-based all-solid-state $\mathrm{Li}$ batteries}

$\mathrm{Li}_{7} \mathrm{La}_{3} \mathrm{Zr}_{2} \mathrm{O}_{12}$ (LLZO) was explored as a solid electrolyte for all-solid-state rechargeable Li batteries with a Li metal anode $[159,160]$. The cyclic voltammogram of the $\mathrm{Li} / \mathrm{LLZO} / \mathrm{Li}$ cell showed that the dissolution and decomposition reactions of lithium occurred reversibly without any reaction with LLZO. This result indicated that 
the LLZO pellet was chemically and electrochemically stable against lithium metal [160]. A full cell composed of a $\mathrm{LiCoO}_{2} / \mathrm{LLZO} / \mathrm{Li}$ configuration was operated successfully at the expected voltage estimated from the redox potential of Li metal and $\mathrm{LiCoO}_{2}$. The discharge capacity of the full cell was $15 \mu \mathrm{A} \mathrm{h} \mathrm{cm}{ }^{-2}$. However, an irreversible behavior was observed at the first discharge and charge cycle due to an interfacial issue between $\mathrm{LiCoO}_{2}$ and LLZ.

The mostly studied LLZO solid electrolytes are $\mathrm{Nb}$ and Ta doped LLZO. The electrochemical performance and charge transfer resistance of an all-solid-state lithium battery $\left(\mathrm{LiCoO}_{2} / \mathrm{Li}_{6.75} \mathrm{La}_{3} \mathrm{Zr}_{1.75} \mathrm{Nb}_{0.25} \mathrm{O}_{12} / \mathrm{Li}\right)$ were measured by Ohta et al. [161]. The interfacial resistance between LCO and LLZONb was comparable to that of lithium ion batteries with liquid organic electrolytes. This battery showed a favorable charge-discharge behavior and exhibited a good stable cycle performance. A capacity retention was approximately $98 \%$ after 100 charge-discharge cycles.

Lithium ion conductor $\mathrm{Li}_{3} \mathrm{BO}_{3}$ (LBO) was used as a buffer layer between $\mathrm{LiCoO}_{2}$ active cathode material and $\mathrm{Nb}$ doped $\mathrm{Li}_{7} \mathrm{La}_{3} \mathrm{Zr}_{2} \mathrm{O}_{12}$ (LLZONb) electrolyte in an all-solid-state Li battery [162]. Sufficient interface contact between the cathode layer and the LLZONb solid electrolyte could be easily achieved with sintering LBO into the cathode layer by an annealing process. The obtained battery exhibited a good electrochemical performance and lower interfacial resistance.

Guo et al. [163] prepared Ta-doped $\mathrm{Li}_{7} \mathrm{La}_{3} \mathrm{Zr}_{2} \mathrm{O}_{12}$ electrolyte supported all-solid-state Li batteries with composite cathodes consisting of poly(vinylidene fluoride) (PVdF): LiTFSI, Ketjen Black, and carbon-coated $\mathrm{LiFePO}_{4}$ on one side and $\mathrm{Li}$ anode on the other side. As shown in Figure 19, the battery shows the first discharge capacity of $150 \mathrm{mAh} \mathrm{g}^{-1}$ at $0.05 \mathrm{C}$ and $93 \%$ capacity retention after 100 cycles at $60^{\circ} \mathrm{C}$. The performance can be further improved by increasing temperature up to $100^{\circ} \mathrm{C}$ (Figure 19d). These results indicate that the lamellar garnet-type ceramic electrolytes are promising for developing high-performance solid-state Li batteries operating at intermediate temperatures. 

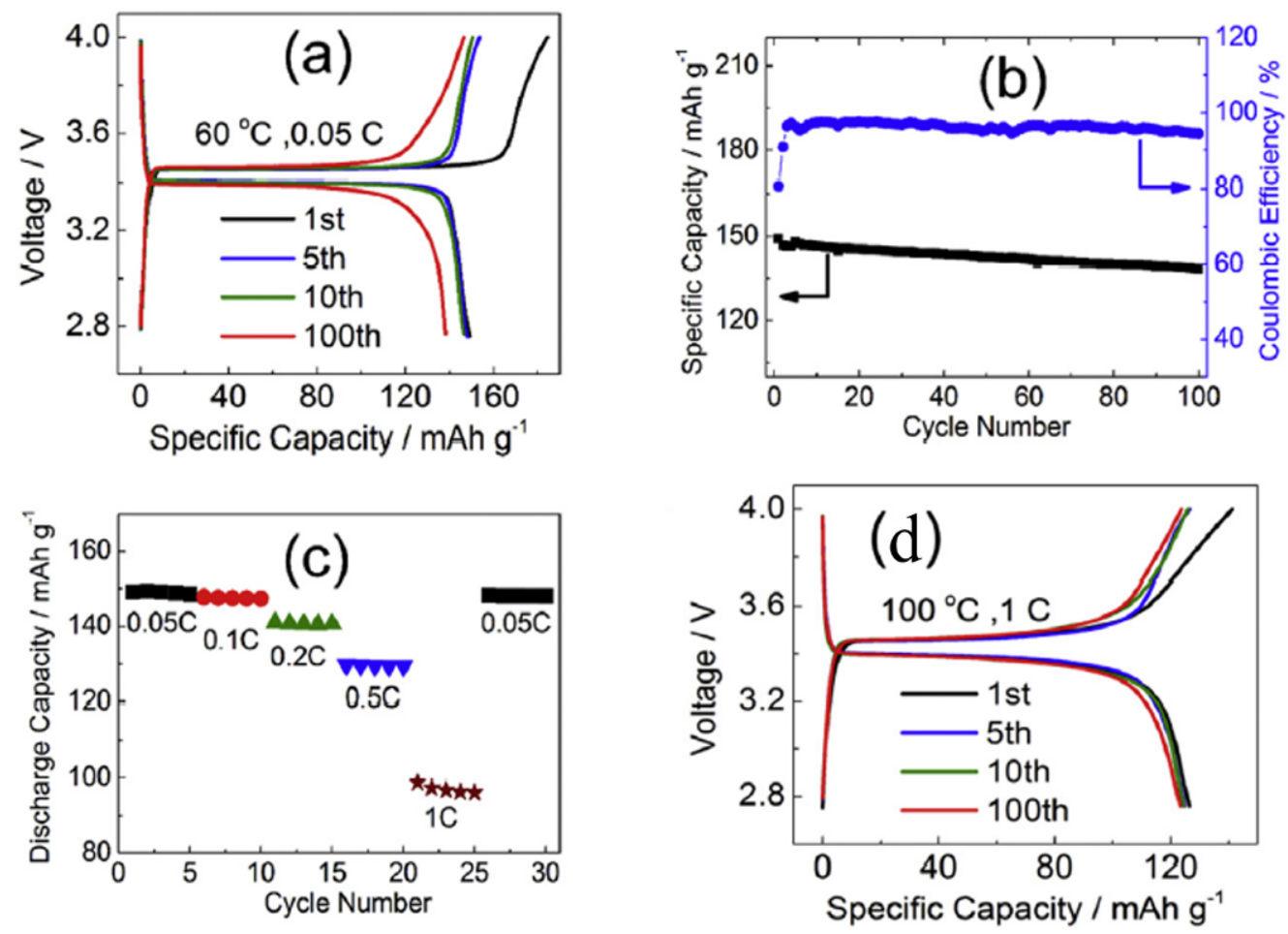

Figure 19 (a) Discharge and charge curves of the LFP:KB:PVdF:LiTFSI/LLZTO/Li batteries measured at $0.05 \mathrm{C}$ and $60^{\circ} \mathrm{C}$; (b) Coulombic efficiency and the specific discharge capacity versus cycle number; (c) Rate performance; (d) Discharge and charge curves of the LFP:KB:PVdF:LiTFSI/LLZTO/Li batteries at $1 \mathrm{C}$ and $100^{\circ} \mathrm{C}$. (Reprinted from ref. 163 with permission from Elsevier Ltd.)

Clarifying the effect of environmental factors on the Li ion conduction of solid electrolytes should be important for practical batteries. Guo et al. [164] examined the effect of moisture on the $\mathrm{Li}$ ion conduction of $\mathrm{Li}_{7} \mathrm{La}_{3} \mathrm{Zr}_{2} \mathrm{O}_{12}$ ceramic and the electrochemical properties of the LLZ-based solid state battery with a $\mathrm{LiFePO}_{4}(\mathrm{LFP})$ film cathode [164]. The secondary phase was observed in LLZ ceramic, when the specimen was exposed to humid air. Thus, a severe degradation of Li ion conduction was observed at the grain boundary. Moreover, $\mathrm{Li}_{7} \mathrm{La}_{3} \mathrm{Zr}_{2} \mathrm{O}_{12}$-based Li-rich garnets tend to react with water and carbon dioxide in air to form a $\mathrm{Li}$-ion insulating $\mathrm{Li}_{2} \mathrm{CO}_{3}$ layer on the surface of the garnet particles, leading to a large interfacial resistance for Li-ion transfer. Goodenough et al. found adding $2 \mathrm{wt} \%$ LIF to garnet 
$\mathrm{Li}_{6.5} \mathrm{La}_{3} \mathrm{Zr}_{1.5} \mathrm{Ta}_{0.5} \mathrm{O}_{12}$ can effectively increase the stability of the garnet electrolyte against moist air [165]. Therefore, the protection of LLZ ceramic from moisture is necessary to gain high performance LLZ-based solid state cell at room temperature.

\subsection{Polymer electrolyte-based all-solid-state Li batteries}

As discussed in Subsection 2.3.2, application of SPEs has also been widely explored in rechargeable lithium batteries. Compared to the conventional liquid electrolyte based lithium batteries, the SPE based electrolytes open up the opportunity for highly safe and flexible fabrication. An interpenetrating network type poly(siloxane-g-ethylene oxide) polymer electrolyte was prepared by Oh et al. in 2003 [166]. $\mathrm{LiNi}_{0.8} \mathrm{Co}_{0.2} \mathrm{O}_{2} / \mathrm{Li}$ battery with this $\mathrm{SPE}$ showed enhanced cycling performance with an initial discharge capacity of $130 \mathrm{mAh} \mathrm{g}^{-1}$. In 2008, Kobayashi et al. [167] blended PEO, poly2-(2-methoxyethoxy) ethyl glycidyl ether (PMEEGE) and lithium bis(trifluoromethylsulfonyl)imide (LiTFSI) in a molar ratio of $[\mathrm{O}] /[\mathrm{Li}]=16 / 1$ to fabricate the SPE. With matching the $\mathrm{LiFePO}_{4} / \mathrm{C}$ battery, an initial reversible capacity of $128 \mathrm{mAh} \mathrm{g}^{-1}$ was obtained at $60{ }^{\circ} \mathrm{C}$ and $1 / 24 \mathrm{C}$. In 2014 , the $\mathrm{LiFePO}_{4} / \mathrm{Li}$ battery assembled with a tunable bifunctional polysiloxane polymer (VC-PMHS) based SPE displayed long cycling performance in a wide temperature range of 25-100 ${ }^{\circ} \mathrm{C}$ with the initial discharge capacities of 88.2 and $140 \mathrm{mAh} \mathrm{g}^{-1}$ at 25 and $100{ }^{\circ} \mathrm{C}$ at 1 C, respectively [106]. Moreover, the $\mathrm{LiFePO}_{4} / \mathrm{Li}$ battery with PEO-MIL-53(Al)-LiTFSI electrolyte showed high current rate and high temperature cycling performance. After 110 cycles, the discharge capacity is $103.5 \mathrm{mAh} \mathrm{g}^{-1}$ at 10 $\mathrm{C}$ and at $120{ }^{\circ} \mathrm{C}$ [101]. In addition, the battery prototypes based on the single-ion SPE $\left(\mathrm{LiFePO}_{4} / \mathrm{A}-\mathrm{BCE} / \mathrm{Li}\right.$ ) exhibited an impressive cycling performance from 60 to $80{ }^{\circ} \mathrm{C}$ (Figure 20) [111]. These demonstrate the potential of using PEO based solid polymer electrolyte in lithium batteries for long-term and high safe application. 


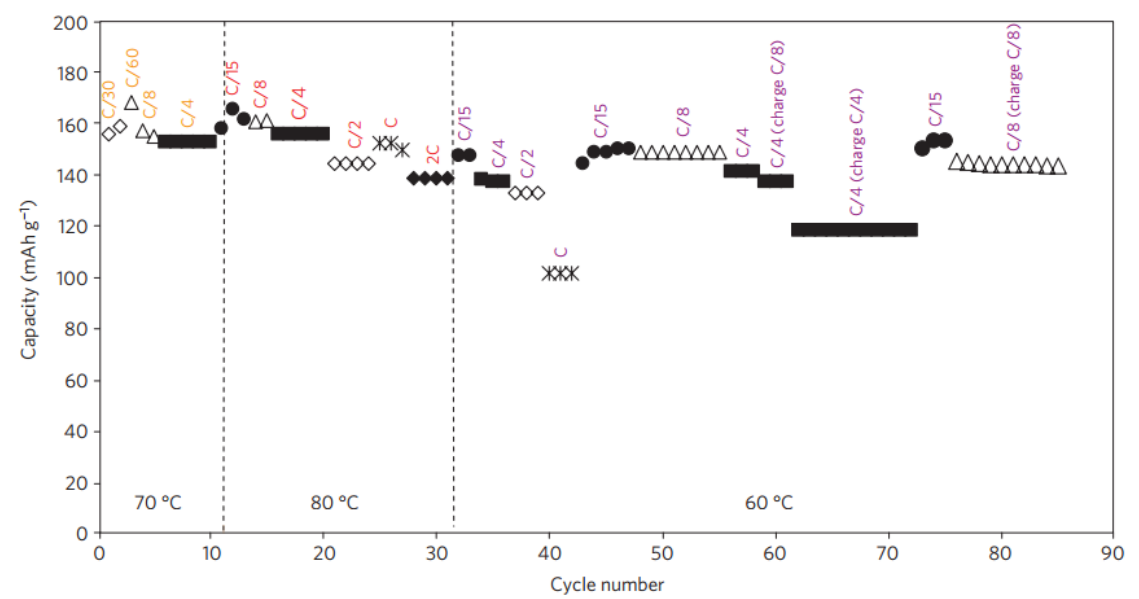

Figure 20 Cyclability of the typical prototype $\mathrm{LiFePO}_{4} / \mathrm{A}-\mathrm{BCE} / \mathrm{Li}$ battery at different temperatures and different rates. Reprinted from ref. 111 with permission from Nature Publishing Group.

Recently, Xu et al. [168] developed a hybrid SPE-inorganic electrolyte membrane by incorporating the $\mathrm{Li}_{10} \mathrm{GeP}_{2} \mathrm{~S}_{12}$ into $\mathrm{PEO}$ matrix. The $\mathrm{LiFePO}_{4} / \mathrm{Li}$ with the as-prepared electrolyte exhibited high capacity retention (92.5\% after 50 cycles at 60 ${ }^{\circ} \mathrm{C}$ ) and impressive capacities of $158,148,138$ and $99 \mathrm{mAh} \mathrm{g}^{-1}$ at current rates of 0.1 $\mathrm{C}, 0.2 \mathrm{C}, 0.5 \mathrm{C}$ and $1 \mathrm{C}$ at $60{ }^{\circ} \mathrm{C}$, respectively.

Besides traditional lithium-ion batteries, SPE also shows a potential application in the next generation of high-performance batteries such as lithium-sulfur (Li-S) battery, lithium-oxygen $\left(\mathrm{Li}-\mathrm{O}_{2}\right)$ battery and $\mathrm{Li}-\mathrm{V}_{2} \mathrm{O}_{5}$ battery. In 2010, Scrosati et al. [169] fabricated a PEO-lithium triflate $\left(\mathrm{PEO}-\mathrm{LiCF}_{3} \mathrm{SO}_{3}\right)$ solid electrolyte with nano-sized zirconia $\left(\mathrm{ZrO}_{2}\right)$ and lithium sulfide $\left(\mathrm{Li}_{2} \mathrm{~S}\right)$. Through applying the SPE in the Li-S batteries, the initial discharge capacity was $900 \mathrm{mAh} \mathrm{g}^{-1}$ at $0.05 \mathrm{C}$ and at $90{ }^{\circ} \mathrm{C}$. In 2015, a macro-structural sulfur cathode was combined with PEO-MIL-53(Al)-LiTFSI electrolyte to inhibit polysulfide dissolution and shuttling in all-solid-state Li-S batteries [170]. After 1000 cycles at $4 \mathrm{C}, 80{ }^{\circ} \mathrm{C}$ and at $0.5 \mathrm{C}, 60{ }^{\circ} \mathrm{C}$, the discharge capacities of 325 and $558 \mathrm{mAh} \mathrm{g}^{-1}$ were obtained, respectively (Figure 21a). Lately, the macro-structural sulfur cathode was matched with the starch based SPE, and the all-solid-state Li-S battery delivered an initial capacity of $1442 \mathrm{mAh} \mathrm{g}^{-1}$ and an average discharge capacity of $864 \mathrm{mAh} \mathrm{g}^{-1}$ at $0.1 \mathrm{C}$ for 100 cycles at room 
temperature (Figure 21b) [107]. After 2000 cycles at $45{ }^{\circ} \mathrm{C}$ and $2 \mathrm{C}$, the discharge capacity of the battery still reached $221 \mathrm{mAh} \mathrm{g}^{-1}$ (Figure 21c). A technique towards realizing energy power and safety with low cost and high sustainability was claimed. Recently, Sun et al. demonstrated a free-standing vanadium pentoxide $\left(\mathrm{V}_{2} \mathrm{O}_{5}\right)$ nanowire-reduced graphene oxide ( $\mathrm{GGO}$ ) composite paper for direct use as a cathode without any additives for high-temperature and safe lithium-vanadium batteries with a solid polymer electrolyte [PEO-MIL-53(Al)-LiTFSI] [171]. The batteries show a fast and stable lithium-ion-storage performance in a wide voltage window of 1.0-4.0V versus $\mathrm{Li}^{+} / \mathrm{Li}$ at $80^{\circ} \mathrm{C}$. An average capacity of $392.2 \mathrm{mAh} \mathrm{g}^{-1}$ at $17 \mathrm{~mA} \mathrm{~g}^{-1}$ and a stable cycling performance over 40 cycles are achieved. More importantly, the composite paper is a promising cathode material for next-generation flexible energy-storage devices.

(a)

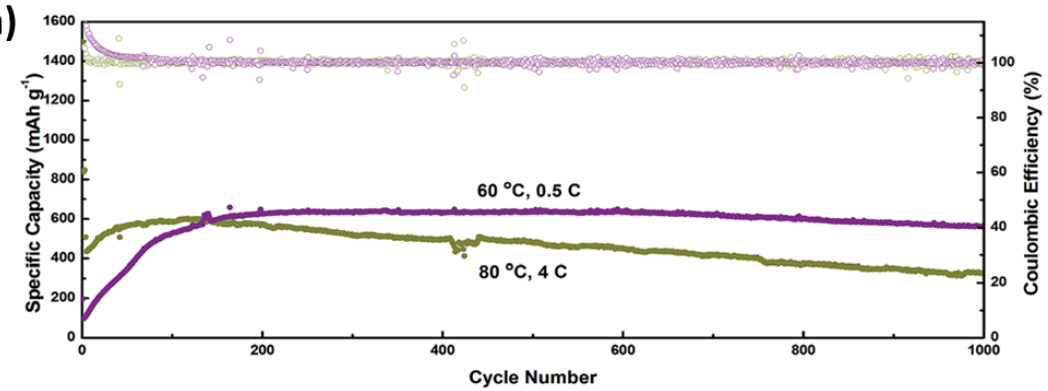

(b)

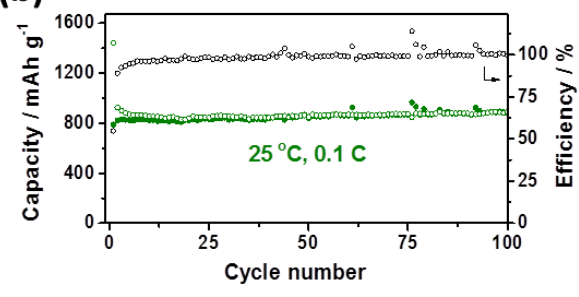

(c)

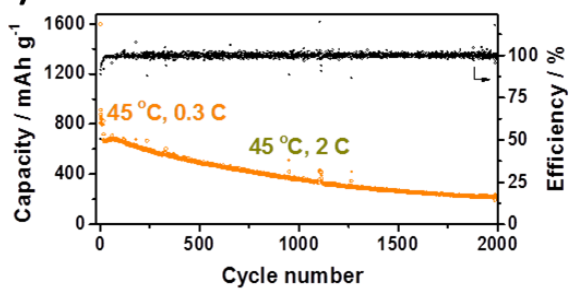

Figure 21 (a) Discharge capacity (solid circle) and Coulombic efficiencies (open circle) of the macro-structural sulfur cathode combined with PEO-MIL-53(Al)-LiTFSI electrolyte at $80 \mathrm{C}, 4 \mathrm{C}$ (dark yellow, after a three-cycle activation at $80{ }^{\circ} \mathrm{C}, 0.2 \mathrm{C}$ ) and at $60{ }^{\circ} \mathrm{C}, 0.5 \mathrm{C}$ (purple). Discharge capacity (solid circle) and Coulombic efficiencies (open circle) of the macro-structural sulfur cathode combined with starch hosted electrolyte at (b) $25{ }^{\circ} \mathrm{C}, 0.1 \mathrm{C}$ and (c) $45{ }^{\circ} \mathrm{C}, 2 \mathrm{C}$. (Reprinted from ref. 107 and 170 with permission from Royal Society of Chemistry). 
Moreover, Yair et al.[172] used PEO as the electrolyte, CNT as the cathode, when the operating temperature was higher than the melting point of the polymer, the SPE-based $\mathrm{Li}-\mathrm{O}_{2}$ cell demonstrated a comparable discharge capacity to glyme-based Li- $\mathrm{O}_{2}$ cells at the same discharge current density. The SPE-based $\mathrm{Li}_{2} \mathrm{O}_{2}$ cells could cycle stably for 40 cycles at a current density of $0.2 \mathrm{~mA} \mathrm{~cm}^{-2}$.

By using solid electrolyte, the safety and cycling performance of the $\mathrm{Li}-\mathrm{V}_{2} \mathrm{O}_{5}$ battery could be significantly improved. In 2015, Lee et al. [173] designed the core-shell silica particles with ion-conducting poly(ethylene glycol) and anion-trapping boron moiety in the shell layer. The ionic conductivity of the solid electrolyte with $30 \mathrm{wt} \%$ of core-shell silica particle in the polymer matrix reached $1.6 \times 10^{-4} \mathrm{~S} \mathrm{~cm}^{-1}$ at $30{ }^{\circ} \mathrm{C}$. The capacity of the SPE based $\mathrm{Li}-\mathrm{V}_{2} \mathrm{O}_{5}$ battery had $80 \%$ retention compared to the initial capacity after 50 cycles. Recently, Liu et al. [174] prepared a novel SPE film by adding natural halloysite nano-clay, which shows exceptional ionic conductivity of $1.11 \times 10^{-4} \mathrm{~S} \mathrm{~cm}^{-1}$ and lithium ion transference number of 0.40 at $25^{\circ} \mathrm{C}$. The impressive performance has been demonstrated in an all-solid-state lithium-sulfur battery with this electrolyte over a wide temperature range of $25-100^{\circ} \mathrm{C}$, which was attributed to the enhanced lithium ions transport in this novel electrolyte.

\section{Progress in improving the solid/solid interface of all-solid-state $\mathrm{Li}$}

\section{batteries}

As discussed in Section 2, electrochemical reactions in all solid-state batteries occur through the solid-solid interface between the electrode and solid electrolyte materials, which is different from that in conventional batteries with liquid electrolytes. Thus, formation of intimate contacts at the solid/solid electrode-electrolyte interfaces is a key to improve electrochemical performance of all-solid-state batteries because charge-transfer reaction proceeds only at the contacted interfaces [175-178]. In general, surface modification techniques with ball-milling, PLD-coating, and softening glassing are proved to be effective in 
forming intimate interface and enhancing contact areas between electrode and electrolyte.

A commonly used approach to fabricate electrode-electrolyte contacts is the preparation of nanocomposites by a ball milling process $[179,180]$. For example, Hayashi et al. [180] successfully prepared electrode-electrolyte nanocomposites by a mechanochemical method. The nano-sized NiS electrode with a large capacity was embedded in the $80 \% \mathrm{Li}_{2} \mathrm{~S}-20 \% \mathrm{P}_{2} \mathrm{~S}_{5}(\mathrm{~mol} \%)$ electrolyte with high $\mathrm{Li}^{+}$conductivity [180]. All-solid-state Li batteries with the nanocomposites showed a larger capacity and better cycling performance than the cell with the electrode obtained by conventional hand-mixing of powders. This was probably due to the increased contact area of solid-solid interface between the electrode and the electrolyte. This mechanochemical technique demonstrated an effective process for solid-state batteries with both high power density and high energy density.

Another approach is the surface coating of active material particles with thin films of solid electrolytes [181]. During the preparation, the mixture of active material and glass electrolyte was heated at around glass transition temperature of the electrolyte to fabricate solid-liquid interfaces. After cooled down to room temperature, favorable electrode-electrolyte contacts could be obtained. The associated all-solid-state $\mathrm{Li}$ batteries with $\mathrm{Li}_{2} \mathrm{~S}-\mathrm{P}_{2} \mathrm{~S}_{5}$ solid electrolytes showed a long cycle life (>500 cycles at room temperature) [26].

To form an effective electrode/solid-electrolyte interface, pulsed laser deposition method was also explored by Sakuda et al. [182] and Aso et al. [183] to coat the $80 \% \mathrm{Li}_{2} \mathrm{~S}-20 \% \mathrm{P}_{2} \mathrm{~S}_{5}(\mathrm{~mol} \%)$ solid electrolyte onto $\mathrm{LiCoO}_{2}$ electrode particles and form electrode/electrolyte composite materials for rechargeable all-solid-state Li batteries $[182,183]$. In the process, $\mathrm{LiNbO}_{3}$ film with a thickness of $7 \mathrm{~nm}$ was formed on $\mathrm{LiCoO}_{2}$ particles in advance. Figure 22a shows a cross-sectional TEM image of the solid electrolyte-coated $\mathrm{LiCoO}_{2}$ particles. The cell can be charged up to $3.6 \mathrm{~V}$ vs. Li-In and discharged to $2 \mathrm{~V}$ vs. Li-In at a current density of $0.13 \mathrm{~mA} \mathrm{~cm}^{-2}$. The cell without $\mathrm{LiCoO}_{2}$ is not able to be charged and discharged. However, the all-solid-state Li battery with a solid electrolyte-coated $\mathrm{LiCoO}_{2}$ can be reversibly charged and 
discharged. The reversible capacity of the battery with $\mathrm{LiCoO}_{2}$ film is about $30 \mathrm{mAh}$ $\mathrm{g}^{-1}$, and can keep a capacity stably for 100 cycles without significant decrease (Figure 22b). Therefore, the coating of sulfide solid-electrolyte on the electrode particles is an effective technique for enhancing the energy density of all-solid-state Li batteries $[26,182]$.
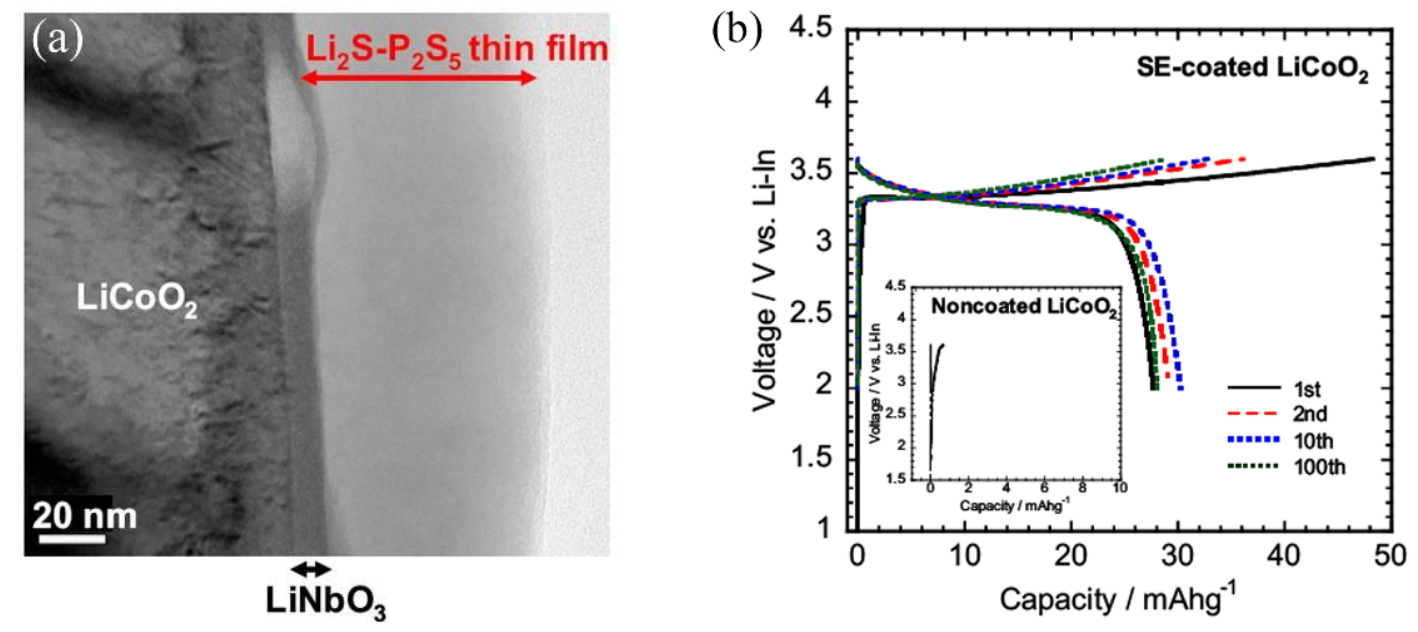

Figure 22 (a) Cross-sectional TEM image of the $\mathrm{Li}_{2} \mathrm{~S}-\mathrm{P}_{2} \mathrm{~S}_{5}$ solid-electrolyte coated $\mathrm{LiCoO}_{2}$ particles, (b) Charge-discharge curves of the all-solid-state cell (In/80Li $2 \mathrm{~S}_{2} 20 \mathrm{P}_{2} \mathrm{~S}_{5} \mathrm{SE} / \mathrm{Li}_{2} \mathrm{~S}-\mathrm{P}_{2} \mathrm{~S}_{5}$ SE-coated $\mathrm{LiCoO}_{2}$ ), the charge-discharge curve of $\mathrm{In} / 80 \mathrm{Li}_{2} \mathrm{~S} .20 \mathrm{P}_{2} \mathrm{~S}_{5} /$ noncoated $\mathrm{LiCoO}_{2}$ is shown in the inset. The positive electrode layer is consisted of only $\mathrm{LiCoO}_{2}$ particles; the solid electrode and electron conductive additive particles are not added to the positive electrode layer. (Reproduced from ref. 182 by permission of ECS- The Electrochemical Society)

To improve rate capability of all-solid-state Li batteries, the contact area of different components in a composite working electrode should be increased. Aso et al. [184] fabricated an all-solid-state Li battery using the mixture of the NiS- vapor grown carbon fiber (VGCF) composite and sulfide-based solid electrolyte (SE) particles as a working electrode. The batteries showed an initial discharge capacity of $590 \mathrm{mAh} \mathrm{g}^{-1}$ at $1.3 \mathrm{~mA} \mathrm{~cm}^{-2}$, and also a better cycle performance than the cell with a mixture of NiS, VGCF, and SE particles. 
The interfacial resistances of all-solid-state $\mathrm{Li}$ batteries with $\mathrm{LiCoO}_{2}$ cathode and sulfide solid electrolytes could be significantly decreased through coating $\mathrm{LiNbO}_{3}$ [185], $\mathrm{Li}_{4} \mathrm{Ti}_{5} \mathrm{O}_{12}$ [186], $\mathrm{LiTaO}_{3}$ [187], $\mathrm{Li}_{2} \mathrm{O}-\mathrm{SiO}_{2}\left[188,189\right.$ ] or $\mathrm{Al}_{2} \mathrm{O}_{3}$ [190] on $\mathrm{LiCoO}_{2}$. The interfacial resistance between $\mathrm{Li}_{7} \mathrm{La}_{3} \mathrm{Zr}_{2} \mathrm{O}_{12}$ and $\mathrm{LiCoO}_{2}$ could be decreased by introducing a thin $\mathrm{Nb}$ layer $(\sim 10 \mathrm{~nm})$ [191]. The $\mathrm{Nb}$ interlayer dramatically improved both the discharge capacity and rate capability of the battery. Moreover, insertion of a Li-alloy thin layer at the interface between Li electrode and solid electrolyte layer led to a stable Li dissolution and deposition in the cells [192-195]. The modification is also effective in establishing homogeneous interfaces between Li metal and solid electrolyte. Very recently, Tatsumisago et al. [196] found that the vacuum-evaporation incorporation of $\mathrm{Au}$ thin film between $\mathrm{Li}$ metal and solid electrolyte could be effective in stabling Li dissolution and deposition.

The strategy constructing one homogeneous layer with mixed conductivity was used in the all-solid-state Li batteries. To eliminate the high interfacial resistance of solid-state batteries, Wang et al. [197] demonstrated a $\mathrm{Li}_{10} \mathrm{GeP}_{2} \mathrm{~S}_{12}$ (LGPS) based battery made from a single material (Figure 23b). The Li-S and Ge-S components in LGPS acted as the cathode and anode, respectively, by mixing LGPS with carbon, which had the similar roles to the $\mathrm{Li}_{2} \mathrm{~S}$ cathode and $\mathrm{GeS}_{2}$ anode. The capacity of this single-LGPS all-solid-state Li battery could reach $104 \mathrm{mAh} \mathrm{g}^{-1}$ (LGPS) (Figure 24d). When the working temperature was increased to $55^{\circ} \mathrm{C}$, the reversible capacity of the battery increased from 70 to $96 \mathrm{mAh} \mathrm{g}^{-1}$ (LGPS) (Figure 24f). The low interfacial resistance was ascribed to the improved interfacial contact, the modified interfacial interactions, and the effective mitigation of the strain/stress at the interface. This work provides a promising strategy for solving interfacial problems in all-solid-state Li batteries. 

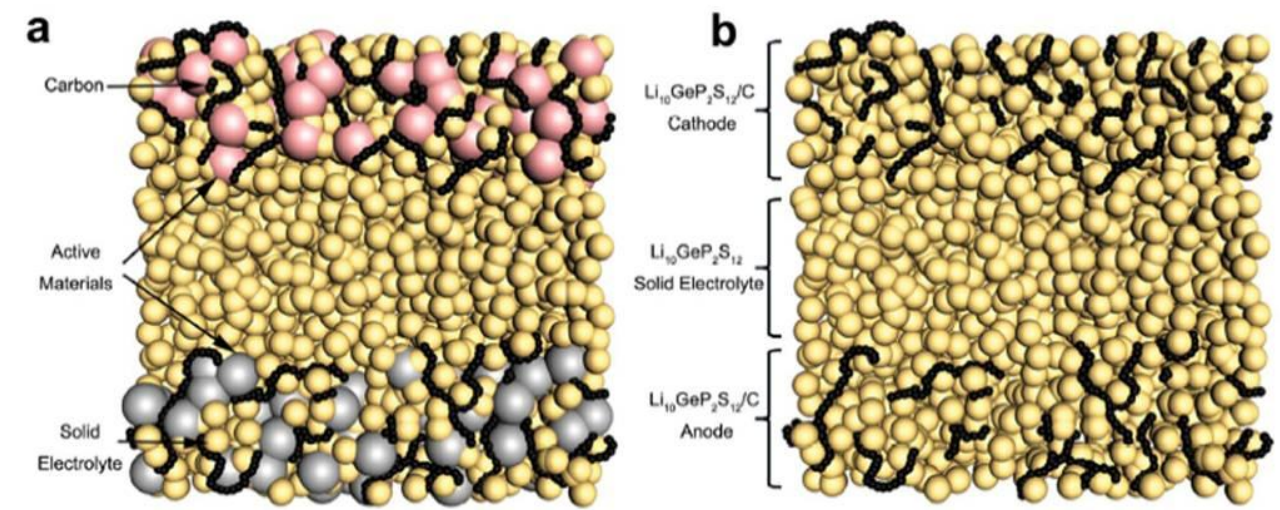

Figure 23 Schematic diagrams of (a) a typical bulk-type all-solid-state Li-ion battery and (b) a single- $\mathrm{Li}_{10} \mathrm{Ge}_{2} \mathrm{~S}_{12}$ all-solid-state Li-ion battery. (Reprinted from ref. 197 with permission from John Wiley and Sons.)
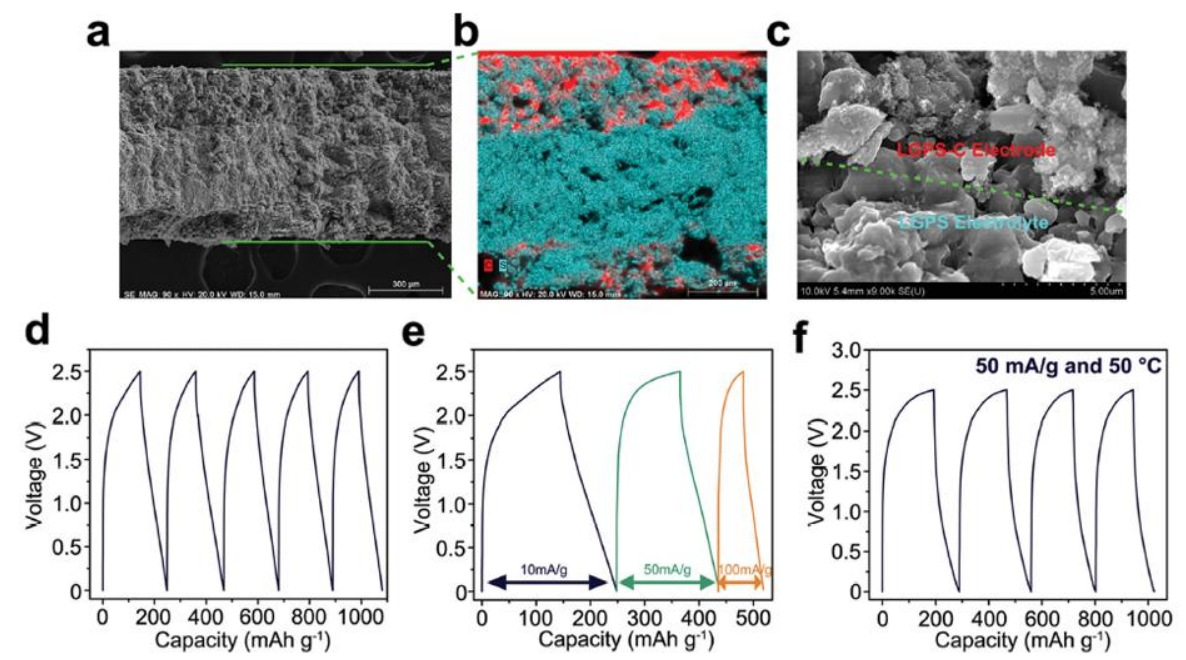

Figure 24 Microstructure and electrochemical performance of the single- $\mathrm{Li}_{10} \mathrm{GeP}_{2} \mathrm{~S}_{12}$ battery. (a) Cross-section SEM images and (b) Elemental mappings of C (red) and S (blue) of the single-LGPS battery, (c) High-magnification image displaying the interface between LGPS electrode and LGPS electrolyte, (d) Charge/discharge curves of the single-LGPS Li battery in the voltage range of $0.0-2.5 \mathrm{~V}$ from the second cycle at different current densities, (f) Charge/discharge curves of the single-LGPS battery in the voltage range of $0.0-2.5 \mathrm{~V}$ from the second cycle at $50^{\circ} \mathrm{C}$ at a current density of $50 \mathrm{~mA} \mathrm{~g}^{-1}$. (Reprinted from ref. 197 with permission from John Wiley and Sons.)

Recently, Hu et al. reported a novel sytrategy to solve the interfacial issue between 
Li metal anode and garnet-type $\mathrm{Li}_{7} \mathrm{La}_{2.75} \mathrm{Ca}_{0.25} \mathrm{Zr}_{1.75} \mathrm{Nb}_{0.25} \mathrm{O}_{12}$ (LLCZN) solid electrolyte toward all-solid-state Li batteries [198]. Ultrathin atomic layer deposition (ALD) coating of $\mathrm{Al}_{2} \mathrm{O}_{3}$ effectively decreased the interfacial impedance from $1710 \Omega$ $\mathrm{cm}^{2}$ of the pristine Li/garnet to $1 \Omega \mathrm{cm}^{2}$ of the stabilized Li/ALD-coated garnet since the $\mathrm{Al}_{2} \mathrm{O}_{3}$ coating on garnet enables a conformal interface of garnet/Li and the higher binding energy of Li with lithiated alumina further enhances the conformal interface. Meanwhile, ultrathin lithiated alumina provides high Li-ion transport paths through the interface and stabilizes the garnet/Li interface. This work represents a major advancement of all-solid-state batteries.

Dynamic observation of the potential profile and its distribution across the electrode/electrolyte interface is helpful in clarifying sources of resistance and constructing high-performance batteries by combining nano-engineering and materials design. Ex-situ analytical characterization of solid-solid interface using TEM was explored by Brazier et al. [199] using a focused ion beam processes crossing the section of a cycled thin film battery. Such preparation of nano-battery could offer a high-resolution characterization of the solid electrolyte-electrode interface. Recently, Meng et al. [200] reported a new approach using in-situ scanning transmission electron (STEM) energy loss spectroscopy (EELS) to characterize the interfacial phenomena in all-solid-state batteries with a simultaneous galvanostatic biasing. They prepared all-solid-state $\mathrm{Li}$ batteries consisting of $2 \mu \mathrm{m} \mathrm{LiCoO}_{2}, 80 \mathrm{~nm}$ amorphous $\mathrm{Si}$, and $1.5 \mu \mathrm{m}$ lithium phosphorous oxynitride LIPON electrolyte with $\mathrm{Au}$ and $\mathrm{Cu}$ as cathode and anode current collectors, respectively. Cross sectional ion-beam image of the battery is shown in Figure 25a. An initial irreversible capacity loss is observed on the first cycle with Coulombic efficiency of $75 \%$ (Figure 25b), while the subsequent cycles show Coulombic efficiencies of nearly 100\%. The STEM-EELS reveals a disordered interfacial layer between cathode and electrolyte that accumulates lithium and evolves to rocksalt $\mathrm{CoO}$ after cycling. Compared to the pristine sample, the ex-situ sample has a remarkable integrated intensity in the disordered LCO layer contouring to the physical morphology of the LiPON/disordered LCO interface (Figure 25c). This layer is formed due to the 
depositing cathode materials, which are structurally unstable in highly delithiated states on LiPON.
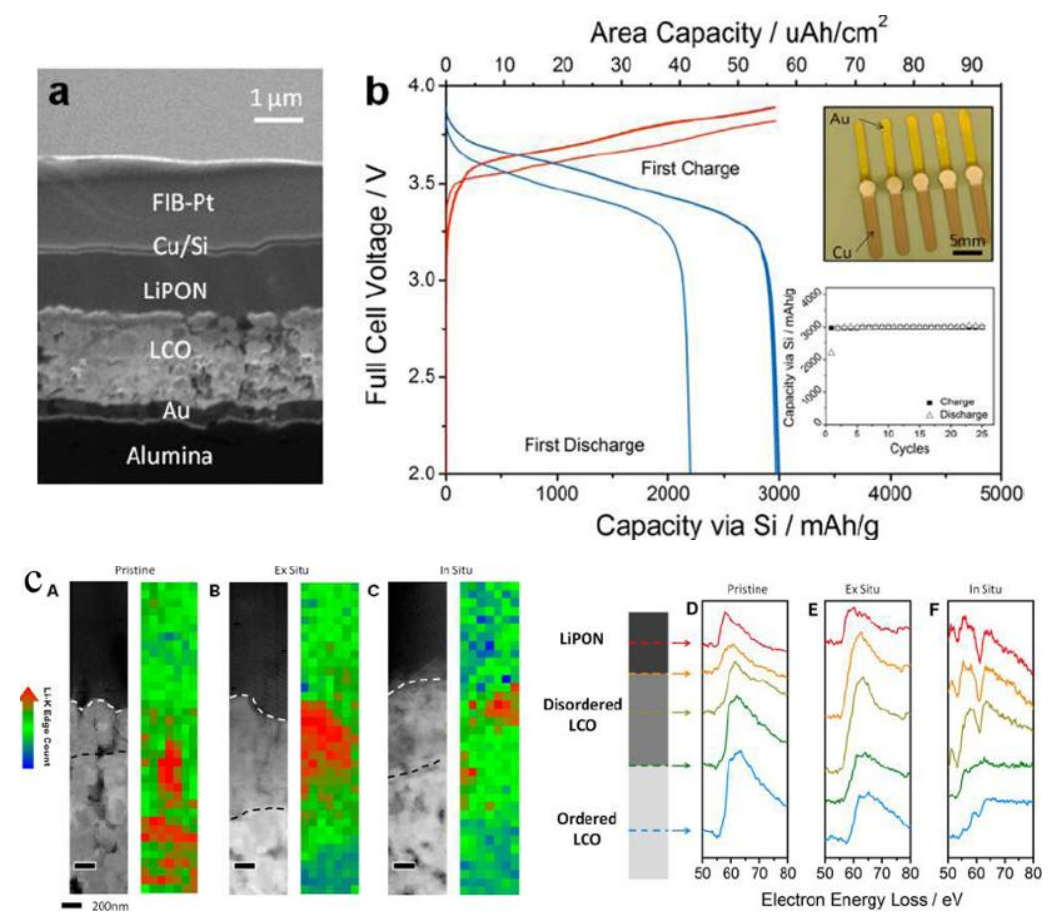

Figure 25. RF-magnetron sputtered all-solid-state Li batteries. (a) Cross sectional ion-beam image of the solid-state battery shows all the solid-state components, (b) The cycling profile of the all-solid-state Li battery. (c) STEM image and EELS characterization. (D-F) Li K-edge spectra from various parts of the layers are shown for (D) pristine, (E) ex-situ, and (F) in-situ samples. (Reprinted with permission from ref. 200. Copyright 2016 American Chemical Society.)

Yamamoto et al. [201] observed the electric potential distribution at the $\mathrm{LiCoO}_{2} /$ solid electrolyte interface (Figure 26) in all-solid-state Li-ion batteries using a quantitative electron holography $(\mathrm{EH})$ method coupled with a transition electron microscope. The results showed the potential distribution across a $\mathrm{LiCoO}_{2}$ positive-electrode/solid-electrolyte interface resulting from Li-ion diffusion during charge-discharge reactions. 


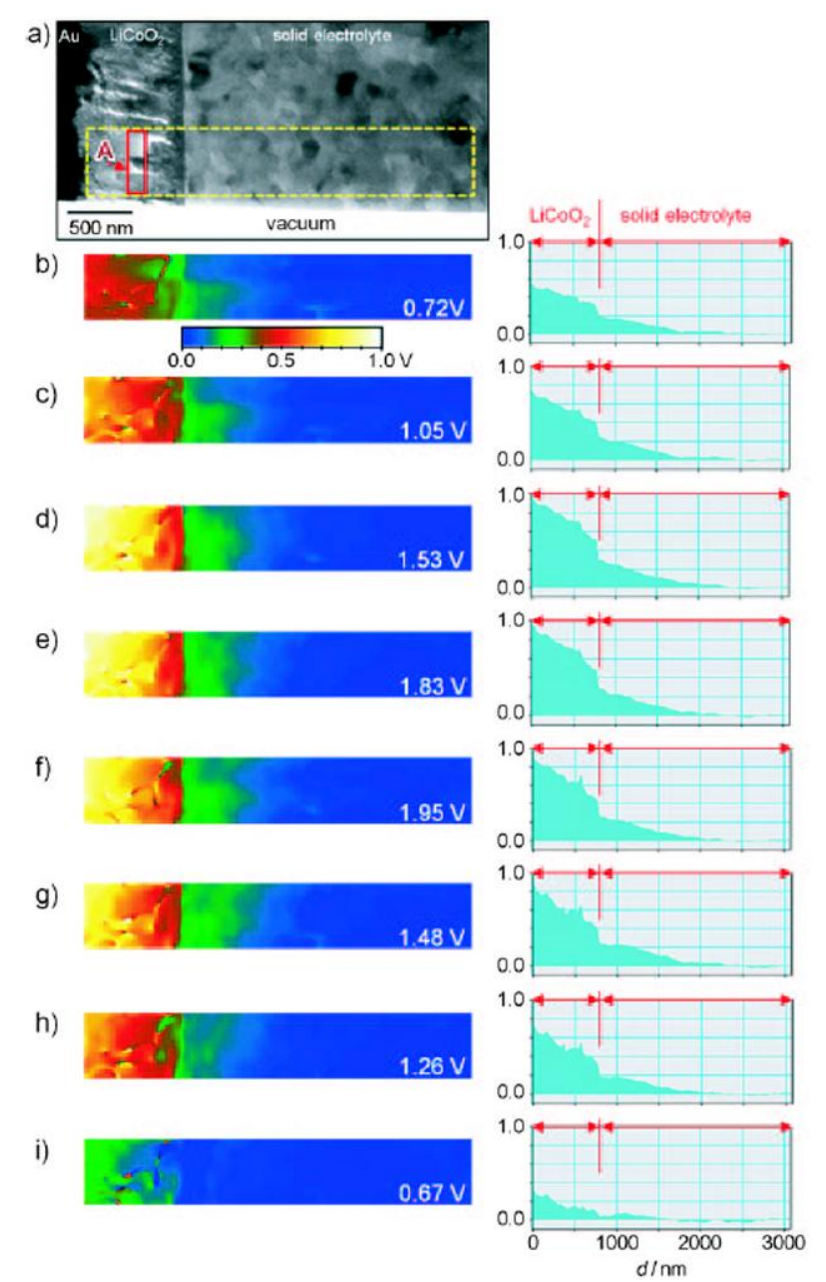

Figure 26 Electric potential distribution around the $\mathrm{LiCoO}_{2} /$ electrolyte interface during cycling. (a) Bright-field TEM image of the interface region. (b-i) 2D potential images (left) and line profiles (right) for the region marked by the dashed line in Figure 26a and collected at different voltages. (Reprinted from ref. 201 with permission from John Wiley and Sons.)

To overcome the limitation of EH, Okumura et al.[202], Yamamoto et al.[203], and Kimoto et al. [204] recently used spatially-resolved EELS in TEM mode (SR-TEM-EELS) to obtain the nanoscale Li-concentration profiles in the in-situ formed negative-electrode/solid-electrolyte interface. Both the changes of nanoscale distribution of elements and the crystal and electronic structure during the electrochemical reactions could be collected simultaneously. It was found that the transition metal $\mathrm{Ti}$ and $\mathrm{O}$ elements could lead to the in-situ formation of negative electrodes during the cycles $[205,206]$. The SR-TEM-EELS images of $\mathrm{Li}$, Ti and O 
around the in-situ-formed-negative-electrode/solid-electrolyte interface are shown in Figure 27 [207]. Nanoscale simultaneous analysis of the images can reveal the $\mathrm{Ti}^{3+} / \mathrm{Ti}^{4+}$ electronic changes, the $\mathrm{Ti} / \mathrm{O}$ electronic hybridization orbits, picometer-scale expansion of $\mathrm{O}-\mathrm{O}$ distances by $\mathrm{Li}$ insertion, and the relationship with the electric potential observed by EH, as shown in Figure 28.

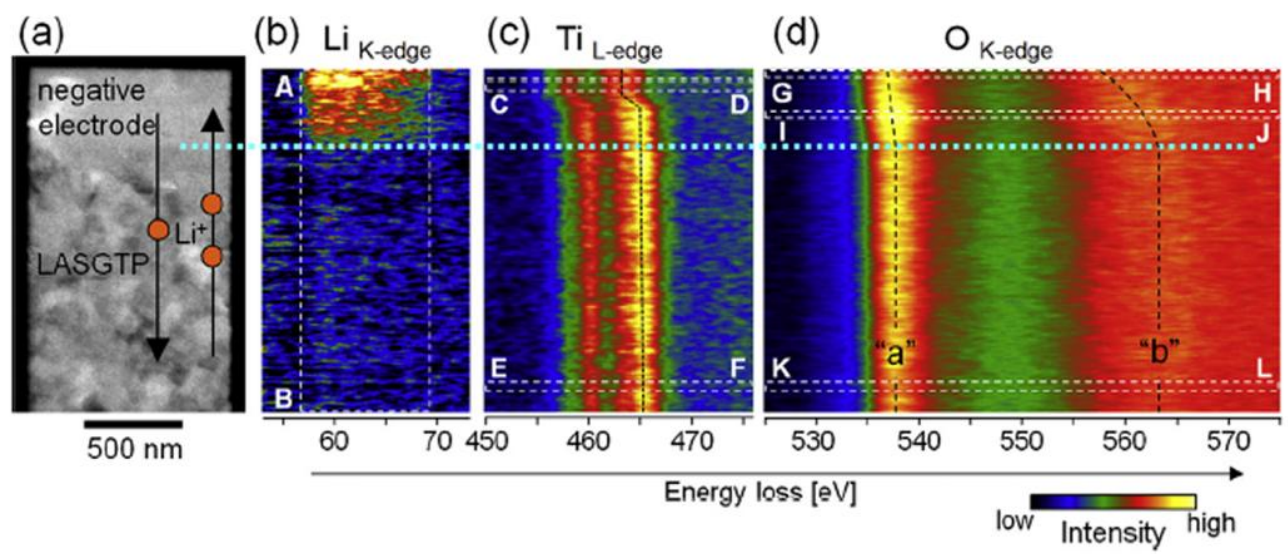

Figure 27 SR-TEM-EELS images of $\mathrm{Li}_{-\mathrm{K}-\text {-edge, }}$ Ti-L-edge, and $\mathrm{O}_{-\mathrm{K}-\text {-edge }}$ around the in-situ-formed-negative-electrode/solid-electrolyte interface. (a) TEM image selected with the rectangular slit, (b) Spectrum image of Li-K-edge, (c) Spectrum image of

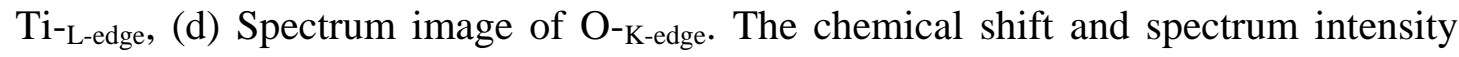
change of peak "a" are ascribed to the electronic hybridization of $\mathrm{Ti}$ and $\mathrm{O}$. The chemical shift of peak " $b$ " is related to the expansion of O-O distance of LASGTP caused by Li insertion. (Reprinted from ref. 207 with permission from Elsevier Ltd.) 

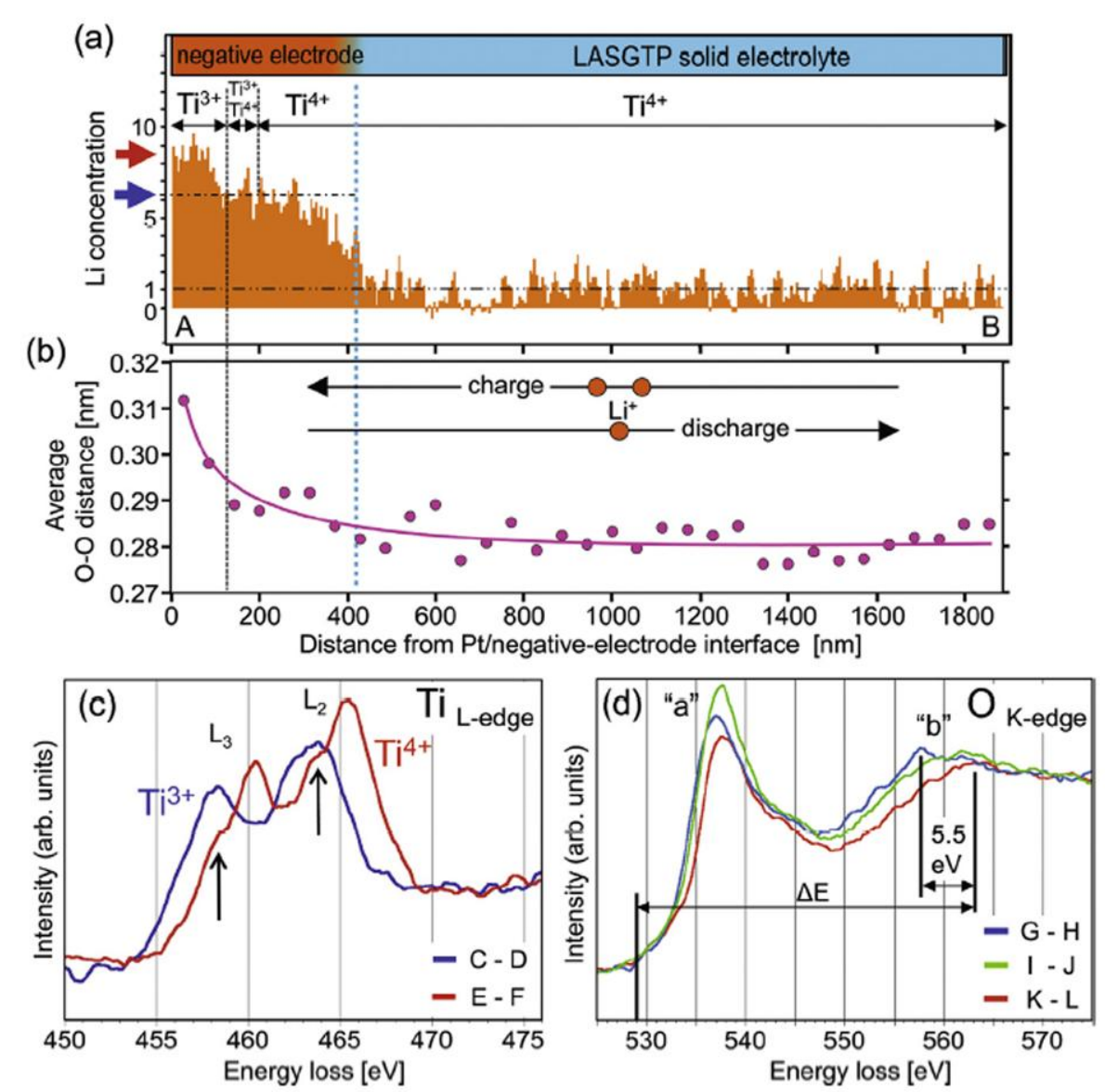

Figure $28 \mathrm{Li}$ concentration profile and its effects on $\mathrm{Ti}$ and $\mathrm{O}$. (a) One-dimensional Li concentration profile along A-B in Figure $27 \mathrm{~b}$ with $\mathrm{Ti}^{4+}$ and $\mathrm{Ti}^{3+}$ regions. (b) Profile of average O-O distance measured by peak " $b$ " of $\mathrm{O}$ spectrum image in Figure $27 \mathrm{~d}$. (c) Spectra of Ti-L-edge along C-D and E-F in Figure 27c. (d) Spectra of $\mathrm{O}_{-\mathrm{K}-e d g e}$ along G-H, I-J, and K-L in Fig. 27d. (Reprinted from ref. 207 with permission from Elsevier Ltd.)

To further enhance the power density in all-solid-state lithium batteries, depth-resolved X-ray absorption spectroscopy (DR-XAS) measurements were employed by Okumura et al. [208] to directly observe the chemical state and local structure at the $\mathrm{LiCoO}_{2}$ electrode-solid electrolyte model interface [208]. It was found that the charge transfer resistance of the $\mathrm{LiCoO}_{2}$ electrode-solid electrolyte interface was decreased with introducing a $\mathrm{NbO}_{2}$ interlayer at the interface evidenced by $\mathrm{AC}$ impedance spectroscopy, while the resistance was increased with adding $\mathrm{ZrO}_{2}$ and $\mathrm{MoO}_{2}$ interlayers. The changes in electronic structure and local structure of the 
$\mathrm{LiCoO}_{2}$ electrode were measured by DR-XAS with a depth resolution of about $7 \mathrm{~nm}$. The introduction of $\mathrm{NbO}_{2}$ layer was found to be effective in restricting the large Co-O bond change at the interface and mitigating the stress at the interface during delithiation, which were observed by the extended X-ray absorption fine structure of DR-XAS.

Mathematical modeling is an important tool in describing the performance of batteries. Equivalent electronic network models based on the macroscopic descriptions of the fundamental electrochemical and physical processes occurring inside various rechargeable all-solid-state Li batteries have been proposed to quantify the relevant processes [209-211]. In addition, the degradation (aging) process of $\mathrm{Li}$ batteries has been addressed as well [212, 213]. Notten et al. [214] developed a mathematical model for all-solid-state Li batteries, including all important physical and electrochemical characteristics, which enabled the description of basic functionality of these devices under a wide variety of operating conditions. The model involved the charge transfer kinetics at the electrode/electrolyte interface, diffusion of Li-ion in the intercalation electrode, as well as diffusion and migration of ions in the electrolyte. The model predictions agreed well with the galvanostatically measured voltage profiles.

\section{Industrialization progress in all-solid-state lithium batteries}

The first generation of all-solid-state lithium batteries used in electric vehicles was manufactured by the France's Bolloré group in 2011. But the advanced all-solid-state batteries are still under the stage of research and development. Few data from the industries are reported. Hence, the batteries in industrialization progress are reviewed according to the limited available data.

\subsection{Inorganic solid electrolyte (ISE) system}

Fuji film Company is focusing on the development of inorganic sulfide electrolyte [215]. As shown in Figure 29, the Fuji film Company has mastered the key technologies, such as coating film, roll to roll process (maximum 20 layers), and bonding technology of electrolyte with electrode. 


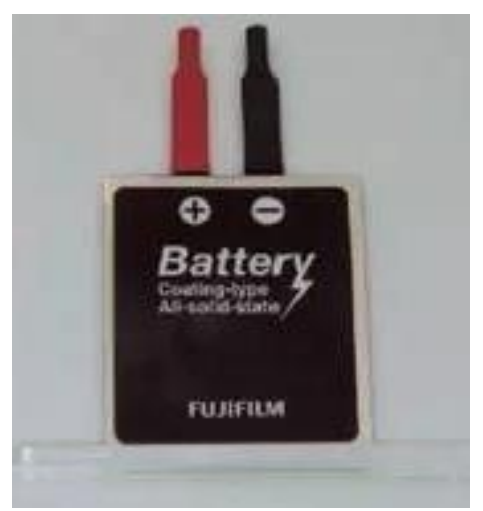

Figure 29 Picture of Fuji film company's all-solid-state lithium batteries with sulfide electrolyte (Reprinted from ref. 215).

As shown in Figure 30, the Samsung Yokohama research institute produced all-solid-state batteries by using a sulfide electrolyte [215]. The battery is composed of Ni-Co-Mn/Li-P-S/graphite, which exhibits an energy density of $175 \mathrm{Wh} \mathrm{kg}^{-1}$.

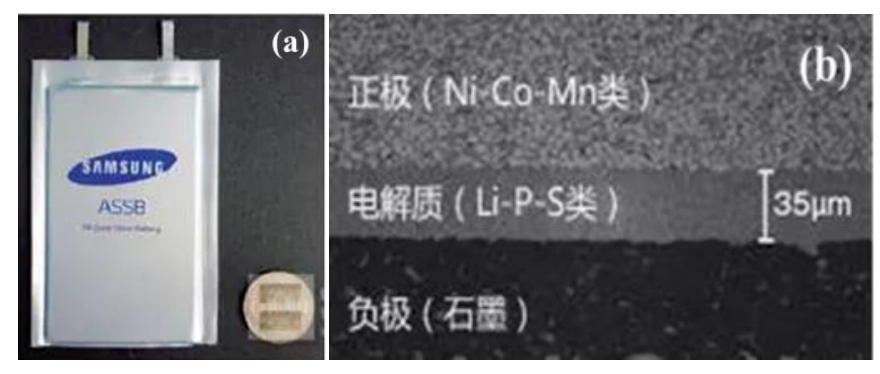

Figure 30 (a) Picture of Samsung Yokohama research institute's all-solid-state lithium-sulfur battery with a sulfide electrolyte; (b) Cross-sectional image of the all-solid-state lithium battery (Reprinted from ref. 215).

In 2015 , at the fifty-sixth battery conference in Japan, Sony showed a flexible all-solid-state lithium battery with LiPON electrolyte and ultrathin $\mathrm{Li}_{\mathrm{x}} \mathrm{M}_{\mathrm{y}} \mathrm{PO}_{\mathrm{z}}$ positive electrode [216]. The batteries could be made into special shapes and work at room temperature.

In 2016, Kanno group at Tokyo institute of technology in collaboration with Toyota Motor Corporation, and High Energy Accelerator research organization [145], developed two ceramic electrolytes of $\mathrm{Li}_{9.54} \mathrm{Si}_{1.74} \mathrm{P}_{1.44} \mathrm{~S}_{11.7} \mathrm{Cl}_{0.3}$ with $2.5 \times 10^{-2} \mathrm{~S} \mathrm{~cm}^{-1}$, and $\mathrm{Li}_{9.6} \mathrm{P}_{3} \mathrm{~S}_{12}$ with $1.0 \times 10^{-3} \mathrm{~S} \mathrm{~cm}^{-1}$ at room temperature. The batteries based on these 
electrolytes operated consistently between -30 and $100{ }^{\circ} \mathrm{C}$. The batteries exhibited long cycling ability (with $75 \%$ capacity retention after 500 cycles).

\subsection{Solid polymer electrolyte (SPE) battery system}

The France's Bolloré group launched a research program nearly fifteen years ago to develop electric vehicles. The "Bluecar" is the first serially produced electric car emerging from the BLUECAR program in 2011 [217,218]. The driving range of the lithium metal polymer (L.M.P.) battery can reach $250 \mathrm{~km}$ after each full charge. The battery was produced by BatScap and composed of $\mathrm{LiFePO}_{4} / \mathrm{PEO} / \mathrm{Li}$, exhibiting an energy density of $1000 \mathrm{Wh} \mathrm{kg}^{-1}$ and capacity retention of $80 \%$ after 1300 cycles (Figure 31). However, the work temperature is required at $60 \sim 80{ }^{\circ} \mathrm{C}$, which was achieved by heating system of the car. It takes six hours to fully recharge the car's battery from a standard power socket, and the time will be cut to two hours on the future fast-charging outlets. Besides, the batteries can be fast-charged for five minutes and give the car power to run $25 \mathrm{~km}$.

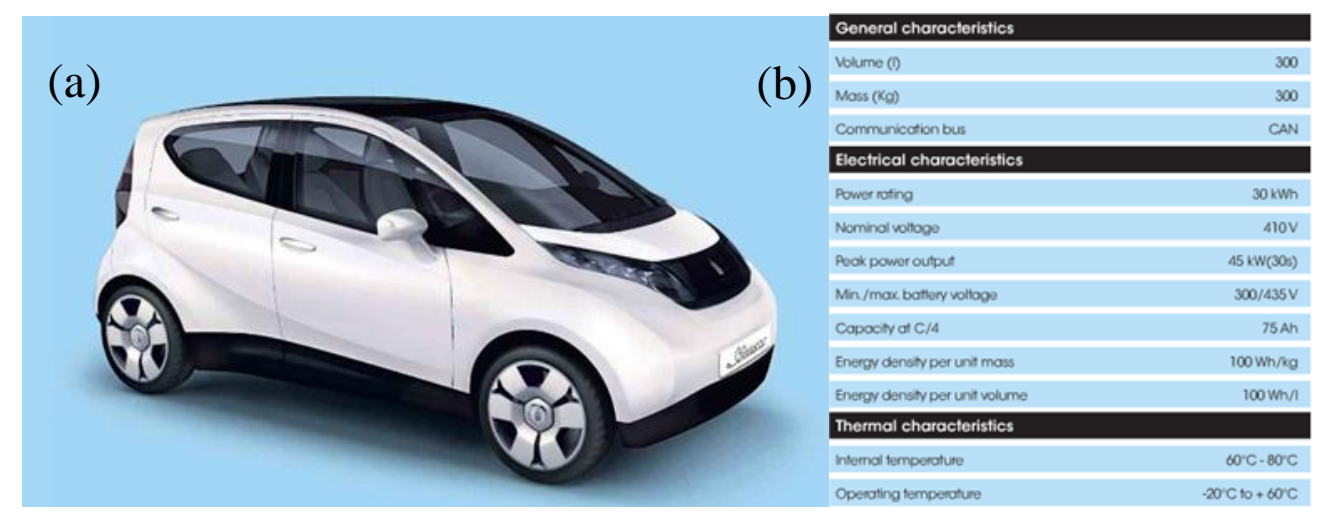

Figure 31 (a) Prototype and (b) technical parameters of "Bluecar" EV (Reprinted from ref. 217 and 218).

Seeo in USA, which was purchased by Bosch in Germany in 2015, has developed a new generation of rechargeable lithium batteries based on a polymer electrolyte called DryLyte $^{\mathrm{TM}}$, as shown in Figure 32 [219]. The batteries exhibited an energy density of $220 \mathrm{Wh} \mathrm{kg}^{-1}$ and an operating voltage of $3.42 \mathrm{~V}$, while they cost a half compared to traditional lithium ion battery. 


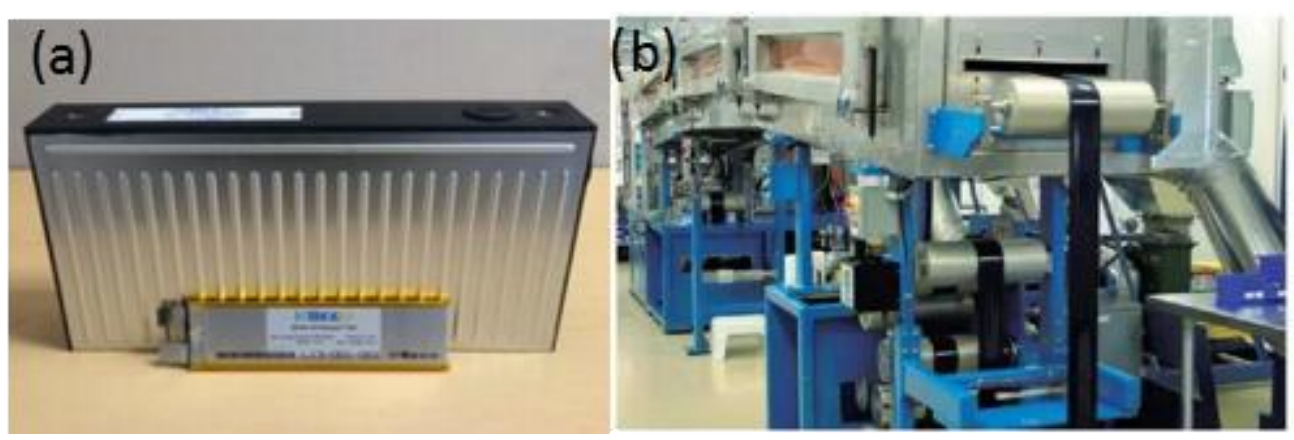

Figure 32 (a) Products and (b) producing process of DryLyte battery (Reprinted from ref. 219).

German KOLIBRI batteries have been applied in Audi A2 [220,221]. The first prototypes of EV Audi A2 could run $605 \mathrm{~km}$, with the highest speed of $130 \mathrm{~km} \mathrm{~h}^{-1}$ and the average speed of $90 \mathrm{~km} \mathrm{~h}^{-1}$. The battery was composed of lithium metal oxide/polymer solid electrolyte film/graphite. Its lifespan should be over $500000 \mathrm{~km}$ and the outcome energy density was claimed to be $300 \mathrm{Wh} \mathrm{kg}^{-1}$.

Since 2015, Dyson has invested $\$ 1.4$ billion to establish a battery factory, and paid $\$ 90$ million for merging a solid-state batteries enterprise of Sakti3 [222]. The energy density of batteries produced by Sakti3 could reach $1000 \mathrm{Wh} \mathrm{L}^{-1}$, which was claimed to be twice higher than that of the conventional lithium ion battery.

The central research institute of electric power industry focuses on development of solid polymer electrolytes [215]. The basic development work was early completed and the corresponding technology was transferred to private enterprise. The cells showed an excellent cyclability beyond three years and a good safety performance.

In China, Xu's group at Ningbo Institute of Industrial Technology (CNITECH), Chinese Academy of Science, has produced 4Ah and 8Ah solid-state batteries with inorganic solid electrolyte. The energy density reached $240 \mathrm{Wh} \mathrm{kg}^{-1}$ and the capacity retention kept $88.7 \%$ after 500 cycles at $0.2 \mathrm{C}$ current rate. Cui's group at Qingdao Institute of Bioenergy and Bioprocess Technology has cooperated with Zhongtian technology company to develop high-performance solid-state lithium-ion polymer batteries in 2015 [223]. The capacity of $10 \mathrm{Ah}$ and an energy density of $250 \mathrm{Wh} \mathrm{kg}^{-1}$ of the battery was reported. 
Besides, other batteries companies in China, such as CATL, ProLogium and Microvast, began to develop the solid lithium batteries in recent years. For instance, ProLogium Corporation displayed the latest high energy density lithium ceramics battery in the Computex of 2016, claiming a high energy density of $810 \mathrm{Wh} \mathrm{L}^{-1}$, as shown in Figure 33 [224].

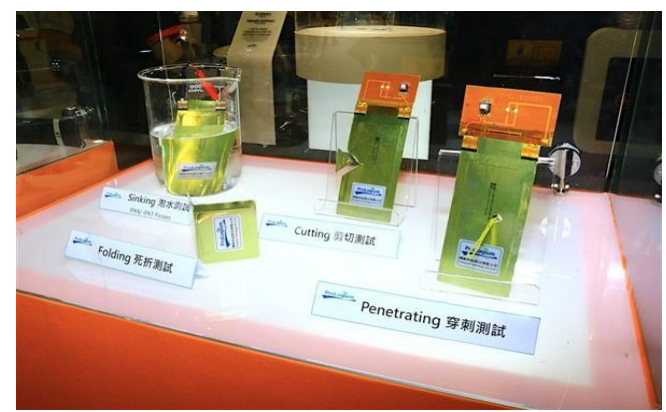

(a)

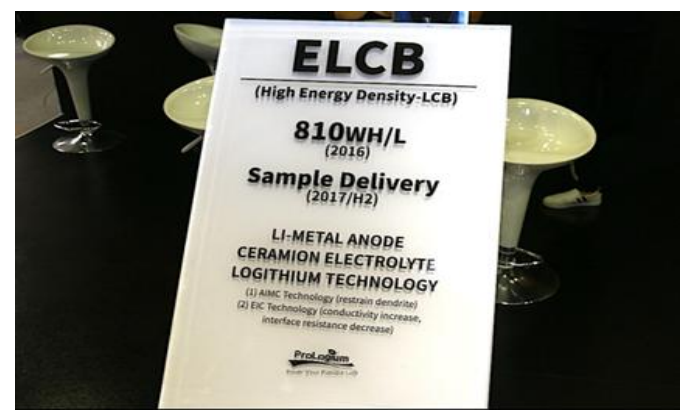

(b)

Figure 33 Photos of (a) Testing and (b) Products of ProLogium batteries (Reprinted from ref. 224).

Although the all-solid-state batteries reduce requirements on packaging and state-of-charge monitoring circuits compared with that of the Li-ion batteries with liquid electrolytes. For their commercialization, cost reduction is still a key issue. Various cost-effective fabrication processes and structural design are highly desired, such as preparation of powders through low cost processes, use of less expensive materials, as well as utilization of monolithic or symmetric cell configurations.

\section{Conclusion and outlook}

Due to safety concerns, there are huge market needs for the solid-state batteries. Despite considerable advances in the all-solid-state Li batteries have been achieved during the past decades, it still takes a long time before they can be successfully employed in practical systems. For all-solid-state Li batteries, one key component is solid electrolyte. The rational choice of the component is determined by a series of requirements including high ionic conductivity, good mechanical properties, and compatibility with the electrode materials. Until now, the reported solid electrolytes 
include perovskite-type ( $\left.\mathrm{Li}(\mathrm{La}) \mathrm{TiO}_{3}\right)$, NASICON-type (LATP, LAGP, etc.), garnet-type $\left(\mathrm{Li}_{7} \mathrm{La}_{3} \mathrm{Zr}_{2} \mathrm{O}_{12}\right)$, nitride or sulfide glass-ceramics-based glass-ceramics, and several kinds of polymer or colloid solid electrolytes. Among the inorganic solid electrolytes, sulfides have several advantages of higher ionic conductivities and ease to form framework structures, etc., however, they have hygroscopic character and less chemical stability. Due to their relatively high ion conductivity, relatively good stability and wide electrochemical window, Li-stuffed garnets are particularly attractive in recent years. However, several challenges still exist as follows, hindering the practical applications and commercialization of all-solid-state Li batteries.

(1) Insufficient ionic conductivity of the electrolytes. Ionic conductivity in ceramic conductors are usually in the range of $10^{-5} \sim 10^{-3} \mathrm{~S} \mathrm{~cm}^{-1}$, which is much lower than that of organic liquid electrolytes $\left(10^{-2} \mathrm{~S} \mathrm{~cm}^{-1}\right)$.

(2) Poor interfacial compatibility between electrode and electrolyte. High solid-solid interfacial resistances are usually produced after the initial charging process due to high strain or stress generated at the interface arising from large volume changes of the electrodes during lithiation/delithiation. Moreover, favorable interfaces between metallic Li and solid electrolytes are difficult to form since gain boundaries and voids usually exist on the surface of solid electrolytes in bulk-type solid-state batteries due to compression of the powders.

(3) Insufficient fundamental understanding of the interfacial process after charge/discharge. The movement of lithium ions and the interfacial evolution are critical for the operation of all-solid-state Li batteries. There are still great challenges to get insight into the changes of nanoscale distribution of elements, as well as the crystal and electronic structure during the electrochemical reactions.

(4) Insufficient system design and performance optimization. The sharp interfaces may cause lamination or large strain during cycles. Rational design of functional grade in the electrode/electrolyte interface and the optimization of electrode materials with the selected electrolytes are still lacked.

To overcome these challenges, the possible research directions are proposed as follows: 
(1) Further increasing the conductivity of the solid electrolytes. Li-ion conductivity in solid electrolytes can be enhanced by increasing the crystallinity and forming nanosized solid interface through the space charge layer (SCL) effect [225-229]. Furthermore, the grain boundary conductivity can be increased with reducing the grain size to nano scale. Besides SCL effect, strain effect and curvature effect may also be used to enhance the ionic conductivity.

(2) Optimizing the electrolyte structure and composition. Most electrolyte studies are still at the stage of trial-and-error so far. The approach for finding optimized electrolyte design and compositions is not straightforward and is often time consuming. Combination of density functional theory (DFT) calculation with high-throughput techniques for materials screening such as materials libraries and combinatorial design are desirable in optimizing the electrolyte structures and compositions [230-235].

(3) Interfacial modification to decrease the interfacial resistance. The engineering of grain boundary and interfacial modification are effective strategies for enhancing ionic conductivity. Tailoring the architecture of the electrolyte surface can maximize accessible interfacial area and reduce the resistance of Li-ion transfer at that interface. An effective approach for reducing the interfacial impedance has been demonstrated by $\mathrm{Hu}$ et al. recently by forming ultrathin ALD coating of $\mathrm{Al}_{2} \mathrm{O}_{3}$ on garnet electrolyte [198]. Another strategy is increasing operating temperature so that the ion motion in solid state systems can be enhanced. This approach has been used by Huang et al.[236] in an all ceramic rechargeable $\mathrm{Na}^{+}$-ion battery. However, it also presents great engineering challenge for the battery systems.

(4) Further fundamental understanding to optimize the performance of materials, components and systems. Using both experimental and theoretical calculation approaches to understand the performance of materials, components and battery systems are necessary for further development. Some advanced in-situ characterizations for material structure optimization and performance failure, like in-situ TEM, are favorable for indentifying the interface evolution during charge-discharge cycles. 
(5) Stabilizing Li anode. Although Li metal presents an ideal anode for rechargeable Li batteries, effective Li metal protection approaches to increase the stability of anode, in particular under moisture are highly desired for practical rechargeable Li batteries. As for these aspects, the readers can refer a recent review paper by Zhang et al. [237]. (6) Optimizing the battery design and operation. Monolithic or symmetric cell configurations are feasible for reducing interfacial resistance and manufacturing costs. Advanced fabrication approaches, like 3D printer, can be utilized to achieve optimal microstructures with low resistance solid electrolyte films. Furthermore, the all-solid-state batteries can make micro flexible metal-supported devices and be integrated with micro-electromechanical systems (MEMS), which may be widely used in flexible electronics.

\section{ACKNOWLEDGMENT}

The authors acknowledge the financial support of the National Science Foundation of China (Nos. 51672029, 51372271, 51274239 and 51172275) and Chinese Academy of Engineering (2016-XY-18). This work was also supported by National Key R \& D Project from Ministry of Science and Technology, China (2016YFA0202702) and the Thousands Talents Program for the pioneer researcher and his innovation team in China.

\section{References}

[1] J.M. Tarascon and M. Armand, Nature 414 (2001) 359-367.

[2] Z. Yang, J. Zhang, M.C.W. Kintner-Meyer, X. Lu, D. Choi and J.P. Lemmon, Chem. Rev. 111 (2011) 3577-3613.

[3] J.B. Goodenough and Y. Kim, Chem. Mater. 22 (2010) 583-603.

[4] J.B. Bates, N.J. Dudney, B. Neudecker, A. Ueda and C.D. Evans, Solid State Ionics 135 (2000) 33-45.

[5] N. Ohta, K. Takada, L. Zhang, R. Ma, M. Osada and T. Sasaki, Adv. Mater. 18 (2006) 2226-2229.

[6] J.H. Woo, J.E. Trevey, A.S. Cavanagh, Y.S. Choi, S.C. Kim, S.M. George, K.H. 
Oh and S. Lee, J. Electrochem. Soc. 159 (2012) A1120-A1124.

[7] K. Yamamoto, Y. Iriyama, T. Asaka, T. Hirayama, H. Fujita, C.A.J. Fisher, K. Nonaka, Y. Sugita and Z. Ogumi, Angew. Chem. Int. Ed. 49 (2010) 4414-4417.

[8] P.J. Gellings and H.J.M. Bouwmeester (ed.), CRC Handbook of Solid State Electrochemistry, CRC Press, New York, 1997.

[9] C.B. Choudary, H.S. Maiti and E.C. Subbaro, in Solid Electrolytes and Their Applications, E.C. Subbarao (ed.) Plenum Press, New York, 1980.

[10] R.S. Tichy, Mechanisms and stability of oxide-ion transport in homogenenous and heterogeneous ceramic membranes, The University of Texas at Austin, Austin, 2001.

[11] O. T. Sorensen, Nonstoichiometric Oxides, Academic Press, INC., New York, 1981.

[12] J. B. Goodenough, Mater. Sci. Forum 7 (1986) 1.

[13] E. Quartarone and P. Mustarelli, Chem. Soc. Rev. 40 (2011) 2525-2540.

[14] M.A. Ratner, P. Johansson and D.F. Shriver, MRS Bull. 25 (2000) 31-37.

[15] R.C. Agrawal and G.P. Pandey, J. Phys. D.: Appl. Phys. 41 (2008) 223001.

[16] M.H. Cohen and D. Turnbull, J. Chem. Phys. 31 (1959) 1164-1169.

[17] J.H. Gibbs and E.A. Di Marzio, J. Chem. Phys. 28 (1958) 373-383.

[18] D.A.G. Bruggeman, Ann. Phys. (Leipzig) 24 (1935) 636-664.

[19] R. Kanno and M. Murayama, J. Electrochem. Soc. 148 (2001) A742-A746.

[20] J. Christensen, P. Albertus, R.S. Sanchez-Carrera, T. Lohmann, B. Kozinsky, R. Liedtke, J. Ahmed and A. Kojic, J. Electrochem. Soc. 159 (2012) R1-R30.

[21] P. Knauth, Solid State Ionics, 180 (2009) 911-916.

[22] L. Sebastian and J. Gopalakrishnan, J. Mater. Chem. 13 (2003) 433-441.

[23] G. Adachi, N. Imanaka and H. Aono, Adv. Mater. 8 (1996) 127-135.

[24] J.B. Goodenough, Solid State Ionics 94 (1997) 17-25.

[25] S. Stramare, V. Thangadurai and W. Weppner, Chem. Mater. 15 (2003) 3974-3990.

[26] T. Minami, A. Hayashi and M. Tatsumisago, Solid State Ionics 177 (2006) 2715-2720. 
[27] V. Thangadurai and W. Weppner, Ionics 8 (2002) 281-292.

[28] S. Teng, J. Tan and A. Tiwari, Curr. Opin. Solid StateMater. Sci. 18 (2014) 29-38.

[29] W.H. Meyer, Adv. Mater. 10 (1998) 439-448.

[30] V. Thangadurai, S. Narayanan and D. Pinzaru, Chem. Soc. Rev. 43 (2014) 4714-4727.

[31] W.G. Zeier, Dalton Trans. 43 (2014) 16133-16138.

[32] J.F.M. Oudenhoven, L. Baggetto and P.H.L. Notten, Adv. Energy Mater. 1 (2011) $10-33$.

[33] V.D. Noto, S. Lavina, G.A. Giffin, E. Negro and B. Scrosati, Electrochim. Acta, 57 (2011) 4-13.

[34] G. Adachi, N. Imanaka and H. Aono, Adv. Mater. 8 (1996) 127-135.

[35] B.B. Owens, J. Power Sources 90 (2000) 2-8.

[36] V. Thangadurai and W. Weppner, Ionics 8 (2002) 281-292.

[37] V. Thangadurai and W. Weppner, Ionics 12 (2006) 81-92.

[38] P. Knauth, Solid State Ionics 180 (2009) 911-916.

[39] E. Quartarone and P. Mustarelli, Chem. Soc. Rev. 40 (2011) 2525-2540.

[40] J.W. Fergus, J. Power Sources 195 (2010) 4554-4569.

[41] J.B. Bates, N.J. Dudney, G.R. Gruzalski, R.A. Zuhr, A. Choudry, C.F. Luck and J.D. Robertson, Solid State Ionics 53-56 (1992) 647-654.

[42] J.B. Bates, N.J. Dudney, G.R. Gruzalski, R.A. Zuhr, A. Choudhury, C.F. Luck and J.D. Robertson, J. Power Sources 43 (1993) 103-110.

[43] J.B. Bates, N.J. Dudney, D.C. Lubben, G.R. Gruzalski, B.S. Kwak, X. Yu and R.A. Zuhr, J. Power Sources 54 (1995) 58-62.

[44] J.B. Bates, N.J. Dudney, B. Neudecker, A. Ueda and C.D. Evans, Solid State Ionics, 135 (2000) 33-45.

[45] T. Minami and M. Tatsumisago, in: T. Minami (Ed.), Solid State Ionics for Batteries, Springer-Verlag, Tokyo, 2005, P1.

[46] A. Hayashi, R. Komiya, M. Tatsumisago and T. Minami, Solid State Ionics $152-153$ (2002) 285-290.

[47] F. Mizuno, A. Hayashi, K. Tadanaga, T. Minami and M. Tatsumisago, Chem. 
Lett. 2002, 1244-1245.

[48] R. Kanno and M. Murayama, J. Electrochem. Soc. 148 (2001) A742-A746.

[49] T. Minami, A. Hayashi and M. Tatsumisago, Solid State Ionics 177 (2006) 2715-2720.

[50] R. Kanno, T. Hata, Y. Kawamoto and M. Irie, Solid State Ionics, 130 (2000) 97-104.

[51] F. Mizuno, A. Hayashi, K. Tadanaga and M. Tatsumisago, Adv. Mater. 17 (2005) 918-920.

[52] K. Minami, A. Hayashi, S. Ujiie and M. Tatsumisago, Solid State Ionics, 192 (2011) 122-125.

[53] N. Kamaya, K. Homma, Y. Yamakawa, M. Hirayama, R. Kanno, M. Yonemura, T. Kamiyama, Y. Kato, S. Hama, K. Kawamoto and A. Mitsui, Nature Mater. 10 (2011) 682-686.

[54] B.R. Shin, Y.J. Nam, D.Y. Oh, D.H. Kim, J.W. Kim and Y.S. Jung, Electrochim. Acta 146 (2014) 395-402.

[55] G. Sahu, Z. Lin, J. Li, Z. Liu, N. Dudney and C. Liang, Energy Environ. Sci. 7 (2014) 1053-1058.

[56] H. Aono, E. Sugimoto, Y. Sadaoka, N. Imanaka and G. Adachi, J. Electrochem. Soc. 137 (1990) 1023-1027.

[57] H. Hosono and Y. Abe, Solid State Ionics 44 (1991) 293-297.

[58] H. Hosono, F. Tsuchitani, K. Imai and Y. Abe, J. Mater. Res. 9 (1994) 755-761.

[59] B.V.R. Chowdari, G.V.S. Rao and G.Y.H. Lee, Solid State Ionics 136-137 (2000) 1067-1075.

[60] J. Fu, Solid State Ionics 96 (1997) 195-200.

[61] X. Xu, Z. Wen, J. Wu and X. Yang, Solid State Ionics 178 (2007) 29-34.

[62] I. Abrahams and E Hadzifejzovic, Solid State Ionics 134 (2000) 249-257.

[63] G. Tan, F. Wu, L. Li, Y. Liu and R. Chen, J. Phys. Chem. C 116 (2012) 3817-3826.

[64] Y. Inaguma, L. Chen, M. Itoh, T. Nakamura, T. Uchida, H. Ikuta and M. Wakihara, Solid State Commun. 86 (1993) 689-693. 
[65] H. Kawai and J. Kuwano, J. Electrochem. Soc. 141 (1994) L78-L79.

[66] O. Bohnke, C. Bohnke and J.L. Fourquet, Solid State Ionics 91 (1996) 21-31.

[67] J. Alonso, J. Sanz, J. Santamaria, C. Leon, A. Varez and M. Fernandez-Diaz, Angew. Chem. Int. Ed. 39 (2000) 619-621.

[68] S. Stramare, V. Thangadurai and W. Weppner, Chem. Mater. 15 (2003) 3974-3990.

[69] V. Thangadurai, H. Kaack and W. Weppner, J. Am. Ceram. Soc. 86 (2003) 437-440.

[70] R. Murugan, V. Thangadurai and W. Weppner, Appl. Phys. A 91 (2008) 615-620.

[71] V. Thangadurai and W. Weppner, J. Solid State Chem. 179 (2006) 974-984.

[72] R. Murugan, V. Thangadurai and W. Weppner, Angew. Chem. Int. Ed. 46 (2007) 7778-7781.

[73] J. Awaka, A. Takashima, K. Kataoka, N. Kijima, Y. Idemoto and J. Akimoto, Chem. Lett. 40 (2011) 60-62.

[74] M.P. O’Callaghan, A.S. Powell, J.J. Titman, G.Z. Chen and E.J. Cussen, Chem. Mater. 20 (2008) 2360-2369.

[75] J.B. Bates, N.J. Dudney, B.J. Neudecker, F.X. Hart, H.P. Jun and S.A. Hackney, J. Electrochem. Soc. 147 (2000) 59-70.

[74] C.A. Geiger, E. Alekseev, B. Lazic, M. Fisch, T. Armbruster, R. Langner, M. Fechtelkord, N. Kim, T. Pettke and W. Weppner, Inorg. Chem. 50 (2011) 1089-1097.

[76] V. Thangadurai and W. Weppner, Adv. Funct. Mater. 15 (2005) 107-112.

[77] W.E. Tenhaeff, E. Rangasamy, Y. Wang, A.P. Sokolov, J. Wolfenstine, J. Sakamoto, N. J. Dudney, ChemElectroChem 2 (2014) 375-378.

[78] E.J. Cussen, J. Mater. Chem. 20 (2010) 5167-5173.

[79] A. Kuhn, V. Epp, G. Schmidt, S. Narayanan, V. Thangadurai and M. Wilkening, J. Phys.: Condens. Matter, 24 (2012) 035901.

[80] I.W. Cheung, K.B. Chin, E.R. Greene, M.C. Smart, S. Abbrent, S.G. Greenbaum, G.K.S. Prakash, S. Surampudi, Electrochim. Acta 48 (2003) 2149-2156. 
[81] M. P. O’Callaghan, A.S. Powell, J.J. Titman, G.Z. Chen and E.J. Cussen, Chem. Mater. 20 (2008) 2360-2369.

[82] R. Bohmer, T. Jorg, F. Qi and A. Titze, Chem. Phys. Lett. 316 (2000) 419-424.

[83] O. Pecher, J. Carretero-Gonzalez, K.J. Griffith and C.P. Grey, Chem. Mater. 29 (2017) 213-242.

[84] J. Han, J. Zhu, Y. Li, X. Yu, S. Wang, G. Wu, H. Xie, S.C. Vogel, F. Izumi, K. Momma, Y. Kawamura, Y. Huang, J.B. Goodenough, Y. Zhao, Chem. Commun. 48 (2012) 9840-9842.

[85] H. Xie, J.A. Alonso, Y. Li, M.T. Fernández-Díaz, J.B. Goodenough, Chem. Mater., 23 (2011) 3587-3589.

[86] Z. Ma, Y. Wang, C.W. Sun, J.A. Alonso, M.T. Fernández-Díaz, L. Chen, Sci. Reports, 4 (2014) 7231.

[87] J.G. Kim, B. Son, S. Mukherjee, N. Schuppert, A. Bates, O. Kwon, M.J. Choi, H.Y. Chung and S. Park, J. Power Sources 282 (2015) 299-322.

[88] G.S. MacGlashan, Y.G. Andreev and P.G. Bruce, Nature, 398 (1999) 792-794.

[89] P. V. Wright, Br. Polym. J., 7 (1975) 319-327.

[90] J. C. M. Armand and M. Duclot, presented in part at the Second International Meeting on Solid Electrolytes, St Andrews in Scotland, 1978.

[91] E. Tsuchida, H. Ohno, K. Tsunemi and N. Kobayashi, Solid State Ionics, 11 (1983) 227-233.

[92] J. E. Weston and B. C. H. Steele, Solid State Ionics 7 (1982) 75-79.

[93] M. Armand, Solid State Ionics 9 (1983) 745-754.

[94] F.Capuano, F. Croce and B. Scrosati, J. Electrochem. Soc. 138 (1991) 1918-1922.

[95] M.C. Borghini, M. Mastragostino, S. Passerini and B. Scrosati, J. Electrochem. Soc. 142 (1995) 2118-2121.

[96] B.K. Choi, Y.W. Kim and K.H. Shin, J. Power Sources, 68 (1997) 357-360.

[97] F. Croce, G. B. Appetecchi, L. Persi and B. Scrosati, Nature, 394 (1998) 456-458.

[98] M.A. Ratner, P. Johansson and D.F. Shriver, MRS Bull. 45 (2000) 31-37.

[99] F. Croce, L. Persi, B. Scrosati, F. Serraino-Fiorya, E. Plichta and M.A. 
Hendrickson, Electrochim. Acta 46 (2001) 2457- 2461.

[100] C.F. Yuan, J. Li, P.F. Han, Y.Q. Lai, Z.A. Zhang and J. Liu, J. Power Sources, 240 (2013) 653-658.

[101] K. Zhu, Y.X. Liu and J. Liu, RSC Adv., 4 (2014) 42278-42284.

[101] R. Khurana, J.L. Schaefer, L.A. Archer and G.W. Coates, J. Am. Chem. Soc., 136 (2014) 7395-7402.

[102] D.C. Lin, W. Liu, Y.Y. Liu, H.R. Lee, P.C. Hsu, K. Liu and Y. Cui, Nano Lett. 16 (2015) 459-465.

[103] X.G. Qi, Q. Ma, L.L. Liu, Y.S. Hu, H. Li, Z.B. Zhou, X.J. Huang and L.Q. Chen, ChemElectroChem 3 (2016) 1-6.

[104] K. Nagaoka, H. Naruse, I. Shinohara and M. Watanabe, J. Polym. Sci., Polym. Lett. Ed. 22 (1984) 659-663.

[105] D. Fish, I. M. Khan and J. Smid, Makromol. Chem., Rapid Commun. 7 (1986) 115-120.

[106] J. Li, Y. Lin, H.H. Yao, C.F. Yuan and J. Liu, ChemSusChem, 7 (2014) 1901-1908.

[107] Y. Lin, J. Li, K. Liu, Y.X. Liu, J. Liu and X.M. Wang, Green Chem. 18 (2016) 3796-3803.

[108] Q.W. Pan, D.M. Smith, H. Qi , S.J. Wang and C.Y. Li, Adv. Mater. 27 (2015) 5995-6001.

[109] P.F. Han, Y.W. Zhu and J. Liu, J. Power Sources, 284 (2015) 459-465.

[110] D.J. Bannister, G.R. Davies, I.M. Ward, J.E. McIntyre, Polymer 25 (1984) 1291-1296.

[111] R. Bouchet, S. Maria, R. Meziane, A. Aboulaich, L. Lienafa, J.P. Bonnet, T.N.T. Phan, D. Bertin, D. Gigmes, D. Devaux, R. Denoyel, M. Armand, Nat. Mater. 12 (2013) 452-457.

[112] Q. Ma, H. Zhang, C.W. Zhou, L.P. Zheng, P.F. Cheng, J. Nie, W.F. Feng, Y.S. Hu, H. Li, X.J. Huang, L.Q. Chen, M. Armand and Z.B. Zhou, Angew. Chem. Int. Ed. 55 (2016) 2521-2525.

[113] K. Fu, Y.H. Gong, J.Q. Dai, A. Gong, X.G. Han, Y.G. Yao, C.W. Wang, Y.B. 
Wang, Y.N. Chen, C.Y. Yan, Y.J. Li, E.D. Wachsman and L.B. Hu, Proc. Natl. Acad. Sci. U. S. A. 113 (2016) 7094-7100.

[114] J.W. Long, B. Dunn, D.R. Rolison, H.S. White, Three-dimensional battery architechtectures, Chem. Rev., 2004, 104, 4463-4492.115 B.J. Neudecker, N.J. Dudney and J.B. Bates, J. Electrochem. Soc. 147 (2000) 517-523.

[116] S.H. Lee, P. Liu and C.E. Tracy, Electrochem. Solid State Lett. 6 (2003) A275-A277.

[117] N.J. Dudney and Y.I. Jang, J. Power Sources, 119 (2003) 300-304.

[118] N.J. Dudney, Mater. Sci. Eng. B, 116 (2005) 245-249.

[119] M. Baba, N. Kumagai, H. Fujita, K. Ohta, K. Nishidte, S. Komaba, B. Kaplan, H. Groult and D. Devilliers, J. Power Sources, 119-121 (2003) 914-917.

[120] Y.S. Park, S.H. Lee, B.I. Lee and S.K. Joo, Electrochem. Solid State Lett. 2 (1999) 58-59.

[121] Y. Iriyama, T. Kako, C. Yada, T. Abe and Z. Ogumi, Solid State Ionics, 176 (2005) 2371-2376.

[122] Y. Iriyama, K. Nishimoto, C. Yada, T. Abe, Z. Ogumi and K. Kikuchi, J. Electrochem. Soc. 153 (2006) A821-A825.

[123] X. Yu, J.B. Bates, G.E. Jellison Jr. and F.X. Hart, J. Electrochem. Soc. 144 (1997) 524-532.

[124] B. Wang, J.B. Bates, F.X. Hart, B.C. Sales, R.A. Zuhr and J.D. Robertson, J. Electrochem. Soc. 143 (1996) 3203-3213.

[125] N.J. Dudney, The Electrochem. Soc. Interface, 2008, 44-48.

[126] W.C. West, J.F. Whitacre, V. White and B.V. Ratnakumar, J. Micromech. Microeng. 12 (2002) 58-62.

[127] N.J. Dudney and B.J. Neudecker, Curr. Opin. Solid StateMater. Sci. 4 (1999) $479-482$.

[128] M.A. Hickner, Mater. Today, 13 (2010) 34-41.

[129] N. Kuwata, J. Kawamura, K. Toribami, T. Hattori and N. Sata, Electrochem. Commun. 6 (2004) 417-421.

[130] S. Lee, P. Liu, C.E. Tracy and D.K. Benson, Electrochem. Solid State Lett. 2 
(1999) 425-427.

[131] Y. Park, S. Lee, B. Lee and S. Joo, Electrochem. Solid State Lett. 2 (1999) 58-59.

[132] S. Zhao, Z. Fu and Q. Qin, Thin Solid Films, 415 (2002) 108-113.

[133] S. Kakuda, T. Momma, T. Osaka, G. B. Appetecchi and B. Scrosati, J. Electrochem. Soc. 142 (1995) L1-L2.

[134] M. Baba, N. Kumagai, H. Kobayashi, O. Nakano and K. Nishidate, Electrochem. Solid State Lett. 2 (1999) 320-322.

[135] S. Ohta, S. Komagata, J. Seki, T. Saeki, S. Morishita and T. Asaoka, J. Power Sources 238 (2013) 53-56.

[136] N. Ohta, K. Takada, L. Zhang, R. Ma, M. Osada and T. Sasaki, Adv. Mater. 18 (2006) 2226-2229.

[137] C. Lethien, M. Zegaoui, P. Roussel, P. Tilmant, N. Rolland and P.A. Rolland, Microelectronic Engineering 88 (2011) 3172-3177.

[138] M. Tatsumisago and M. Nagao, A. Hayashi, J. Asian Ceram. Soc. 1 (2013) $17-25$.

[139] M. Tatsumisago, F. Mizuno and A. Hayashi, J. Power Sources, 159 (2006) 193-199.

[140] H. Muramatsu, A. Hayashi, T. Ohtomo, S. Hama and M. Tatsumisago, Solid State Ionics 182 (2011) 116-119.

[141] M. Tatsumisago, A. Hayashi, Solid State Ionics 225 (2012) 342-345.

[142] K. Minami, A. Hayashi, S. Ujiie and M. Tatsumisago, Solid State Ionics 192 (2011) 122-125.

[143] M. Nagao, A. Hayashi and M. Tatsumisago, Electrochim. Acta 56 (2011) 6055-6059.

[144] A. Sakuda, A. Hayashi and M. Tatsumisago, Sci. Reports 3 (2013) 2261.

[145] Y. Kato, S. Hori, T. Saito, K. Suzuki, M. Hirayama, A. Mitsui, M. Yonemura, H. Iba and R. Kanno, Nat. Energy 1 (2016) 16030.

[146] B. Kumar, J. Kumar, R. Leese, J.P. Fellner, S.J. Rodrigues and K.M. Abraham, J. Electrochem. Soc. 157 (2010) A50-A54. 
[147] H. Kitaura and H. Zhou, Energy Environ. Sci. 5 (2012) 9077-9084.

[148] F. Li, H. Kitaura and H. Zhou, Energy Environ. Sci. 6 (2013) 2302-2311.

[149] E. Kobayashi, L.S. Plashnitsa, T. Doi, S. Okada and J. Yamaki, Electrochem. Commun. 12 (2010) 894-896.

[150] K. Hoshina, K. Yoshima, M. Kotobuki and K. Kanamura, Solid State Ionics 2012, 209-210 (2012) 30-35.

[151] Y. Iriyama, C. Yada, T. Abe, Z. Ogumi and K. Kikuchi, Electrochem. Commun. 8 (2006) 1287-1291.

[152] K. Takada, Acta Mater. 61 (2013) 759-770.

[153] Y. Inaguma, L. Chen, M. Itoh, T. Nakamura, T. Uchida, H. Ikuta and M. Wakihara, Solid State Commun. 86 (1993) 689-693.

[154] T. Abe, M. Ohtsuka, F. Sagane, Y. Iriyama and Z. Ogumi, J. Electrochem. Soc. 151 (2004) A1950-A1953.

[155] O. Bohnke, Solid State Ionics 179 (2008) 9-15.

[156] M. Kotobuki, Y. Suzuki, H. Munakata, K. Kanamura, Y. Sato, K. Yamamoto and T. Yoshida, J. Electrochem. Soc. 157 (2010) A493-A498.

[157] C. Li, B. Zhang and Z. Fu, Thin Solid Films 515 (2006) 1886-1892.

[158] M. Kotobuki, Y. Suzuki, H. Munakata, K. Kanamura, Y. Sato, K. Yamamoto and T. Yoshida, J. Power Sources 195 (2010) 5784-5788.

[159] K. Fu, Y. Gong, J. Dai, A. Gong, X. Han, Y. Yao, C. Wang, Y. Wang, Y. Chen, C. Yan, Y. Li, E.D. Wachsman and L. Hu, Proc. Natl. Acad. Sci. U. S. A. 113 (2016) 7094-7099.

[160] M. Kotobuki, H. Munakata, K. Kanamura, Y. Sato and T. Yoshida, J. Electrochem. Soc. 157 (2010) A1076-A1079.

[161] S. Ohta, T. Kobayashi, J. Seki and T. Asaoka, J. Power Sources 202 (2012) $332-335$.

[162] S. Ohta, S. Komagata, J. Seki, T. Saeki, S. Morishita and T. Asaoka, J. Power Sources 238 (2013) 53-56.

[163] F. Du, N. Zhao, Y. Li, C. Chen, Z. Liu and X. Guo, J. Power Sources 300 (2015) 24-28. 
[164] C. Ahn, J. Choi, J. Ryu, B. Hahn, J. Kim, W. Yoon, J. Choi, J. Lee and D. Park, J. Power Sources 272 (2014) 554-558.

[165] Y. Li, B.Y. Xu, H.H. Xu, H.N. Duan, X.J. Lv, S. Xin, W.D. Zhou, L.G. Xue, G.T. Fu, A. Manthiram and J.B. Goodenough, Angew. Chem. Int. Ed. 55 (2016) DOI: 10.1002/anie.201608924.

[166] B. Oh, D. Vissers, Z. Zhang, R. West, H. Tsukamoto and K. Amine, J. Power Sources 119-121 (2003) 442-447.

[167] Y. Kobayashi, S. Seki, Y. Mita, Y. Ohno, H. Miyashiro, P. Charest, A. Guerfi and K. Zaghib, J. Power Sources 185 (2008) 542-548.

[168] Y.R. Zhao, C. Wu, G. Peng, X.T. Chen, X.Y. Yao, Y. Bai, F. Wu, S.J. Chen and X.X. Xu, J. Power Sources 301 (2016) 47-53.

[169] J. Hassoun and B. Scrosati, Adv. Mater. 22 (2010) 5198-5201.

[170] C. Zhang, Y. Lin and J. Liu, J. Mater. Chem. A 3 (2015) 10760-10766.

[171] Y. Zhang, J.Y. Lai, Y.D. Gong, Y.M. Hu, J. Liu, C.W. Sun and Z.L. Wang, ACS Appl. Mater. Interfaces 8 (2016) 34309-34316.

[172] M. Balaish, E. Peled, D. Golodnitsky and Y. Ein-Eli, Angew. Chem. Int. Ed. 54 (2015) 436-440

[173] J. Shim, D.G. Kim, H.J. Kim, J.H. Lee and J.C. Lee, ACS Appl. Mater. Interfaces 7 (2015) 7690-7701.

[174] Y. Lin, X.M. Wang, J. Liu, and J.D. Miller, Nano Energy 31 (2017) 478-485.

[175] A. Sakuda, A. Hayashi and M. Tatsumisago, Chem. Mater. 22 (2010) 949-956.

[176] F. Mizuno, A. Hayashi, K. Tadanaga and M. Tatsumisago, J. Electrochem. Soc. 152 (2005) A1499-A1503.

[177] A. Hayashi, Y. Nishio, H. Kitaura and M. Tatsumisago, Electrochem. Commun. 10 (2008) 1860-1863.

[178] M. Tatsumisago, M. Nagao and A. Hayashi, J. Asian Ceram. Soc. 1 (2013) $17-25$.

[179] M. Nagao, A. Hayashi and M. Tatsumisago, J. Mater. Chem. 22 (2012) 10015-10020. 
[180] A. Hayashi, Y. Nishio, H. Kitaura and M. Tatsumisago, Electrochem. Commun. 10 (2008) 1860-1863.

[181] H. Kitaura, A. Hayashi, T. Ohtomo, S. Hama and M. Tatsumisago, J. Mater. Chem. 21 (2011) 118-124.

[182] A. Sakuda, A. Hayashi, T. Ohtomo, S. Hama and M. Tatsumisago, Electrochem. Solid State Lett. 13 (2010) A73-A75.

[183] K. Aso, A. Sakuda, A. Hayashi and M. Tatsumisago, ACS Appl. Mater. Interfaces 5 (2013) 686-690.

[184] A. Sakuda, A. Hayashi, T. Ohtomo, S. Hama and M. Tatsumisago, J. Power Sources 196 (2011) 6735-6741.

[185] N. Ohta, K. Takada, I. Sakaguchi, L. Zhang, R. Ma, K. Fukuda, M. Osada and T. Sasaki, Electrochem. Commun. 9 (2007) 1486-1490.

[186] N. Ohta, K. Takada, L. Zhang, R. Ma, M. Osada and T. Sasaki, Adv. Mater. 18 (2006) 2226-2229.

[187] K. Takada, N. Ohta, L. Zhang, K. Fukuda, I. Sakaguchi, R. Ma, M. Osada and T. Sasaki, Solid State Ionics 179 (2008) 1333-1337.

[188] A. Sukuda, H. Kitaura, A. Hayashi, K. Tadanaga and M. Tatsumisago, Electrochem. Soli-State Lett. 11 (2008) A1-A3.

[189] A. Sakuda, H. Kitaura, A. Hayashi, K. Tadanaga and M. Tatsumisago, J. Electrochem. Soc. 156 (2009) A27-A32.

[190] J.H. Woo, J.E. Trevey, A.S. Cavanagh, Y.S. Choi, S.C. Kim, S.M. George, K.H. Oh and S. Lee, J. Electrochem. Soc. 159 (2012) A1120-A1124.

[191] T. Kato, T. Hamanaka, K. Yamamoto, T. Hirayama, F. Sagane, M. Motoyama and Y. Iriyama, J. Power Sources 260 (2014) 292-298.

[192] D. Santhanagopalan, D. Qian, T. McGilvray, Z. Wang, F. Wang, F. Camino, J. Graetz, N. Dudney and Y.S. Meng, J. Phys. Chem. Lett. 5 (2014) 298-303.

[193] M. Nagao, A. Hayashi and M. Tatsumisago, Electrochemistry 80 (2012) 734-736.

[194] K. Okita, K. Ikeda, H. Sano, Y. Iriyama and H. Sakaebe, J. Power Sources 196 (2011) 2135-2142. 
[195] M. Hiratani, K. Miyauchi and T. Kudo, Solid State Ionics 28-30 (1988) 1406-1410.

[196] A. Kato, A. Hayashi and M. Tatsumisago, J. Power Sources 309 (2016) 27-32.[197] F. Han, T. Gao, Y. Zhu, K.J. Gaskell and C. Wang, Adv. Mater. 27 (2015) 3473-3483.

[198] X.G. Han, Y. Gong, K. Fu, X.F. He, G.T. Hitz, J.Q. Dai, A. Pearse, B.Y. Liu, H. Wang, G. Rubloff, Y.F. Mo, V. Thangadurai, E.D. Watchsman and L. Hu, Nat. Mater. 16 (2017) DOI:10.1038/NMAT4821.

[199] A. Brazier, L. Dupont, L. Dantras-Laffont, N. Kuwata, J. Kawamura and J.M. Tarascon, Chem. Mater. 20 (2008) 2352-2359.

[200] Z. Wang, D. Santhanagopalan, W. Zhang, F. Wang, H.L. Xin, K. He, J. Li, N. Dudney and Y.S. Meng, Nano Lett. 16 (2016) 3760-3767.

[201] K. Yamamoto, Y. Iriyama, T. Asaka, T. Hirayama, H. Fujita, C.A.J. Fisher, K. Nonaka, Y. Sugita and Z. Ogumi, Angew. Chem. Int. Ed. 49 (2010) 4414-4417.

[202] T. Okumura, T. Nakatsutsumi, T. Ina, Y. Orikasa, H. Arai, T. Fukutsuka, Y. Iriyama, T. Uruga, H. Tanida, Y. Uchimoto and Z. Ogumi, J. Mater. Chem. 21 (2011) 10051-10060.

[203] K. Yamamoto, Y. Iriyama, T. Asaka, T. Hirayama, H. Fujita, K. Nonaka, K. Miyahara, Y. Sugita and Z. Ogumi, Electrochem. Commun. 20 (2012) 113-116.

[204] K. Kimoto, T. Sekiguchi and T. Aoyama, J. Electron Microsc. 46 (1997) 369-374.

[205] S. Terada, T. Aoyama, F. Yano and Y. Mitsui, J. Electron Microsc. 51 (2002) 291-296.

[206] W. Ra, M. Nakayama, Y. Uchimoto and M. Wakihara, J. Phys. Chem. B 109 (2005) 1130-1134.

[207] M. Nakayama, T. Usui, Y. Uchimoto, M. Wakihara and M. Yamamoto, J. Phys. Chem. B 109 (2005) 4135-4143.

[208] K. Yamamoto, R. Yoshida, T. Sato, H. Matsumoto, H. Kurobe, T. Hamanaka, T. Kato, Y. Iriyama and T. Hirayama, J. Power Sources 266 (2014) 414-421. 
[209] W.S. Kruijt, P.H.L. Notten and H.J. Bergveld, J. Electrochem. Soc. 145 (1998) 3764-3773.

[210] P.H.L. Notten, W.S. Kruijt and H.J. Bergveld, J. Electrochem. Soc. 145 (1998) 3774-3783.

[211] H.J. Bergveld, W.S. Kruijt and P.H.L. Notten, J. Power Sources 77 (1999) 143-158.

[212] D. Danilov and P.H.L. Notten, Abstract 390, in Proceedings of the $12^{\text {th }}$ IMLB Conference, Nara, Japan, 2004.

[213] D. Danilov and P.H.L. Notten, in Proceedings of the $5^{\text {th }}$ IEEE Vehicle Power and Propulsion Conference, IEEE, Dearborn, 2009, p317.

[214] D. Danilov, R.A.H. Niessen and P.H.L. Notten, J. Electrochem. Soc. 158 (2011) A215-A222.

[215] Rapid development of all solid batteries during ten years, website: http://www.najiaoluo.com/caijing/170934.html.

[216] Development history of SONY's lithium battery, website: http://news.bjx.com.cn/html/20151124/684701.shtml.

[217] Forbes. French Billionaire Vincent Bolloré Launches Electric Car Sharing Service In Indianapolis. Forbes.

[218] M. Vervaeke and G. Calabrese, Int J Vehicle Des, 68 (2015) 245-264.

[219] U. Grape, High-Voltage Solid Polymer Batteries for Electric Drive Vehicles, Technical Report, Seeo incorporation, 2014, DE-EE0005449.

[220] J. Tollefson, Nature 494 (2013) 409-410.

[221] J. Guziński, M. Adamowicz, J. Kamiński, Układy napędowe pojazdów elektrycznych, Automatyka, Elektryka, Zakłócenia 13 (2013) 64-75.

[222] T. Henderson, Crains Detroit Business 26 (2010) 2-3.

[223] Zhongtian corporate website: http://www.chinaztt.com.

[224] ProLogium Corporation website: http://www.prologium.com.tw/.

[225] X.X. Guo and J. Maier, Ionically conducting two-dimensional heterostructures, Adv. Mater., 2009, 21, 2619-2631.

[226] C.C. Liang, J. Electrochem. Soc. 120 (1973) 1289-1292. 
[227] J. Maier, Nat. Mater. 4 (2005) 805-815.

[228] J. Maier, Prog. Solid State Chem. 23 (1995) 171-263.

[229] J. Haruyama, K. Sodeyama, L. Han, K. Takada, Y. Tateyama, Chem. Mater. 26 (2014) 4248-4255.

[230] K. Fujimura, A. Seko, Y. Koyama, A. Kuwabara, I. Kishida, K. Shitara, C.A.J. Fisher, H. Moriwake and I. Tanaka, Adv. Energy Mater. 3 (2013) 980-985.

[231] T. Mueller, G. Hautier, A. Jain and G. Ceder, Chem. Mater. 23 (2011) 3854-3862.

[232] R. Jalem, T. Aoyama, M. Nakayama and M. Nogami, Chem. Mater. 24 (2012) $1357-1364$.

[233] G. Hautier, C. Fischer, V. Ehrlacher, A. Jain and G. Ceder, Inorg. Chem. 50 (2011) 656-663.

[234] G. Hautier, A. Jain, H. Chen, C. Moore, S.P. Ong and G. Ceder, J. Mater. Chem. 21 (2011) 17147-17153.

[235] Y. Wang, W.D. Richards, S.P. Ong, L.J. Miara, J.C. Kim, Y. Mo and G. Ceder, Nat. Mater. 14 (2015) 1026-1031.

[236] T. Wei, Y. Gong, X. Zhao and K. Huang, Adv. Func. Mater. 24 (2014) $5380-5384$.

[237] D. Wang, W. Zhang, W. Zheng, X. Cui, T. Rojo and Q. Zhang, Adv. Sci. 2016, 1600168 . 


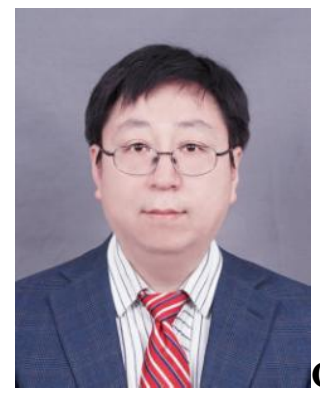

Chunwen Sun received his Ph.D. degree in Condensed Matter Physics from the Institute of Physics (IOP), Chinese Academy of Sciences (CAS) in 2006. He is a professor and group leader of Energy Storage Materials and Devices at Beijing Institute of Nanoenergy and Nanosystems (BINN), CAS. He has received a number of awards, including the Outstanding Overseas Talents by the Institute of Physics CAS (2011), and the Second Prize of Military Progress Prize in Science and Technology Advancement in China (2013). His research interests include energy storage and conversion, e.g., lithium-ion batteries, metal-air batteries, all-solid-state batteries, fuel cells and self-powered systems.

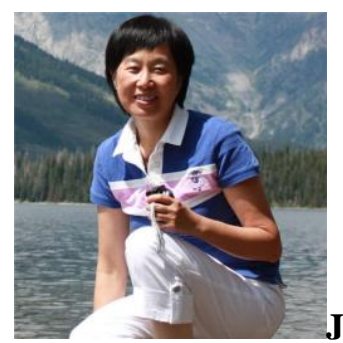

Jin Liu is a Professor in the School of Metallurgy and Environment, Central South University, China. She received her Ph.D. degree from the Department of Chemistry, University of Utah, USA, in 2006. Her research interests include electrochemistry and surface chemistry.

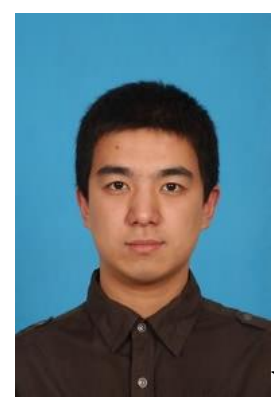

Yudong Gong received his Master's degree in China University of Mining and Technology (Beijing) in 2014. He is currently a Ph.D. student under the supervision of Professor 
Lixin Cao at Institute of Physics, Chinese Academy of Sciences (CAS), and a visiting student under the supervision of Professor Chunwen Sun at Beijing Institute of Nanoenergy and Nanosystems (BINN), CAS. His research interests are synthesis and characterization of nanostructured pervoskite oxides as cathodes for lithium-oxygen batteries.

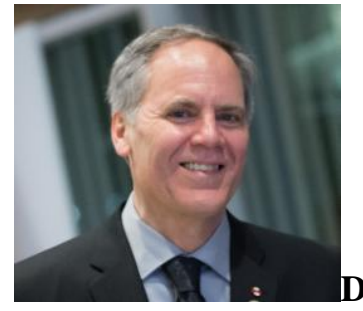

Dr. David P. Wilkinson is a Professor and Canada Research Chair in the Department of Chemical and Biological Engineering at the University of British Columbia (UBC). He previously held the positions of Executive Director of the UBC Clean Energy Research Center, Principal Research Officer and Senior Advisor with the National Research Council of Canada Institute for Fuel Cell Innovation, Director and Vice President of Research and Development at Ballard Power Systems, and Group Leader at Moli Energy. His main research interests are in electrochemical and photochemical devices, energy conversion and storage materials, and processes to create clean and sustainable energy and water.

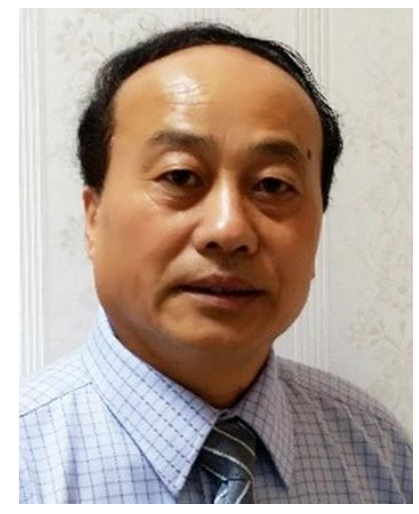

Dr. Jiujun Zhang is a Professor at Shanghai University. He is a Principal Research Officer (Emeritus) and Technical Core Competency Leader at the National Research Council of Canada Energy (NRC). Dr. Zhang received his BS and MSc in electrochemistry from Peking University in 1982 and 1985, respectively, and his $\mathrm{PhD}$ in electrochemistry from Wuhan University in 1988. Dr. Zhang has over 30 years of scientific research experience, particularly in the area of electrochemical energy storage and conversion. He is also the Adjunct Professor at the University of British Columbia and the University of Waterloo. 


\section{Graphical Abstract:}

The all-solid-state lithium batteries with solid electrolytes are considered to be the new generation of devices for energy storage. To accelerate the research and development, the overall picture about the current state of all solid-state lithium batteries was reviewed in this article with major focus on the material aspects. In particular, the importance of the electrolytes and their associated interfaces with electrodes as well as their effects on the battery performance are emphasized by in-depth discussion and data analysis. To overcome the challenges, several possible research directions are also suggested for facilitating the further improvement on the battery performance.

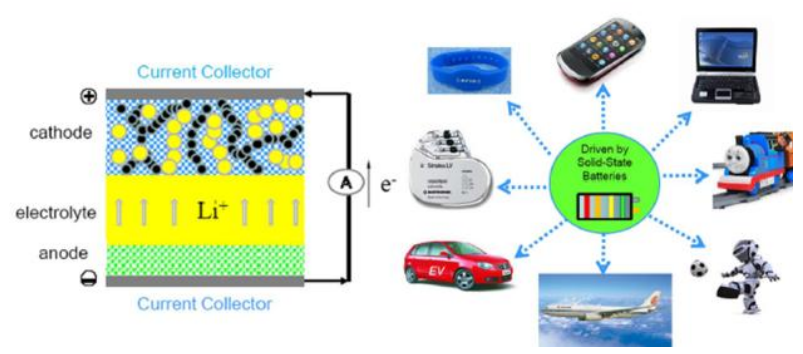

